\author{
UNIVERSIDADE DE SÃO PAULO \\ INSTITUTO DE QUÍMICA \\ Programa de Pós-Graduação em Ciências Biológicas (Bioquímica)
}

LUCIANA PRINCIPAL ANTUNES

METAGENÔMICA E METATRANSCRITÔMICA DA MICROBIOTA DA COMPOSTAGEM DO PARQUE ZOOLÓGICO DE SÃO PAULO

São Paulo

05/09/2016 


\section{METAGENÔMICA E METATRANSCRITÔMICA DA MICROBIOTA DA COMPOSTAGEM DO PARQUE ZOOLÓGICO DE SÃO PAULO}

Tese apresentada ao Instituto de Química da Universidade de São Paulo para obtenção do Título de Doutor em Ciências, área Bioquímica

Orientadora: Profa. Dra. Aline Maria da Silva Co-orientador: Prof. Dr. João Carlos Setubal

São Paulo

2016 


\section{Ficha Catalográfica}

Elaborada pela Divisão de Biblioteca e

Documentação do Conjunto das Químicas da USP.

\section{Antunes, Luciana Principal}

A636m Metagenômica e metatranscritômica da microbiota da compostagem do parque zoológico de São Paulo / Luciana Principal Antunes. -- São Paulo, 2016. $106 \mathrm{p}$.

Tese (doutorado) - Instituto de Química da Universidade de São Paulo. Departamento de Bioquímica

Orientador: Silva, Aline Maria da

Co-orientador: Setubal, João Carlos

1. Genoma : Biologia molecular I. T. II. Silva, Aline Maria da, orientador III. Setubal, João Carlos, co-orientador.

$$
574.88 \text { CDD }
$$


Luciana Principal Antunes

Metagenômica e metatranscritômica da microbiota da compostagem do Parque Zoológico de São Paulo

Tese apresentada ao Instituto de Química da Universidade de São Paulo para obtenção do Título de Doutor em Ciências, área Bioquímica.

Aprovado em:

\section{Banca Examinadora}

Prof. Dr.

Instituição:

Assinatura:

Prof. Dr.

Instituição:

Assinatura:

Prof. Dr.

Instituição:

Assinatura:

Prof. Dr.

Instituição:

Assinatura:

Prof. Dr.

Instituição:

Assinatura: 


\section{AGRADECIMENTOS}

Aos meus orientadores, Profa. Dra. Aline Maria da Silva e Prof. Dr. João Carlos Setubal por compartilhar comigo de seu tempo, de suas experiências e conhecimento ao longo destes anos e por me apoiar, incentivar e me dar autonomia. Além de promoverem um ambiente agradável e de fraternidade em seus grupos de pesquisa e fornecerem visões científicas complementares e que enriqueceram a minha formação.

À Fundação Parque Zoológico de São Paulo (FPZSP) por abraçar o projeto Metazoo e por possibilitar o seu desenvolvimento. À toda equipe do parque e, em especial, Dr. Paulo Magalhães Bressan (Presidente), Dr. João Batista da Cruz (Diretor Científico) e Dra. Patricia Ramos.

A Dra. Layla Farage Martins, especialista de laboratório do CATG, por todo o apoio na execução e interpretação de experimentos e por sua amizade.

Ao técnico de laboratório Alexandre Sanches por todo o suporte necessário para a realização de experimentos e por sua companhia.

Ao Prof. Dr. Julio Cezar Franco de Oliveira, da Unifesp campus Diadema, que foi o meu primeiro orientador de iniciação científica, me acompanhou e fez parte da minha vida acadêmica até aqui. Me inspirou como professor e como pessoa.

Aos demais professores integrantes do projeto Metazoo: Dra. Renata C. Pascon, Dr. Marcelo A. Vallim, Dra. Cristina Vianna, Dr. Sergio Verjovski-Almeida, Dr. Luciano Digiampietri, Dr. Ronaldo Quaggio e Dr. Luiz Juliano Neto por toda ajuda e aprendizado.

Aos amigos de laboratório de Biologia Molecular e Genômica de Microrganismos do IQ-USP que me acompanharam durante o meu trabalho e com quem dividi bons momentos que guardo na memória: Ana Paula Souza, Ms. Fernando Tria, Ms. Gustavo Antonio Chaves, Dr. Joaquim Martins, Karen Cristina Lombardi, Dr. Paulo Adriano Zaini, Ms. Paulo Marques Pierry, Oseias Feitosa Júnior, Dra. Roberta Verciano Pereira Yokogawa, Ms. Rodrigo Rafagnin Duarte e Dr. Wesley Santana.

Aos amigos integrantes do projeto Metazoo: Ms. Andrew Thomas, Dr. Deibs Barbosa, Deyvid Amgarten, George Condomitti, Gianluca Major Silva, Dra. Layla Farage Martins, Ms. Leandro Nascimento Lemos, Raquel Riyuzo e Dra. Roberta 
Verciano Pereira Yokogawa, pela disponibilidade e auxílio essencial durante todas as etapas deste trabalho e pela amizade.

Aos colegas do Laboratório de Bioinformática do IQ-USP pelo acolhimento e pelas discussões que engrandeceram este trabalho.

A todos os professores, funcionários e colegas que pude ter contato no IQUSP, pelos valiosos ensinamentos.

À minha mãe Durvalina, ao meu pai Antonio e aos meus irmãos Ezequiel, Rodrigo, Evandro e Gustavo por toda paciência e amor durante a minha formação, pelos valiosos conselhos, exemplos e por me ensinar a buscar os meus objetivos.

À Fundação de Amparo e Pesquisa do Estado de São Paulo por conceder bolsas de mestrado e doutorado direto (Processos 2011/04442-2 e 2013/08148-7).

Este trabalho foi realizado com apoio financeiro da FAPESP (Projeto Temático 2011/50870-6), CAPES (Edital Biologia Computacional n 51/2013) e da Pró-Reitoria de Pesquisa-USP (Programa de Incentivo à Pesquisa Edital 2012). 
“...Quem quer passar além do Bojador Tem que passar além da dor. Deus ao mar o perigo e o abismo deu, Mas nele é que espelhou o céu. "

Fernando Pessoa 
Antunes, L.P. Metagenômica e metatranscritômica da microbiota da compostagem do Parque Zoológico de São Paulo. 2016. 105p. Tese (Doutorado) - Programa de Pós-Graduação em Bioquímica. Instituto de Química, Universidade de São Paulo, São Paulo.

As compostagens abrigam uma grande riqueza microbiológica, englobando populações com distintos requerimentos e tolerâncias fisiológicas que se sucedem ao longo do processo de biodegradação aeróbica da matéria orgânica e que resultam na elevação espontânea de temperatura até $80^{\circ} \mathrm{C}$. Com a utilização de abordagens de metagenômica e metatranscritômica, investigamos a composição e a diversidade taxonômica, bem como as funções metabólicas de comunidades microbianas da compostagem termofílica do Parque Zoológico de São Paulo. Foram analisadas amostras em série temporal de duas composteiras (ZC3 e ZC4), as quais exibiram temperaturas entre $50^{\circ} \mathrm{C}-75^{\circ} \mathrm{C}$ ao longo de 99 dias do processo. Verificamos que a degradação de toda a biomassa foi realizada essencialmente por bactérias, e que a estrutura e composição das comunidades microbianas variam ao longo do processo, com elevada abundância relativa das Ordens Clostridiales, Bacillales e Actinomycetales, assim como observado em outros sistemas de compostagem. Entre os organismos abundantes no processo, identificamos unidades taxonômicas operacionais (OTUs) referentes a organismos não-cultiváveis e/ou com genoma ainda desconhecido. O genoma parcial de uma destas OTUs foi reconstruído, a qual provavelmente pertence a um novo gênero da ordem Bacillales. A dinâmica do processo de compostagem foi evidenciada pela variação do número de OTUs e do índice de diversidade filogenética ao longo do tempo, sendo que o início do processo e a fase após a revira apresentaram a maior diversidade. Os resultados indicam que o processo de revira (aeração da massa de composto) impacta fortemente a estrutura e a composição da microbiota e que a desconstrução da biomassa vegetal ocorre de forma sinérgica e sequencial. A variedade de microrganismos e de funções metabólicas ativas na compostagem termofílica reforça o seu potencial de ser uma promissora fonte de bactérias e enzimas termorresistentes úteis em processos industriais.

Palavras-chaves: Metagenômica, Metatranscritômica, Compostagem. 
Antunes, L.P. Metagenomics and metatranscriptomics of the São Paulo Zoo Park composting microbiota. 2016. 105p. PhD Thesis - Graduate Program in Biochemistry. Instituto de Química, Universidade de São Paulo, São Paulo.

Composting harbors considerable microbial richness, comprising populations with distinct physiological requirements and tolerances that succeed one another throughout the aerobic biodegradation of the organic matter, resulting in spontaneous temperature rise up to $80^{\circ} \mathrm{C}$. Using metagenomic- and metatranscritomic-based approaches, we investigated the composition and taxonomic diversity as well as metabolic functions of microbial communities of a thermophilic composting operation in the São Paulo Zoo Park. We have analyzed time-series samples from two composting cells (ZC3 and ZC4) which exhibited sustained thermophilic profile $\left(50^{\circ} \mathrm{C}-75^{\circ} \mathrm{C}\right)$ over 99 days of the process. We found that all biomass degradation was essentially performed by bacteria. The structure and composition of microbial communities vary throughout the process with a high relative abundance of Clostridiales, Bacillales and Actinomycetales, as observed in other composting systems. Among the organisms abundant in the process, we identify Operational Taxonomic Units (OTUs) of uncultivated organisms or with unknown genomes. The partial genome of one of these OTUs was obtained and shown to belong probably to a new genus of Bacillales. Our time-series data showed that the number of OTUs and phylogenetic diversity index changed during composting revealing the dynamics of the process, with the beginning and the stage after turning procedure presenting the highest diverse microbiota. These results indicate that the turning procedure (compost aeration) strongly impacts the microbiota structure and composition and that the deconstruction of the biomass occurs synergistically and sequentially. The huge diversity of microorganisms and metabolic functions active in thermophilic composting strengthen its potential as a promising source of new bacteria and thermostable enzymes that may be helpful in industrial processes.

Keywords: Metagenomics, Metatranscriptomics, Composting. 
AA: Atividade Auxiliar

BLAST: Basic Local Alignment

Search Tool

CATG: Centro Avançado de Tecnologias em Genômica, IQUSP

CAZY: Carbohydrate-Active Enzymes

CBM: Carbohydrate-Binding Module

CDS: sequência codificadora

cDNA: DNA complementar

CCD: Charge-Coupled Device

CE: Carboxilesterase

COG: Cluster of Orthologous Group

CT: cycle threshold

dbCAN: Database for CarbohydrateActive Enzyme Anotation

DEPC: dietilpirocarbonato

DNA: Ácido desoxirribonucleico

DNAse: desoxirribonuclease

ETA: Estação de Tratamento de Água

ETE: Estação de Tratamento de Esgoto

FPZSP: Fundação Parque

Zoológico de São Paulo

$\mathrm{GH}$ : Glicosil hidrolase

GT: Glicosil transferase

ICP-AES: Inductively Coupled

Plasma - Atomic Emission

Spectrometry

IMG/M: Integrated Microbial

Genomes \& Microbiomes System

MG-RAST: Metagenomics Analysis

Server

mRNA: RNA mensageiro

M5NR: M5 Non-redundant Protein

Database

NGS: Next Generation Sequencing

OTU: Operational Taxonomic Unit

$\mathrm{pb}$ : par de bases
PCR: reação em cadeia da

polimerase

PD: Índice de Diversidade

Filogenética

PE: Paired End

PL: Polissacarídeo Liase

QIIME- Quantitative Insights Into

Microbial Ecology

qPCR: PCR quantitativo

Q30: Quality score of 30 (Parâmetro de qualidade do sequenciamento)

RDP: Ribosomal Database Project

RIN: RNA Integrity Number

RNA: Ácido ribonucleico

RNAse: ribonuclease

RNA-seq: Sequenciamento de cDNA em grande-escala

rRNA: RNA ribossômico

SLH: Surface Layer Homology

SOAP: Short Oligonucleotide

Analysis Package

SOD: Superóxido Dismutase

tRNA: RNA transportador

UC: Unidade compostagem da FPZSP

USEARCH: Ultra-fast Sequence Analysis

V3: Região hipervariável 3 do rRNA 16S

V4: Região hipervariável 4 do rRNA $16 S$

S: Svedberg (coeficiente de sedimentação) 
1. Introdução. 12

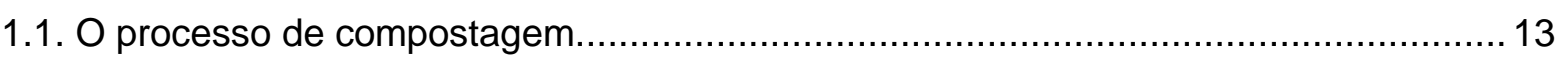

1.2. Diversidade da microbiota associada a compostagem ............................................. 17

1.3. Abordagens independentes de cultivo para estudos de comunidades microbianas .... 20

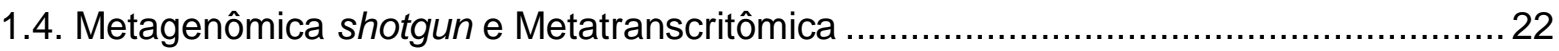

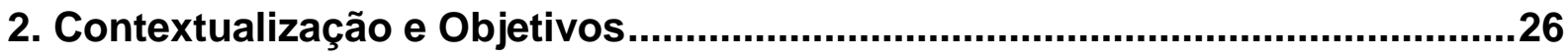

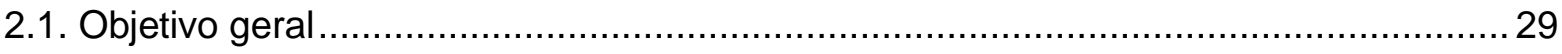

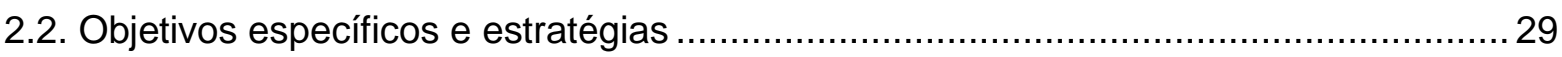

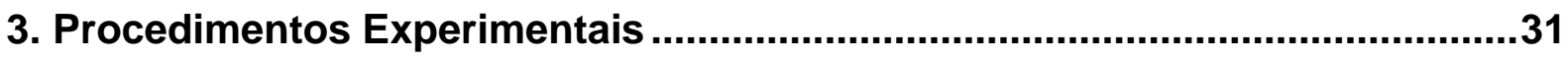

3.1. Unidade de Compostagem do Parque Zoológico de São Paulo ................................... 31

3.2. Coleta de amostras das composteiras ZC3 e ZC4 ……........................................ 32

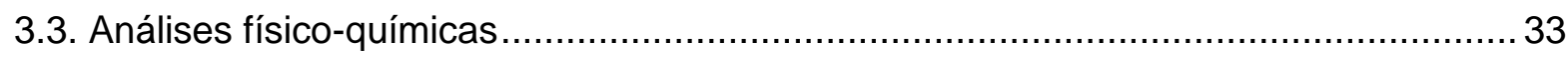

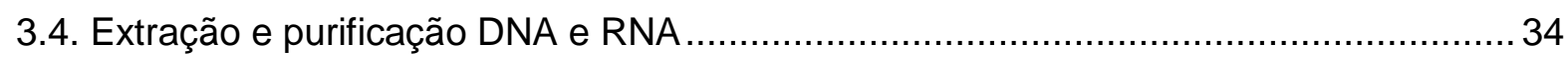

3.5. Preparação de bibliotecas de fragmentos de DNA (Metagenômica shotgun) ............... 36

3.5.1. Sequenciamento shotgun na plataforma 454-Roche...................................36

3.5.2. Bibliotecas de fragmentos de DNA para sequenciamento na plataforma

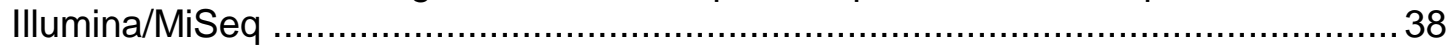

3.6. Preparação de bibliotecas de amplicons do gene rRNA16S (Metagenômica 16S) ...... 39

3.7. Preparação de bibliotecas de cDNA para RNA-seq (Metatranscritômica) .................... 40

3.7.1. Depleção de rRNA das amostras de RNA total ...........................................40

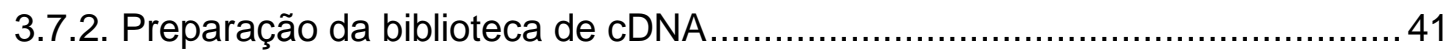

3.8. Quantificação de bibliotecas de fragmentos de DNA e de cDNA …………………...... 43

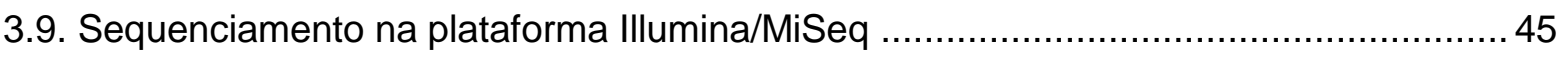

3.10. Processamento e análise computacional das sequências obtidas ........................... 49

3.10.1. Pré-processamento e anotação de sequências de metagenomas e de

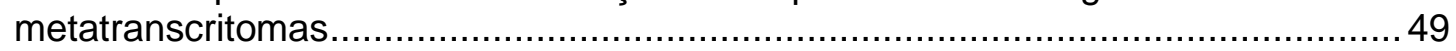

3.10.2. Processamento e análise de sequências de amplicons do gene rRNA16S .50

4. Resultados e Discussão

4.1. Perfil de temperatura, $\mathrm{pH}$ e umidade e análise elementar das composteiras ZC3 e ZC4.

4.2. Variação da estrutura e composição da comunidade microbiana durante a compostagem 60

4.3. Análises de riqueza e diversidade da microbiota da compostagem. .65

4.4. Espécies de bactérias mais abundantes na compostagem e reconstrução do genoma de um provável novo gênero bacteriano.

4.5. Potencial metabólico da microbiota da compostagem ................................................ 71

4.6. Transcritos relacionados a degradação de biomassa vegetal em ZC4 ………............ 80 
4.7. Classificação taxonômica de CDSs expressas nos metatranscritomas ....................... 85

5. Conclusões e Perspectivas .............................................................................88

6. Referências Bibliográficas .............................................................................91

Apêndice 1 ...................................................................................................... i

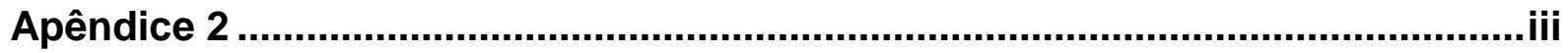




\section{Introdução}

Comunidades microbianas estão presentes virtualmente em todos os ambientes como solo, rios, lagos, oceanos e também associadas a hospedeiros animais e vegetais. Além de ambientes naturais, comunidades microbianas são constituintes de ambientes engenheirados, como as compostagens, as quais são empregadas na degradação de material orgânico incluindo a biomassa recalcitrante de origem vegetal. Estas comunidades apresentam diferentes graus de complexidade e de riqueza de espécies, exibem variados tipos de interações e associações com dinâmicas diversas frente a alterações das condições físico-químicas do habitat (Ley et al., 2006; Barton \& Northup, 2011; Rasche et al., 2011; Shade et al., 2012; Lauber et al., 2013; Lopez-Gonzalez et al., 2015a). Os membros dessas microbiotas atuam como consórcios que podem cooperar mutuamente compartilhando enzimas e metabólitos e/ou competir por nutrientes e espaço, além de produzir substâncias (ex: bacteriocinas e antibióticos) que intereferem na estrutura e composição da respectiva comunidade microbiana (Bapteste \& Boucher, 2008; Proft, 2009; Barton \& Northup, 2011; Riley, 2011; Xia et al., 2014).

É crescente o interesse na caracterização de microbiotas dos mais variados ambientes, para uma compreensão das interações microbianas que sustentam estas comunidades e também do papel biológico que desempenham em seu respectivo habitat e/ou nas relações, benéficas ou não, com seus hospedeiros (Hess et al., 2011; Xia et al., 2011; Rinke et al., 2013; Franzosa et al., 2014; Franzosa et al., 2015; Ledford, 2015; Tian et al., 2015).

O emprego de abordagens independentes de cultivo tem contribuído de maneira extraordinária para a caracterização detalhada de comunidades microbianas diversas, possibilitando, inclusive, a descrição de novos filos, gêneros e espécies de bactérias e arqueas, ainda não cultiváveis nas condições laboratoriais comumente empregadas, e que tem sido coletivamente denominados de microbial dark matter (Rinke et al., 2013; Gies et al., 2014; Hedlund et al., 2014; Castelle et al., 2015; Eloe-Fadrosh et al., 2016a; EloeFadrosh et al., 2016b). O sequenciamento direto do gene do rRNA16S da microbiota de amostras ambientais permitiu a ampliação do número de filos 
bacterianos de 12 para mais de 70 (Pace, 2009). O advento da metagenômica tem possibilitado a predição de novos taxa (filos, ordens, gêneros, espécies candidatos), reconstrução de genomas de organismos ainda não passíveis de cultivo in vitro e a descoberta de novas capacidades metabólicas desempenhadas por esses microrganismos, permitindo inferir suas funções nos microbiomas onde estão inseridos as quais podem ser verificadas através estudos de metatranscritômica, metaproteômica e metametabolômica (Hess et al., 2011; Simmons et al., 2014; Xia et al., 2014; Yarza et al., 2014; Brown et al., 2015; Castelle et al., 2015; Franzosa et al., 2015; Aguiar-Pulido et al., 2016b; Eloe-Fadrosh et al., 2016a; Eloe-Fadrosh et al., 2016b). Além disso, a descoberta do potencial metabólico de um microrganismo por abordagens independentes de cultivo está orientando esforços para a elaboração de meios de cultura direcionados para a reconstrução das condições necessárias para o crescimento de microrganismos até então não cultiváveis em laboratório ou a elaboração de sistemas de consórcios, o que já foi empregado com sucesso para o cultivo da Maritimus nitrosopumilus e de membros da OP10 (Solden et. al., 2016).

Neste trabalho aplicamos metodologias independentes de cultivo, como a metagenômica e metatranscritômica, para caracterizar a comunidade microbiana de um processo de compostagem termofílica, na expectativa de descrever a composição e a dinâmica da microbiota residente que é responsável pela degradação da biomassa vegetal, e também vislumbrando a possibilidade de acessar a microbial dark matter enriquecida neste ambiente engenheirado a partir de sequências não classificadas nos bancos de dados, os quais são conhecidamente enriquecidos em sequências de organismos cultiváveis.

\subsection{O processo de compostagem}

A compostagem permite a reciclagem da matéria orgânica por meio da decomposição aeróbica de resíduos orgânicos sob condições termofílicas e é conduzida por populações de microrganismos presentes nos próprios resíduos e eficientes para degradar materiais recalcitrantes de origem vegetal que são utilizados como fonte de carbono e energia (Figura 1) (Golueke, 1992; Haug, 
1993; Alfreider et al., 2002; Vargas-Garcia et al., 2010). A compostagem pode ser definida como um processo de biodegradação aeróbica da matéria orgânica com a geração de calor e elevação espontânea de temperatura a $50^{\circ} \mathrm{C}-65^{\circ} \mathrm{C}$, podendo apresentar picos de temperatura acima de $70^{\circ} \mathrm{C}$. O principal produto da compostagem é um material estável (composto maduro) rico em substâncias húmicas, o qual pode ser empregado com adubo orgânico. Assim, a compostagem é uma alternativa eficaz e econômica para o tratamento de resíduos, o que a torna o sistema mais importante de reciclagem de energia renovável (Haug, 1993; Inácio \& Miller, 2009; Allgaier et al., 2010; Moreno et al., 2013; Bhattacharya et al., 2016).

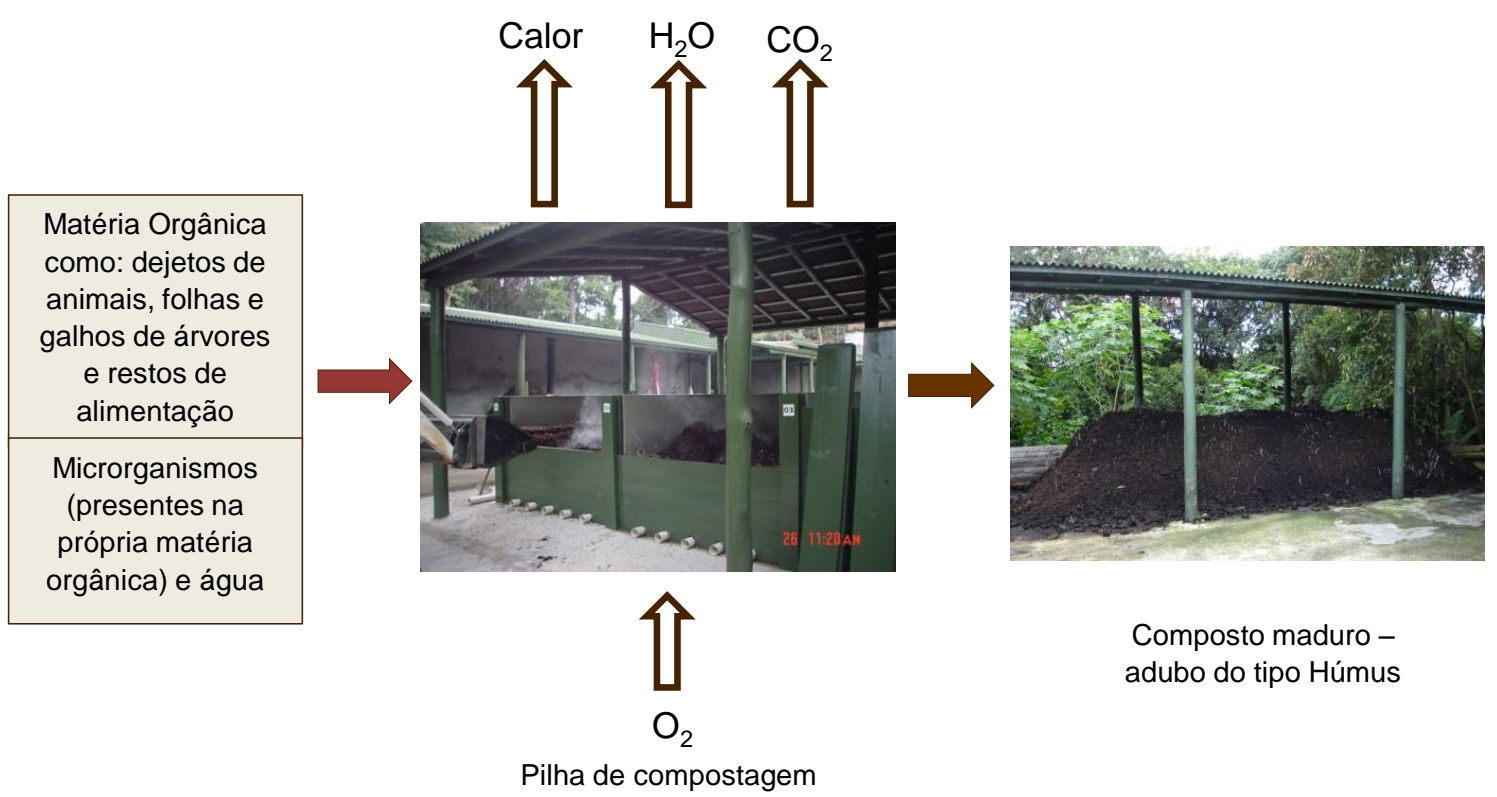

Figura 1: Esquematização do processo de compostagem. Fotos tiradas na UC da FPZSP.

O processo de compostagem diferencia-se da degradação que ocorre na natureza por ser termofílico, ainda que possua períodos de temperaturas mesofílicas, e ser por definição um processo predominantemente aeróbico. $\mathrm{Na}$ compostagem ocorre uma sucessão da microbiota decorrente de variações nas condições ambientais predominantes nas diferentes fases do processo, sendo que tais condições podem resultar da ação dos microrganismos sob a matéria orgânica. Por exemplo, a variação da temperatura que é verificada ao longo do 
processo resulta na substituição de grupos de microrganismos de acordo com suas temperaturas ótimas de geração (Figura 2). Assim a transformação da matéria orgânica em adubo ocorre de maneira dinâmica por meio da atuação sinérgica de uma ampla variedade de microrganismos (Rynk et al., 1992; Blanc et al., 1999; Peters et al., 2000; Dees \& Ghiorse, 2001; Alfreider et al., 2002; Hansgate et al., 2005; Schloss et al., 2005; Tiquia, 2005; Tiquia et al., 2005; Guo et al., 2007; Gajalakshmi \& Abbasi, 2008; Franke-Whittle et al., 2009; Inácio \& Miller, 2009; Partanen et al., 2010; Moreno et al., 2013).

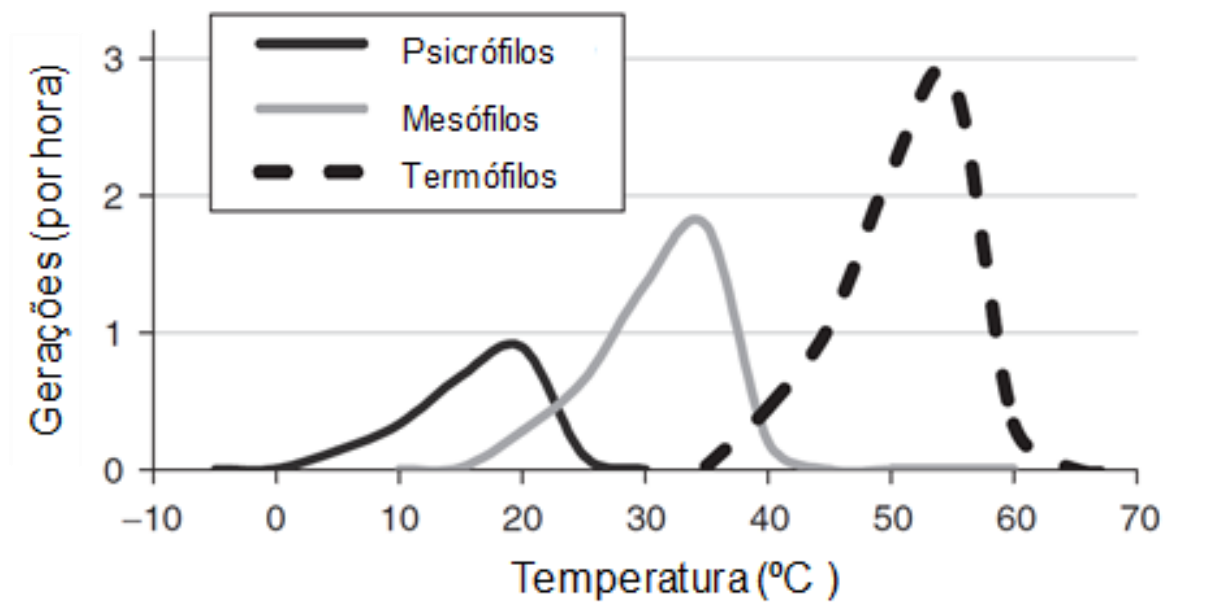

Figura 2: Perfil de substituição de microrganismos de acordo com a temperatura ótima de crescimento de cada grupo. Figura adaptada de Insam \& Bertoldi, 2007.

Os sistemas de compostagens podem ser classificados quanto ao seu isolamento do ambiente externo como abertos, semiabertos ou fechados (biorreatores), ou quanto a frequência da etapa de revira, sendo considerados estáticos, semi-estáticos ou dinâmicos (Rynk et al., 1992; Fitzpatrick et al., 2005; Gajalakshmi \& Abbasi, 2008). O tempo necessário para a transformação dos resíduos orgânicos em adubo é determinado pela configuração do sistema de compostagem e pela combinação de diferentes fatores, tais como: a natureza da matéria orgânica utilizada como substrato, a razão Carbono:Nitrogênio, a temperatura alcançada e a duração da fase termofílica, o teor de umidade, a concentração de oxigênio e o pH. Estes fatores podem ser estabelecidos no momento da montagem da composteira e/ou ajustados durante o processo (Ingelmo et al., 2012; Moreno et al., 2013). 
$\mathrm{Na}$ montagem da composteira, geralmente, a matéria orgânica é misturada de forma estratificada, por exemplo: estrume e matéria orgânica vegetal, em camadas alternadas, no intuito de atingir a proporção 30:1 de Carbono/Nitrogênio e de propiciar uma aeração passiva adequada e teor de umidade de 50-60\% (Rynk et al., 1992; Liang et al., 2003). Durante o processo, a razão C:N diminui para valores entre 10-15:1, devido principalmente a perda de Carbono na forma de gás $\mathrm{CO}_{2}$, produzido no processo de degradação da biomassa e que pode indicar uma intensa atividade metabólica, além da possível fixação de Nitrogênio pela microbiota residente (Gajalakshmi \& Abbasi, 2008).

Durante o processo na compostagem se observa a distinção de até três fases: (1) fase inicial de ativação da degradação da matéria orgânica, a qual apresenta temperaturas $<50^{\circ} \mathrm{C}$ e pode durar algumas horas a dias; (2) fase de intensa degradação da biomassa caracterizada pelo aumento rápido da temperatura $\left(50^{\circ} \mathrm{C}-80^{\circ} \mathrm{C}\right)$ e pode durar alguns dias a meses; e (3) fase final de maturação, na qual o composto gradativamente resfria até atingir a temperatura ambiente (Ryckeboer et al., 2003a; Insam \& de Bertoldi, 2007). A distribuição de microrganismos e nutrientes na composteira pode ser heterogênea tanto na escala temporal quanto espacial, no último caso relacionada com a existência de microambientes na pilha da matéria orgânica. Neste cenário, as diferentes fases estariam associadas a populações específicas de microrganismos com diferentes aptidões e requerimentos nutricionais, desde as fontes de carbono mais simples (mono e oligossacarídeos) até as mais complexas (lignocelulose e proteínas) (Golueke, 1992; Ryckeboer et al., 2003a; Insam \& de Bertoldi, 2007; Partanen et al., 2010; Moreno et al., 2013). Portanto, a degradação das fontes de carbono disponíveis no processo depende da capacidade da microbiota residente em produzir tanto enzimas hidrolíticas específicas para estes substratos quanto de proteínas acessórias (Ryckeboer et al., 2003a) (Tuomela et al., 2000; Hassen et al., 2001; Mayende et al., 2006; Allgaier et al., 2010; DeAngelis et al., 2010; Rastogi et al., 2010; D'Haeseleer et al., 2013; Eichorst et al., 2013).

As compostagens são consideradas fontes promissoras para a descoberta de bactérias termofílicas e de enzimas termoestáveis, sobretudo de 
enzimas relacionadas com a degradação de lignocelulose, as quais são vantajosas para aplicação industrial (Allgaier et al., 2010; Federici et al., 2011; Gladden et al., 2011; Dougherty et al., 2012; D'Haeseleer et al., 2013; Yang et al., 2013; Blumer-Schuette et al., 2014; Habbeche et al., 2014; Jurado et al., 2014; Mhuantong et al., 2015). Com este propósito, processos de compostagem vêm sendo explorados por abordagens dependentes e independentes de cultivo (Dees \& Ghiorse, 2001; Partanen et al., 2010; D'Haeseleer et al., 2013; de Gannes et al., 2013; Martins et al., 2013; Simmons et al., 2014; Tkachuk et al., 2014; Lopez-Gonzalez et al., 2015a; Wang et al., 2016).

A degradação da lignocelulose requer a ação de múltiplas enzimas e domínios proteicos que atuam de modo sinérgico na estrutura da fibra vegetal, entre elas: celulases, hemicelulases, ligninases, pectinases, atividades auxiliares (AAs) e módulos de ligação à celulose (CBMs) (Van Dyk \& Pletschke, 2012). A degradação da lignina promove o relaxamento da matriz vegetal, juntamente com a ação de hemicelulases, e possibilita o acesso de outras enzimas para a despolimerização da celulose (Huang et al., 2010; Moreno et al., 2013; Pérez et al., 2002). Além disso, a degradação da lignina fornece o substrato para a síntese das substâncias húmicas cujo acúmulo pode ser um indicativo da qualidade do composto maduro (Tuomela et al., 2000; Goyal et al., 2005).

\subsection{Diversidade da microbiota associada a compostagem}

A sucessão de populações de microrganismos que ocorre no processo de compostagem pode ser interpretada como a ação de um grupo que modifica o ambiente que ele está inserido e favorece o desenvolvimento de um grupo sucessor. A sua dinâmica é complexa e depende tanto de fatores ambientais (configuração da composteira, natureza da matéria orgânica, aeração, pH, etc.) como de relações ecológicas entre as populações de microrganismos atuantes incluindo bactérias, arqueas e fungos; sendo as bactérias consideradas as protagonistas do processo de degradação (Brown et al., 2008; Inácio \& Miller, 2009; Moreno et al., 2013). 
Entre as consequências da degradação realizada pela microbiota, que favorece alguns grupos em detrimento de outros, está a elevação da temperatura do composto acima de $45^{\circ} \mathrm{C}$ que resulta na gradativa substituição de microrganismos mesófilos por termófilos. Contudo, quando a produção de calor se torna menor do que a sua dissipação para o ambiente, devido a diminuição da atividade microbiana e a escassez dos substratos facilmente degradáveis, a composteira volta a ser colonizada por microrganismos mesófilos, os quais degradam compostos orgânicos complexos mais lentamente. Nesta fase, a produção de substâncias húmicas se torna mais expressiva para formação do composto maduro (McDonough, 1983; Haug, 1993; Tuomela et al., 2000; Insam \& de Bertoldi, 2007; Gajalakshmi \& Abbasi, 2008).

A microbiota associada à compostagem tem sido explorada há décadas por meio de abordagens dependentes de cultivo, sendo que linhagens de bactérias e fungos com potencial biotecnológico já foram isoladas de distintos processos de compostagem e em diferentes fases (Dees \& Ghiorse, 2001; Anastasi et al., 2005; Bitencourt et al., 2010; Pascon et al., 2011; Chandna et al., 2013b; Jurado et al., 2014; Lopez-Gonzalez et al., 2015a; Lopez-Gonzalez et al., 2015b; Oliveira et al., 2015; Storey et al., 2015). Em um recente trabalho de prospecção, mais de 4000 linhagens bacterianas pertencentes a 187 espécies distintas foram isoladas de diferentes fases da compostagem, a maioria pertencente aos filos Actinobacteria, Firmicutes e Proteobacteria, sendo uma alta proporção de bactérias termotolerantes (Lopez-Gonzalez et al., 2015a).

Por outro lado, abordagens moleculares independentes de cultivo, como análise de perfis de restrição de amplicons de rDNA (RAPD), eletroforese em gel desnaturante (DGGE) e hibridização de DNA, além da clonagem e sequenciamento do gene do rRNA16S, possibilitaram estudos mais abrangentes da diversidade de comunidades microbianas e revelaram que Actinomycetales, Bacillales, Clostridiales and Lactobacillales estão entre as ordens mais representadas na compostagem (Peters et al., 2000; Alfreider et al., 2002; Guo et al., 2007; Steger et al., 2007b; Franke-Whittle et al., 2009; Partanen et al., 2010; Zainudin et al., 2014). Lactobacillales é comumente 
associada a fase inicial do processo de temperaturas mesofílicas; enquanto as ordens Bacillales, Clostridiales e Actinomycetales têm sido relacionadas a fase termofílica. Apesar de terem ampliado a detecção de grupos microbianos, estas abordagens são limitadas por viéses inerentes de técnicas que envolvem obtenção e clonagem de amplicons do gene de rRNA ou hibridização de DNA (Bent \& Forney, 2008; Hong et al., 2009; Rajendhran \& Gunasekaran, 2011; Gonzalez et al., 2012).

Nos últimos anos, o desenvolvimento de abordagens metagenômicas e de sequenciamento de DNA de alto desempenho (Caporaso et al., 2012; Logares et al., 2014), juntamente com o aprimoramento dos protocolos de purificação de DNA de amostras complexas (como solo e compostagem) (Lombard et al., 2011; Penton et al., 2016) ampliaram muito as possibilidades de capturar informações completas e detalhadas da composição filogenética e da diversidade de genes de comunidades microbianas, e tais abordagens tem sido aplicadas no estudo de populações microbianas de compostagens e de consórcios microbianos dela derivados. Estes estudos, embora tenham confirmado que os filos mais abundantes na compostagem são Actinobacteria, Firmicutes, Bacteroidetes e Proteobacteria, não exploraram a dinâmica da sucessão microbiana no processo de compostagem (de Gannes et al., 2013; Martins et al., 2013; Neher et al., 2013; Storey et al., 2015; Zhang et al., 2016).

A capacidade destes grupos de microrganismos de conduzir o processo de degradação da matéria orgânica vem da sua capacidade de produzir enzimas para hidrólise dos substratos disponíveis (Ryckeboer et al., 2003a), sendo que para a hidrólise de uma única fonte de carbono, como a celulose, pode requerer a ação conjunta de diferentes enzimas e proteínas acessórias (Eichorst et al., 2013). Nesta tarefa, Clostridiales tem desempenhado um papel de destaque por possuir um complexo multi-enzimático denominado celulosomo de degradação da celulose que é expresso em condições termofílicas típicas do processo de compostagem (Izquierdo et al., 2010; Xia et al., 2014). Actnomycetales foi a ordem mais abundante de um consórcio derivado de compostagem de arroz, sendo que mais de $46 \%$ das enzimas classificadas pelo CAZy codificadas no metagenomas eram relativas a esta ordem (Wang et al., 2016). Nesse consórcio, os transcritos de enzimas de 
degradação da lignocelulose com expressão aumentada foram atribuídas principalmente ao gênero Micromonospora.

Os gêneros Bacillus, Clostridium, Thermus, Thermobispora e Streptomyces também são conhecidos como degradadores de celulose e já foram isolados ou detectados a partir de fases termofílicas de compostagem (Kato et al., 2004; Lopez-Gonzalez et al., 2015a; Wang et al., 2016). Além disso, um pequeno número de espécies de fungos também foi identificado em compostagens (Ryckeboer et al., 2003b; Anastasi et al., 2005; Hultman et al., 2010; Lopez-Gonzalez et al., 2015b).

\subsection{Abordagens independentes de cultivo para estudos de comunidades microbianas}

Como mencionado anteriormente, o emprego de abordagens independentes de cultivo tem contribuído de maneira extraordinária para 0 estudo de comunidades microbianas possibilitando o acesso a vasta e, ainda desconhecida, diversidade de microrganismos que não são cultiváveis com as técnicas e meios comumente empregados. Estas abordagens podem ser divididas em três categorias: (1) análise do perfil da comunidade microbiana (microbial community fingerprinting) através de RAPD, DGGE ou hibridização de DNA; (2) sequenciamento de alto desempenho de regiões hipervariáveis do gene do rRNA16S, precedido ou não pela etapa de clonagem; e (3) sequenciamento de alto desempenho do DNA total extraído da comunidade microbiana.

O emprego do sequenciamento de gene do rRNA16S em trabalhos de diversidade de comunidades microbianas utilizando-se como fonte de estudo 0 DNA extraído de amostras ambientais foi proposto na década de 1980 (Pace et al., 1985). Na década de 1990, foi empregado no estudo de ecologia da comunidade de plânctions do Mar do Sargasso e pela primeira vez foi realizado o sequenciamento direto da biblioteca de clones de rRNA utilizando a tecnologia Sanger. $\mathrm{Na}$ década seguinte, o surgimento das tecnologias de sequenciamento de alto desempenho a um relativo menor custo financeiro, menor tempo e menor exigência de infraestrutura laboratorial, permitiu o rápido aumento do número de trabalhos descrevendo comunidades ambientais e 
associadas a organismos hospedeiros (Binnewies et al., 2006; Hiergeist at al, 2015; Venter et al.,2004).

A utilização do gene rRNA 16S como marcador filogenético está consolidada principalmente por apresentar características como: baixa taxa de transferência horizontal, baixa taxa de recombinação gênica, ser capaz de diferenciar espécies proximamente relacionadas e ser 0 gene mais representado em base de dados (Schloss et al., 2011; Schloss \& Westcott, 2011; Yarza et al., 2014). Esta abordagem é particularmente interessante nos estudos de comunidades de microrganismos associadas a um hospedeiro, uma vez que, permite o acesso direto a esta microbiota sem a interferência (ou contaminação) do genoma do hospedeiro, e com um número menor de sequências a ser analisadas computacionalmente (Rajan et al, 2015). Além disso, o vasto número de trabalhos que utilizam esta abordagem permite a realização de comparações entre diferentes comunidades, ressalvadas as diferenças metodológicas empregadas (DeLong \& Pace, 2001; Tringe \& Hugenholtz, 2008; Pace, 2009).

Apesar da ampla utilização do gene do rRNA16S, esta abordagem tem limitações de ordem metodológica, tais como: (1) ocorrência de viéses na etapa de amplicação como a incorporação de erros nas sequências do amplicon, possibilidade da geração de quimeras e falha na amplificação do 16S de espécies sub-representadas na amostra de DNA; (2) tamanho do amplicon é limitado pela plataforma de sequenciamento e (3) o par de primers utilizado não necessariamente cobrirá toda a diversidade da amostra, visto que estes primers tem sido definidos a partir de sequências de genes do rRNA16S de bactérias cultiváveis. A avaliação do desempenho de mais de 500 pares de primers para amplificação de segmentos do gene do rRNA16S revelou que apenas 10 pares apresentavam resultados satisfatórios considerando a cobertura ( $85 \%)$ obtida ao nível de filo (Klindworth et al., 2013; Eloe-Fadrosh et al., 2016a).

Apesar destas limitações, o sequenciamento de alto desempenho de bibliotecas de amplicons do rRNA16S é amplamente empregado na caracterização taxonômica de comunidades microbianas, sendo comumente referido como metagenômica 16S. Através desta abordagem são identificadas 
as OTUs (Unidades Taxonômicas Operacionais) presentes na comunidade microbiana, bem como sua abundância relativa. A OTU representa um grupo de sequências muito próximas ( $>97 \%$ de identidade) que se separa das demais OTUs pela aplicação de técnicas de agrupamento hierárquico utilizando limites de identidade de sequência independentemente de inferências filogenéticas (Yarza et al., 2014). Em uma aproximação, uma OTU pode corresponder a uma espécie microbiana, mas nem sempre há resolução para esta definição com precisão, já que algumas espécies podem apresentar sequências quase idênticas de regiões do gene rRNA 16S.

Algumas das limitações mencionadas, podem ser contornadas com a realização de mais de uma reação de amplificação, uso de pares de primers diferentes e utilização de ferramentas de bioinformática para remoção de sequências com baixa qualidade e de potenciais sequências quiméricas, dentre outros artefatos (Caporaso et al., 2010b; Kuczynski et al., 2011; Schloss \& Westcott, 2011; McDonald et al., 2012; Aronesty, 2013; Edgar, 2013; Cole et al., 2014; Eloe-Fadrosh et al., 2016b).

$\mathrm{Na}$ caracterização de uma comunidade microbiana, além da descrição da sua composição taxonômica, normalmente são realizadas análises de riqueza e de diversidade, as quais permitem comparar ambientes distintos e oferecem uma medida da complexidade da comunidade. A riqueza de uma amostra pode ser definida como o número de OTUs presentes na mesma. Enquanto a diversidade é uma medida da riqueza e da distribuição das abundâncias das OTUs nesta comunidade e pode ser calculada utilizando diferentes índices, que ainda podem ser associados a medidas de distância e índices de dissimilaridade como Jaccard, Sorenson e Bray-Curtis (AguiarPulido et al., 2016a).

\subsection{Metagenômica shotgun e Metatranscritômica}

O termo Metagenômica foi proposto por em 1998 e se refere ao estudo do genoma de espécies distintas presentes em uma amostra ambiental (Handelsman et al., 1998). A abordagem metagenômica atualmente referida como metagenômica shotgun não necessita de primers para a amplificação de genes marcadores filogenéticos, uma vez que, utiliza o sequenciamento do 
DNA total extraído da comunidade fragmentado aleatoriamente (shotgun). Esta estratégia permite a caracterização taxonômica a partir de sequências de genes codificadores de proteínas (CDS), superando assim as limitações da Metagenômica 16S, descrita anteriormente (Tringe \& Rubin, 2005; EloeFadrosh et al., 2016a).

O desenvolvimento da metagenômica shotgun permitiu a caracterização da estrutura de diferentes comunidades microbianas com a possibilidade de recuperação de genomas incompletos e a reconstrução de genomas completos de microrganismos de divisões e filos candidatos da microbiota não cultivável, além de possibilitar a descoberta de novos genes e a elaboração de inferências acerca das funções executadas pela comunidade (Tyson et al., 2004; Venter et al., 2004; Binnewies et al., 2006; Dinsdale et al., 2008; Simon \& Daniel, 2011; Rinke et al., 2013). No entanto, os seus dados conferem uma maior incerteza quanto a afiliação de genes a organismos específicos e demandam um maior esforço de sequenciamento, em termos de cobertura do genoma e de análise computacional; deste modo, as duas abordagens de metagenômica são complementares para a descrição da estrutura de uma comunidade e na realização de inferências de funcionalidade (Shakya et al., 2013; Poretsky et al., 2014).

O rápido aprimoramento de tecnologias de sequenciamento de DNA de alto desempenho (Next-generation sequencing, NGS) (Mardis, 2013) teve um papel essencial no avanço e na disseminação da utilização de abordagens de metagenômica, possibilitando a obtenção de um grande volume de dados de sequências a um custo financeiro relativamente baixo e em menor tempo. As sequências obtidas (reads) são submetidas a uma etapa de préprocessamento, onde são triadas por qualidade e tamanho, seguido pela remoção de sequências adaptadoras e potencialmente quiméricas. Posteriormente a este processamento, é realizada ou não a montagem das sequências (reads) para a obtenção de contigs. Na metagenômica shotgun tanto reads como contigs são anotados para a predição de função por meio do auxílio de plataformas de anotação como MG-RAST e IMG-M, além de serem submetidos a classificação taxonômica por programas como MyTaxa 
(Markowitz et al., 2008; Glass et al., 2010; Luo et al., 2014; Aguiar-Pulido et al., 2016a).

Complementando a revolução que a metagenômica proporcionou na caracterização de comunidades microbianas, a metatranscritômica vai além da avaliação do potencial genético predito pela metagenômica shotgun e possibilita a identificação de quais os genes estão efetivamente sendo expressos na amostra ambiental em um dado momento ou condição. A metatranscritômica permite ainda avaliar alterações nas funções expressas e a elaborar inferências acerca de impacto de determinadas condições na expressão gênica da comunidade microbiana (Toseland et al., 2014).

A metatranscritômica é uma abordagem baseada no sequenciamento em grande-escala de cDNAs (RNA-seq) que permite a caracterização e a quantificação do metatranscritoma completo e tem, virtualmente, o potencial para detecção de todos os transcritos expressos pela comunidade microbiana em estudo (Carvalhais et al., 2012; Aguiar-Pulido et al., 2016b). Os primeiros estudos de metatranscritômica datam de 2005 e, esta abordagem já foi empregada no estudo de comunidades microbianas de oceanos e solos e também da microbiota associada ao intestino humano (Botero et al., 2005; Poretsky et al., 2005; Urich et al., 2008; Shi et al., 2009; Carvalhais et al., 2012; Franzosa et al., 2014). A utilização da metatranscritômica em estudos de comunidades associadas a ambientes de degradação de biomassa vegetal permitiu identificar os genes expressos cujos produtos estão diretamente envolvidos na decomposição da lignocelulose (Simmons et al., 2014; Xia et al., 2014).

Os protocolos de metatranscritômica, geralmente compreendem uma etapa de enriquecimento da amostra na população de mRNAs que pode ser realizada por procedimentos que resultam na depleção das moléculas de rRNA, previamente a síntese de cDNA e sequenciamento NGS. As sequências (reads) obtidas são submetidas a montagem para a obtenção de contigs que, juntamente com reads não montadas são encaminhados para a anotação funcional e classificação taxonômica, de modo similar ao procedimento realizado nas análises de sequências de metagenômica shotgun. Além disso, são realizadas análises da abundância dos transcritos através do mapeamento 
das reads nos contigs de metatranscritômica ou em genomas de referência (Aguiar-Pulido et al., 2016a). 


\section{Contextualização e Objetivos}

Em um trabalho anterior foi realizada uma avaliação da diversidade da microbiota da compostagem do Parque Zoológico de São Paulo através de metagenômica shotgun e pirossequenciamento de DNA de amostras de duas composteiras distintas (ZC1 e ZC2) que se apresentavam em fases diferentes do processo (Martins et al., 2013). A análise de ambos metagenomas mostrou que os perfis filogenéticos destes dois microbiomas eram muito diferentes e diversos, sendo que um deles apresentou a dominância do gênero Lactobacillus. Contudo, foi constatado uma concordância da distribuição de categorias funcionais proteicas quando os metagenomas da ZC1 e ZC2 foram comparados com sete metagenomas públicos de ambientes de degradação de biomassa. Os resultados obtidos possibilitaram a proposição de que o processo de degradação da biomassa, incluindo a desconstrução de lignocelulose, é completamente realizado por enzimas bacterianas provavelmente produzidas por Clostridiales e Actinomycetales. Além disso, verificamos que a compostagem do Parque Zoológico abriga, como era esperado, uma grande diversidade microbiana, que possivelmente resulta da combinação da riqueza filogenética de comunidades do solo e do fragmento de Mata Atlântica lá existente e da microbiota associada aos animais do próprio Zoológico.

O Parque Zoológico de São Paulo está localizado na área urbana da cidade de São Paulo (2338'56.9"S 46³7'18.7"W) ocupando uma área de $900.000 \mathrm{~m}^{2}$ que inclui um fragmento de Mata Atlântica (Figura 3) (Bitencourt et al., 2010). O acervo do Parque compreende $\sim 400$ espécies de animais da fauna nativa e exótica, totalizando aproximadamente 4000 animais. O Parque possui diversos lagos, nascentes, estações de tratamento de água e de esgoto e a unidade de compostagem (UC) (Figura 4A). A UC processa todos os resíduos orgânicos gerados no Parque, produzindo composto maduro que é utilizado como adubo na produção de verduras e hortaliças que são consumidas pelos animais do Parque, fechando, assim, um ciclo de sustentabilidade. 


\section{CONTEXTUALIZAÇÃO E OBJETIVOS}

A

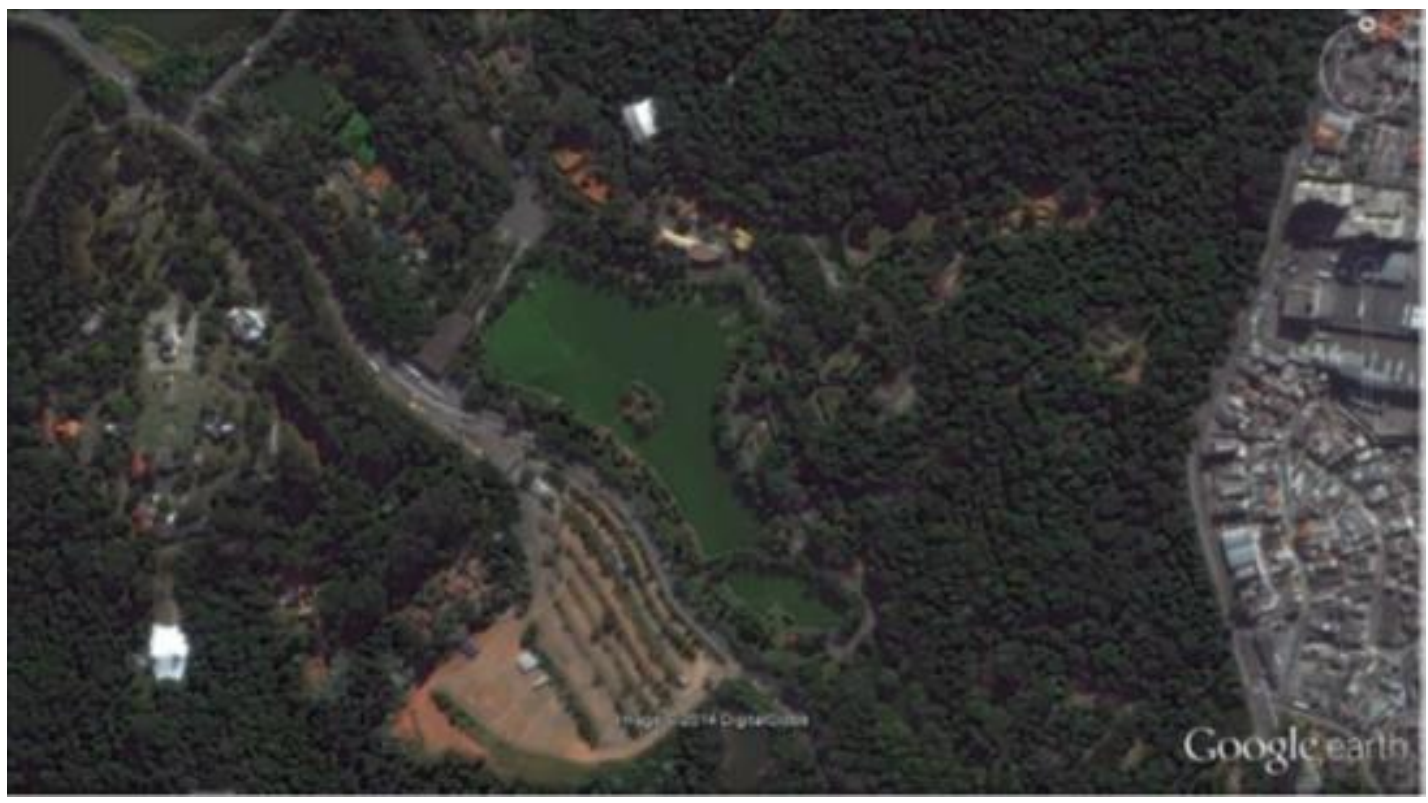

B

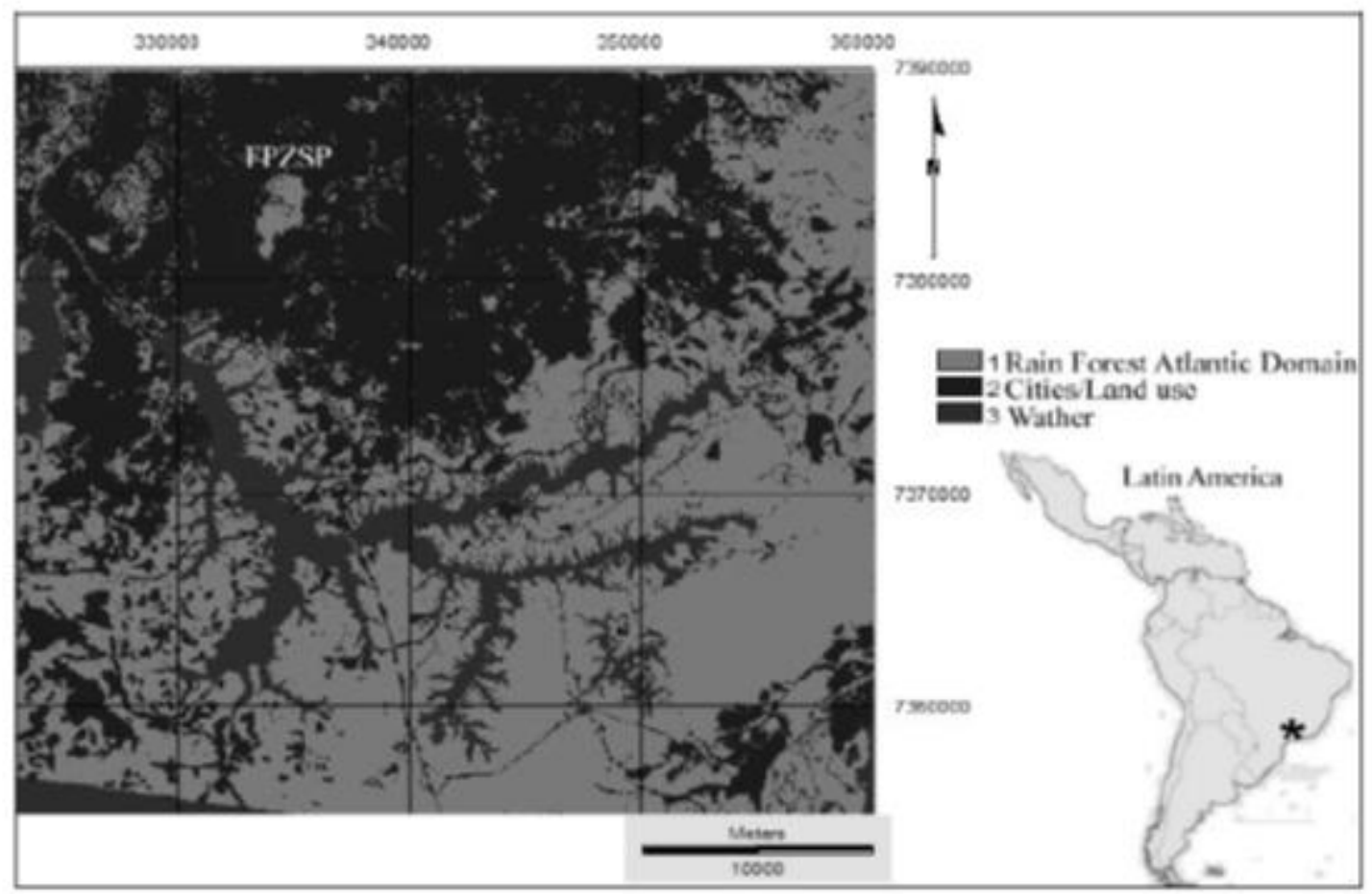

Figura 3: Localização da FPZSP na Zona Sul da cidade de São Paulo. (A) Vista aérea, imagem obtida através do programa Google Earth, altitude do ponto de visão $1.78 \mathrm{~km}, 2^{\circ} 39^{\prime} 04.72$ 'S, 46³7'05.78”O. (B) Imagem de satélite na qual está representado: áreas de ocupação urbana e de uso da terra (preto), de domínio da Mata Atlântica (cinza) e recurso hídrico (cinza escuro) (Figura retirada de Bitencourt et al., 2010). 
A

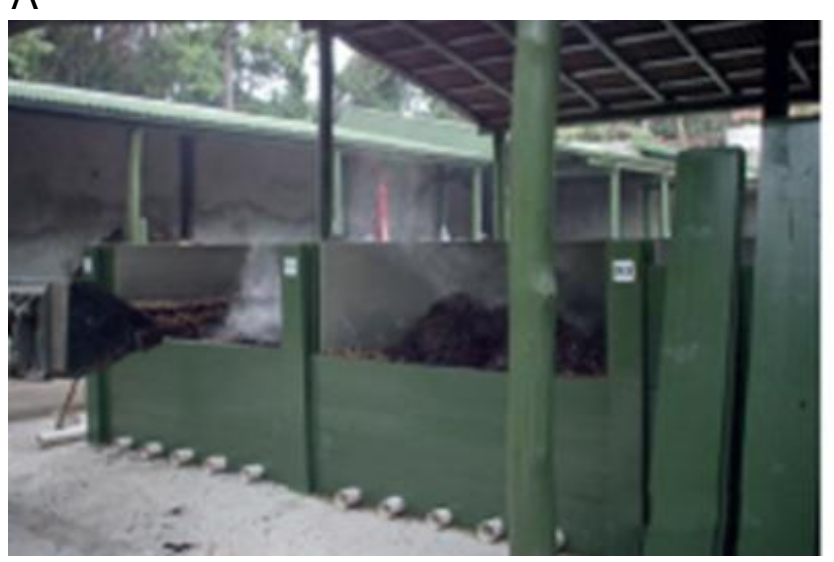

B

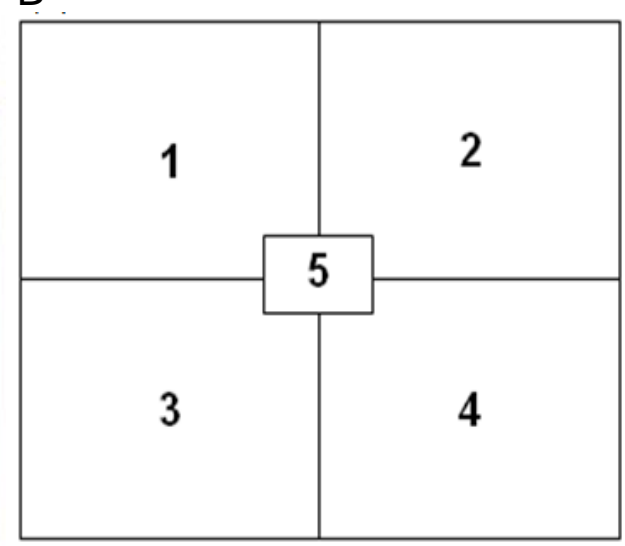

C

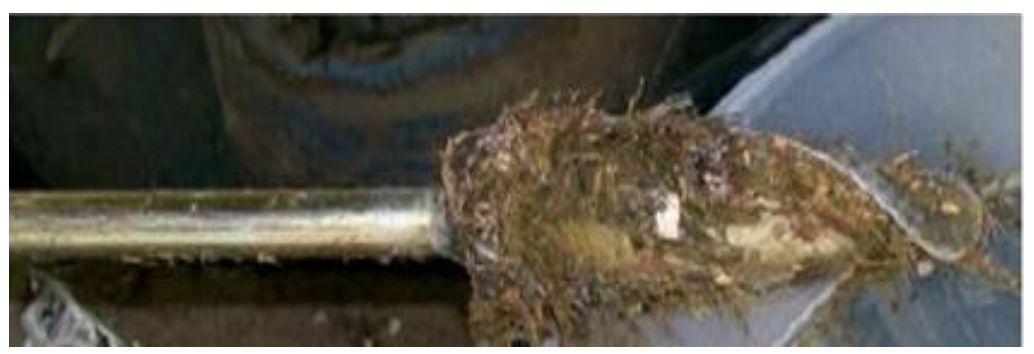

Figura 4: Composteiras da FPZSP e esquema de amostragem. (A) Composteiras da Unidade de Compostagem (UC) da FPZSP. (B) Esquema superfície da composteira mostrando os cinco pontos para coleta de amostras e para a medição da temperatura. (C) Ponta do trado utilizado para coleta de amostra. Imagens retiradas de Bitencourt et al., 2010.

Em continuidade ao primeiro estudo de prospecção molecular da diversidade microbiana da comunidade associada a compostagem do Parque Zoológico de São Paulo (Martins et al., 2013), foi proposto um estudo mais detalhado para avaliar alterações na comunidade microbiana e no seu potencial genético ao longo do processo de transformação dos resíduos orgânicos em adubo. É importante ressaltar que a compostagem no Zoológico atinge temperaturas elevadas $\left(60-75^{\circ} \mathrm{C}\right)$ e, portanto, é razoável supor que, nestes estágios ocorra um enriquecimento da microbiota em grupos taxonômicos termofílicos, os quais seriam uma fonte promissora de enzimas termoestáveis. Assim, o trabalho aqui apresentado esta inserido neste contexto e para o seu desenvolvimento foram propostos os objetivos e as estratégias explicitadas a seguir. 


\subsection{Objetivo geral}

Investigar a composição e a diversidade taxonômica das comunidades microbianas ao longo do processo de compostagem do Parque Zoológico de São Paulo, com abordagens independentes de cultivo, e identificar as funções bioquímicas expressas por estas populações microbianas, principalmente aquelas relacionadas à degradação de biomassa lignocelulósica.

\subsection{Objetivos específicos e estratégias}

Investigar a estrutura do microbioma da compostagem e determinar quais os membros desta comunidade estão ativos ao longo da série temporal e contribuindo para que o processo de degradação da biomassa ocorra. Além, de analisar o potencial gênico e os genes expressos pela comunidade, com ênfase nos relacionados com a degradação da lignocelulose. Para isto utilizamos as seguintes estratégias:

- Obter amostras de duas composteiras (ZC3 e ZC4) ao longo do processo de compostagem;

- Isolar DNA das amostras com pureza e integridade adequados para os protocolos de metagenômica shotgun e metagenômica 16S;

- Isolar RNA total das amostras com pureza e integridade adequados para o procedimento de enriquecimento da população de mRNA, síntese de cDNA e sequenciamento (metatranscritômica);

- Caracterizar a composição taxonômica e funcional, bem como suas variações ao longo do processo de compostagem, a partir do vasto conjunto de dados dos metagenomas e metatranscritomas sequenciados no âmbito deste trabalho;

- Aferir parâmetros físico-químicos das amostras coletadas e/ou das composteiras, tais como temperatura, $\mathrm{pH}$, concentração de elementos químicos como $\mathrm{C}, \mathrm{N}, \mathrm{K}$ e $\mathrm{P}$, entre outros; 
- Correlacionar os grupos taxonômicos que compõem a microbiota da compostagem com funções relacionadas a degradação da biomassa lignocelulósica;

- Identificar os microorganismos mais abundantes nas comunidades microbianas do sistema de compostagem em estudo. 


\section{Procedimentos Experimentais}

\subsection{Unidade de Compostagem do Parque Zoológico de São Paulo}

O procedimento para montagem das composteiras utilizado na Unidade de Compostagem (UC) na Fundação Parque Zoológico de São Paulo (FPZSP) é uma adaptação de processos de compostagem previamente descritos (Rynk et al., 1992; Diaz et al., 2007). A compostagem é realizada em células de concreto de $8 \mathrm{~m}^{3}$ com adição de matéria orgânica, na razão aproximada de 30:1 de Carbono/Nitrogênio $(\mathrm{C} / \mathrm{N})$. A manutenção do nível adequado de aeração ocorre por difusão passiva de gases entre o topo do material adicionado na composteira e as perfurações de tubos de PVC (policloreto de vinila) de $44 \mathrm{~mm}$ de diâmetro instalados na sua base, os quais apresentam suas extremidades abertas para o ambiente (Figura 4A). Além disso, os substratos são distribuídos em camadas durante a montagem de modo a evitar a compactação excessiva do composto (Diaz et al., 2007). A última camada colocada consiste de palha vegetal, que contribui para 0 isolamento térmico do composto em relação a temperatura do ambiente. A umidade recomendada (50-60\%) é mantida pela rega esporádica com água ou com o chorume gerado no processo de compostagem.

Os substratos que são diariamente compostados na UC incluem dejetos e cama dos animais do Parque Zoológico, restos de alimentação, podas de árvores e folhas da mata e dos jardins do parque; carcaças de animais mortos do acervo, chorume gerado no processo de compostagem e lodo produzido nas estações de tratamentos de esgoto e de água existentes no Parque Zoológico. A UC foi instalada em 2003 como parte do Sistema de Gestão Ambiental da FPZSP, ocupa uma área de $1500 \mathrm{~m}^{2}$ do Parque Zoológico, pavimentada e coberta, com 44 células de concreto (Figura 4A). A UC processa 4 ton. de matéria orgânica por dia gerando aproximadamente 180 ton. de composto maduro por mês, o qual é utilizado como adubo na Divisão de Produção Rural da FPZSP, em Araçoiaba da Serra (SP), e nos jardins do Parque Zoológico (Da Cruz, 2004; Oliveira et al., 2015).

Usualmente as células são preenchidas com a matéria orgânica, alternando-se camadas de material vegetal previamente triturado e dejetos dos animais com demais substratos, e uma camada de composto retirado de 
composteiras em fase mais adiantada do processo (após 60-70 dias). Após 0 preenchimento de cada célula, a temperatura do material orgânico é medida semanalmente e quando diminui abaixo de $55^{\circ} \mathrm{C}$, o que normalmente ocorre após 60-65 dias do início do processo, a pilha é revirada utilizando o trator BobCat skid-steer loader (Bobcat Company, North Dakota, USA), para promover aeração, sendo a oxigenação recomendada $>5 \%$. Após a revira, ocorre a elevação da temperatura. Após $\sim 100$ dias, o processo de compostagem é considerado acabado na célula de concreto e o composto maduro é transferido para uma pilha e misturado ao composto maduro oriundo de outras células de compostagem, onde permanece por até 3 semanas antes de ser utilizado como adubo orgânico.

\subsection{Coleta de amostras das composteiras ZC3 e ZC4}

Neste trabalho coletamos amostras de duas composteiras denominadas ZC3 e ZC4, que foram montadas, respectivamente, em 27/06/2011 e 05/08/2013. O procedimento de montagem destas composteiras foi realizado como descrito acima, exceto por não ter sido adicionadas carcaças de animais, chorume e lodo produzido nas estações de tratamentos de esgoto e de água do Parque.

Durante o processo de compostagem da ZC3, realizamos coletas de amostras após 1, 30, 64, 78 e 99 dias de sua montagem e serão referidas como D01, D30, D64, D78 e D99 de ZC3. No caso da composteira ZC4, as coletas foram realizadas após $1,3,7,15,30,64,67,78$ e 99 dias de sua montagem (amostras D01, D03, D07, D15, D30, D64, D67, D78 e D99 de ZC4). Nesta tarefa contamos com a supervisão do Dr. João Batista da Cruz e com auxílio dos funcionários da UC da FPZSP.

As coletas seguiram 0 procedimento previamente padronizado (Bitencourt et al., 2010; Martins et al., 2013) utilizando-se um trado (Figura 4B e 4C) que foi introduzido verticalmente no topo da pilha na composteira em quatro pontos equidistantes próximos as extremidades e no centro para retirada cinco sub-amostras de $\sim 100 \mathrm{~g}$ de material. As sub-amostras foram reunidas, misturadas homogeneamente em um recipiente compondo uma amostra que foi, em seguida, distribuída em tubos Falcon estéreis de $50 \mathrm{~mL}$ ou 
$15 \mathrm{~mL}$. Estas alíquotas foram congeladas em gelo seco, transportadas para o laboratório, liofilizadas e armazenadas em ultra-freezer a $-80^{\circ} \mathrm{C}$ (amostras destinadas à extração de DNA e análise elementar) ou processadas imediatamente no laboratório da FPZSP (amostra destinada a medida de pH e umidade).

Para extração de RNA total, $\sim 1 \mathrm{~g}$ da amostra fresca (apenas amostras de ZC4) foi imediatamente misturado com $\sim 3 \mathrm{~mL}$ de LifeGuard (Mobio Laboratories, Carlsbad, USA), seguido pela homogeneização da suspensão e acondicionamento a temperatura ambiente, durante um período máximo de uma semana até a etapa de extração do RNA. Nesse caso, todo o material (tubos e espátulas) utilizado na manipulação foi tratado previamente com RNase Away (Life Technologies, Grand Island, EUA).

\subsection{Análises físico-químicas}

As composteiras ZC3 e ZC4 ou suas respectivas amostras foram submetidas a medidas de temperatura, $\mathrm{pH}$, teor de umidade e a análise química elementar. Análises de concentração de gases também foram realizadas na composteira ZC4 e outras composteiras da UC.

A temperatura das composteiras ZC3 e ZC4 foi, sempre que possível, aferida diariamente em quatro pontos equidistantes próximos as extremidades e no centro (Figura 4B) e a uma profundidade de $60 \mathrm{~cm}$ a partir do topo da pilha, utilizando um termômetro digital com uma sonda de aço inoxidável de cabo longo. A temperatura do ambiente também foi registrada.

Para a avaliação do $\mathrm{pH}$, foi preparada uma suspensão do composto fresco em uma solução de $0,9 \%$ de cloreto de sódio estéril, e o pH foi medido em medidor de $\mathrm{pH}$ a temperatura ambiente. $\mathrm{O}$ teor de umidade foi estimado através da secagem das amostras em forno de micro-ondas, como descrito (Rynk et al., 1992).

A concentração de Carbono, Hidrogênio e Nitrogênio foi avaliada utilizando o equipamento PerkinEImer 2400 séries II CHNS/O analyzer (PerkinElmer Massachusetts, EUA). Análises para determinação da concentração de diferentes elementos ( $\mathrm{Al}, \mathrm{Fe}, \mathrm{Mg}, \mathrm{P}, \mathrm{As}, \mathrm{Cd}, \mathrm{Cr}, \mathrm{Cu}, \mathrm{K}, \mathrm{Ni}, \mathrm{Pb}$, Se e $\mathrm{Zn}$ ) foram realizadas por espectrometria de emissão ótica com acoplamento de plasma 
induzido (ICP-AES) (Spectro, Kleve, Alemanha). Estas análises foram realizadas na Central Analítica do Instituto de Química da USP (http://ca.iq.usp.br/).

A medida da concentração de gases $\left(\mathrm{CO}_{2}, \mathrm{O}_{2}, \mathrm{CH}_{4}, \mathrm{CO}\right.$ e $\left.\mathrm{H}_{2}\right)$ em diferentes profundidades da composteira foi realizada pelo Prof. Dr. Carlos A. Mendonça (IAG-USP), utilizando o equipamento Landtec System Analyzer acoplado a uma sonda de $1 \mathrm{~m}$ de comprimento. Esta análise foi realizada em ZC4 após 30 dias do início do processo e em outra composteira da UC, após 5 dias da etapa de revira.

\subsection{Extração e purificação DNA e RNA}

As alíquotas liofilizadas das amostras coletadas das composteiras ZC3 e ZC4 foram pulverizadas em almofariz e pistilo esterilizados até que o composto apresentasse aspecto de pó bem fino. Deste material, $\sim 2 \mathrm{~g}$ foram utilizados para a extração de DNA com o kit MoBio PowerMax Soil DNA (MoBio Laboratories) seguindo modificações que padronizamos anteriormente (Martins et al., 2013). O DNA extraído foi submetido a uma etapa adicional de purificação utilizando o kit QIAamp mini spin columns (Qiagen, Valencia, USA) e acondicionado a $-20^{\circ} \mathrm{C}$.

As alíquotas destinadas a extração do RNA foram, primeiramente, removidas da solução de preservação LifeGuard (MoBio Laboratories, Carlsbad, USA), seguindo instruções do fabricante. Em seguida, estas alíquotas foram submetidas ao protocolo de extração de RNA do kit MoBio PowerSoil Total RNA isolation (MoBio Laboratories, Carlsbad, USA). Para a eliminação do DNA residual das preparações de RNA foi utilizado a DNAse do kit Illustra RNASpin (GE Healthcare Life Sciences, Marlborough, USA). O RNA extraído e purificado foi aliquotado e armazenado a $-80^{\circ} \mathrm{C}$. A completa remoção de DNA genômico foi confirmada por PCR utilizando primers das regiões V3 e V4 do gene rRNA 16S (ver seção 3.6.).

As preparações de DNA e RNA foram avaliadas e quantificadas pela medida das absorbâncias a 260nm, 280nm, 320nm e 230nm no espectrofotômetro ND-1000 (NanoDrop Technologies). Quantificação adicional foi realizada, por meio, de leituras de fluorescência em um espectrofluorímetro 
(excitação em $480 \mathrm{~nm}$ e intensidade de emissão medida a $520 \mathrm{~nm}$ ) com a utilização do QuantiT Picogreen dsDNA Assay Kit Quant-iT Ribogreen RNA Assay (Invitrogen) (Tabelas 1 e 2).

A integridade das preparações de DNA e RNA foi avaliada por eletroforese capilar no equipamento 2100 BioAnalyzer (Agilent Technologies), respectivamente, com DNA 7500 kit ou RNA 6000 Nano kit. Para as amostras de RNA foi possível aferir o número de integridade do RNA (RIN) (Schroeder et al., 2006), sendo que as amostras selecionadas para a construção das bibliotecas de cDNA e posterior sequenciamento apresentaram RIN entre 6,3 e 7,8 (Tabela 2).

Tabela 1: Medida da concentração e da qualidade do DNA metagenômico purificado das amostras de ZC3 e ZC4.

\begin{tabular}{|c|c|c|c|c|c|c|c|}
\hline \multicolumn{2}{|c|}{ Amostra } & $\begin{array}{c}\text { Data da } \\
\text { coleta }\end{array}$ & $\begin{array}{l}\text { Volume } \\
\text { total } \\
\text { uL }\end{array}$ & $\begin{array}{c}\text { Concentração } \\
\text { (NanoDrop) } \\
\text { ng/uL }\end{array}$ & $260 / 280$ & $260 / 230$ & $\begin{array}{c}\text { Concentração } \\
\text { (Picogreen) } \\
\text { ng/uL }\end{array}$ \\
\hline \multirow{5}{*}{ ZC3 } & D01 & $28 / 06 / 11$ & 1000 & 109,73 & 1,83 & 2,16 & 111,14 \\
\hline & D30 & $27 / 07 / 11$ & 1000 & 19,00 & 1,82 & 1,47 & 15,00 \\
\hline & D64 & $30 / 08 / 11$ & 500 & 68,00 & 1,76 & 1,21 & 53,12 \\
\hline & D78 & $13 / 09 / 11$ & 500 & 7,54 & 1,80 & 1,21 & 16,25 \\
\hline & D99 & $04 / 10 / 11$ & 3000 & 13,00 & 1,82 & 2,30 & 6,88 \\
\hline \multirow{9}{*}{ ZC4 } & D01 & $06 / 08 / 13$ & 2000 & 53,70 & 2,31 & 1,57 & 22,40 \\
\hline & D03 & $08 / 08 / 13$ & 2000 & 56,80 & 2,26 & 1,25 & 21,34 \\
\hline & D07 & $12 / 08 / 13$ & 2000 & 21,20 & 1,94 & 1,22 & 11,08 \\
\hline & D15 & $20 / 08 / 13$ & 2000 & 14,10 & 1,86 & 1,07 & 7,35 \\
\hline & D30 & 04/09/13 & 300 & 39,00 & 1,81 & 1,66 & 23,58 \\
\hline & D64 & $08 / 10 / 13$ & 100 & 5,40 & 1,92 & 1,43 & 4,10 \\
\hline & D67 & $11 / 10 / 13$ & 100 & 3,40 & 1,83 & 1,69 & 2,81 \\
\hline & D78 & $22 / 10 / 13$ & 100 & 29,50 & 1,83 & 1,92 & 19,55 \\
\hline & D99 & $12 / 11 / 13$ & 100 & 32,90 & 1,81 & 2,05 & 22,33 \\
\hline
\end{tabular}

Tabela 2: Medida concentração e da qualidade do RNA total purificado das amostras de ZC4.

\begin{tabular}{|r|c|c|c|c|c|}
\hline Amostra & $\begin{array}{c}\text { Volume } \\
\text { total } \\
\text { (uL) }\end{array}$ & $\begin{array}{c}\text { Concentração } \\
\text { (NanoDrop) } \\
\text { ng/uL }\end{array}$ & A260/A280 & A260/A230 & RIN \\
\hline D01 & 60 & 1,05 & 1,66 & 0,75 & 6,9 \\
\hline D03 & 60 & 5,75 & 2,05 & 1,94 & 7,6 \\
\hline D07 & 60 & 3,97 & 1,99 & 1,85 & 6,4 \\
\hline ZC4 & 60 & 5,50 & 1,96 & 1,64 & 7,2 \\
\hline D15 & 60 & 4,45 & 2,03 & 2,14 & 6,5 \\
\hline D30 & 60 & 9,05 & 1,95 & 2,05 & 7,8 \\
\hline D64 & 60 & 7,72 & 2,08 & 1,05 & 6,3 \\
\hline D78 & 60 & 12,34 & 2,12 & 2,12 & 7,8 \\
\hline D99 & 60 & & & & \\
\hline
\end{tabular}




\subsection{Preparação de bibliotecas de fragmentos de DNA (Metagenômica shotgun)}

O DNA purificado das amostras de compostagem foi submetido a fragmentação aleatória (shotgun) para construção de bibliotecas de fragmentos de DNA compatíveis com o sequenciamento de alto desempenho na plataforma 454-Roche (amostras de ZC3) e na plataforma MiSeq/lllumina (amostras de ZC3 e ZC4).

\subsubsection{Sequenciamento shotgun na plataforma 454-Roche.}

Para a preparação de bibliotecas de fragmentos de DNA para o pirossequenciamento (Ahmadian et al., 2006) na plataforma 454-Roche, utilizamos entre $0,5-1 \mu \mathrm{g}$ de DNA total purificado de acordo com o protocolo do fabricante, que, resumidamente, consiste na nebulização do DNA com nitrogênio ultrapuro para a sua fragmentação, polimento das extremidades dos fragmentos de DNA, ligação de oligonucleotídeos marcadores e de adaptadores específicos nas extremidades 3'e 5', imobilização das moléculas de DNA em microesferas, PCR em emulsão, recuperação das microesferas e enriquecimento daquelas onde a amplificação clonal do fragmento de DNA foi eficiente, montagem da PicoTiterPlate contendo estas microesferas e 0 sequenciamento propriamente dito.

Foram realizadas 3 corridas das bibliotecas das cinco amostras de ZC3, no equipamento 454 Genome Sequencer FLX da Roche Applied Science instalado no Centro Avançado de Tecnologias em Genômica (CATG) do Departamento de Bioquímica do IQ-USP com auxílio da Dra. Layla Farage Martins. Na primeira e segunda corridas foi utilizado o kit GS-FLX Plus e na terceira corrida foi utilizado o Kit GS-FLX 454 Titanium. As métricas desse sequenciamento estão apresentadas na Tabela 3. 
PROCEDIMENTOS EXPERIMENTAIS

Tabela 3: Métricas do sequenciamento e da montagem de sequências metagenômicas das amostras de ZC3.

\begin{tabular}{|c|c|c|c|c|c|c|c|c|c|c|}
\hline \multicolumn{11}{|c|}{ Sequenciamento shotgun (Metagenômica shotgun) } \\
\hline \multirow{2}{*}{ Parâmetros } & \multicolumn{2}{|c|}{ D01 } & \multicolumn{2}{|c|}{ D30 } & \multicolumn{2}{|c|}{ D64 } & \multicolumn{2}{|c|}{ D78 } & \multicolumn{2}{|c|}{ D99 } \\
\hline & (A) & (B) & (A) & (B) & $(A)$ & $(\mathrm{B})$ & (A) & (B) & (A) & $(\mathrm{B})$ \\
\hline Número total de reads $\mathrm{PE}$ & 520074 & 2270264 & 737772 & 2145650 & 771427 & 1265240 & 1063197 & 2169689 & 711081 & 1509658 \\
\hline Tamanho médio dos reads (pb) & 441 & 170 & 456 & 168 & 473 & 220 & 460 & 223 & 455 & 229 \\
\hline $\begin{array}{l}\text { Tamanho do Metagenoma não } \\
\text { montado }(\mathrm{pb})^{*}\end{array}$ & 229379927 & $\underset{*}{772598899}$ & 336965302 & $\underset{*}{722769482}$ & 364908522 & $\underset{*}{557561329}$ & 489666559 & $\underset{*}{970119798}$ & 323585594 & $\underset{*}{691581550}$ \\
\hline $\begin{array}{l}\text { Tamanho do Metagenoma } \\
\text { montado (pb) }\end{array}$ & 99374672 & 91049842 & 154178375 & 75162465 & 151490080 & 72084723 & 221702398 & 149615890 & 134924924 & 103783150 \\
\hline Número de reads em contigs & 261879 & 934704 & 320630 & 642220 & 321818 & 423598 & 434903 & 717453 & 331181 & 557619 \\
\hline Número de contigs† & 208638 & 192597 & 335023 & 172923 & 319374 & 163444 & 480843 & 348389 & 283713 & 229445 \\
\hline Maior contig (bp) & 6902 & 11253 & 5323 & 6137 & 6606 & 5653 & 4354 & 5960 & 9563 & 9198 \\
\hline Tamanho médio do contig (pb) & 476 & 472 & 460 & 434 & 474 & 441 & 461 & 429 & 475 & 452 \\
\hline Tamanho do contig N50 (pb) & 458 & 435 & 457 & 404 & 465 & 414 & 459 & 409 & 465 & 426 \\
\hline Número de singletons & 258195 & 1335560 & 417142 & 1503430 & 449609 & 841642 & 628294 & 1452236 & 379900 & 952039 \\
\hline \multicolumn{11}{|c|}{ Sequenciamento do amplicon das regiões V3-V4 do gene rRNA 16S (Metagenômica 16S) } \\
\hline Parâmetros & \multicolumn{2}{|c|}{ D01 } & \multicolumn{2}{|c|}{ D30 } & \multicolumn{2}{|c|}{ D64 } & \multicolumn{2}{|c|}{ D78 } & \multicolumn{2}{|c|}{ D99 } \\
\hline Número total de reads $\mathrm{PE}$ & \multicolumn{2}{|c|}{3796538} & \multicolumn{2}{|c|}{4862931} & \multicolumn{2}{|c|}{2508305} & \multicolumn{2}{|c|}{4436611} & \multicolumn{2}{|c|}{2661313} \\
\hline $\begin{array}{l}\text { Tamanho médio dos reads } \\
\text { (pb) } \pm \text { desvio padrão }\end{array}$ & \multicolumn{2}{|c|}{$453 \pm 13$} & \multicolumn{2}{|c|}{$453 \pm 13$} & \multicolumn{2}{|c|}{$454 \pm 16$} & \multicolumn{2}{|c|}{$457 \pm 13$} & \multicolumn{2}{|c|}{$457 \pm 13$} \\
\hline \multicolumn{11}{|c|}{ (A) Roche 454 GS FLX Titanium } \\
\hline \multicolumn{11}{|c|}{ (B) Paired-end reads obtidos com Illumina-MiSeq (500 ciclos) } \\
\hline \multicolumn{11}{|c|}{$\begin{array}{l}\text { * soma dos reads paired-end: read1 e read2 } \\
\text { † apenas contigs com tamanho } \geq 300 \mathrm{pb}\end{array}$} \\
\hline
\end{tabular}




\subsubsection{Bibliotecas de fragmentos de DNA para sequenciamento na plataforma Illumina/MiSeq}

Para sequenciamento shotgun na plataforma Illumina/MiSeq, as bibliotecas de fragmentos de DNA foram preparadas com o Nextera DNA Sample Prep kit, seguindo-se o protocolo do fabricante disponível no Nextera DNA Sample Preparation Guide versão de outubro de 2012. A primeira etapa do protocolo consiste na fragmentação do DNA com simultânea inserção de sequências adaptadoras às extremidades dos fragmentos de DNA (tagmentation) mediadas por transposons e transposase. O sucesso deste protocolo depende de quantificação precisa do DNA e da ausência de contaminantes na preparação que podem inibir a transposase. A quantidade inicial de DNA total sugerida pelo protocolo é de 50ng, no entanto, foi necessário reduzir esta quantidade para $35 \mathrm{ng}$ para uma melhor eficiência da tagmentation das amostras. Esta quantidade inicial de DNA foi diluída em $20 \mu \mathrm{L}$ e adicionada em uma placa de 96 poços. Foram adicionados $25 \mu \mathrm{L}$ do Tagment DNA Buffer em cada poço contendo amostra de DNA, além de $5 \mu \mathrm{L}$ da Tagment DNA Enzyme. A placa foi incubada a $55^{\circ} \mathrm{C}$ por 5 minutos, sendo mantida a $10^{\circ} \mathrm{C}$ após o processo. Em seguida, as amostras foram purificadas utilizando 0 kit QIAquick PCR purification e ao final ressuspendidas em $25 \mu \mathrm{L}$ de EB buffer (tampão incluído no kit).

A etapa posterior, consistiu em uma amplificação por PCR, na qual foram adicionados dois índices, "i7" e "i5" cujas combinações eram únicas para cada biblioteca a ser sequenciada, além dos adaptadores P5 e P7 que são exigidos no processo de geração de clusters e no sequenciamento. Aos $20 \mu \mathrm{L}$ da preparação de DNA purificado após tagmentation foi adicionado $15 \mu \mathrm{L}$ de Nextera PCR Master Mix e 5 $\mathrm{LL}$ de PCR Primer Cocktail, seguido pela incubação em termociclador programado para $72^{\circ} \mathrm{C}$ por 3 minutos, $98^{\circ} \mathrm{C}$ por 30 segundos, e 5 ciclos de $98^{\circ} \mathrm{C}$ por 10 segundos, $63^{\circ} \mathrm{C}$ por 30 segundos e $72^{\circ} \mathrm{C}$ por 3 minutos, sendo mantido a $10^{\circ} \mathrm{C}$ após término dos ciclos.

Após a PCR, foi realizada a purificação da biblioteca de DNA utilizando AMPure XP beads (Beckman Coulter, Inc., Brea, EUA), que promove uma seleção por tamanho, removendo fragmentos pequenos da biblioteca. Para isso, os $40 \mu \mathrm{L}$ da reação de PCR foram transferidos para poços de uma placa 
(compatível com o suporte magnético) e foram adicionados $25 \mu \mathrm{L}$ das AMPure $X P$ beads em cada poço contendo uma amostra. A placa com as amostras foi incubada por 5 minutos a temperatura ambiente. Em seguida, a placa foi posicionada no suporte magnético por 2 minutos até que o sobrenadante se tornasse claro. O sobrenadante foi descartado e o precipitado foi submetido a duas lavagens com $200 \mu \mathrm{L}$ de etanol $80 \%$. As beads foram então secadas por 15 minutos com a placa no suporte magnético e as amostras eluídas em $32,5 \mu \mathrm{L}$ do Resuspension Buffer, com a placa removida do suporte metálico, por incubação por 2 minutos a temperatura ambiente. Em seguida, a placa foi posicionada no suporte magnético por 2 minutos e, cada biblioteca foi recuperada em $30 \mu \mathrm{L}$ do sobrenadante e armazenada a $-20^{\circ} \mathrm{C}$. As bibliotecas de fragmentos foram quantificadas e sequenciadas na plataforma Illumina/MiSeq como descrito adiante (itens 3.8 e 3.9 ).

\subsection{Preparação de bibliotecas de amplicons do gene rRNA16S (Metagenômica 16S)}

Para a construção da biblioteca de amplicons das regiões variáveis V3 e V4 do gene rRNA $16 \mathrm{~S}$ foi utilizado um par de primers derivado dos primers SD-Bact-0341-b-S-17 e S-D-Bact-0785-a-A-21 previamente descritos (Klindworth et al., 2013). O qual incluía sequências de adaptadores compatíveis com o sequenciamento na plataforma llumina/MiSeq. As sequências do par de primers utilizado está apresentada abaixo:

341F 5'-TCGTCGGCAGCGTCAGATGTGTATAAGAGACAGCCTACGGGNGGCWGCAG

785R 5'-GTCTCGTGGGCTCGGAGATGTGTATAAGAGACAGGACTACHVGGGTATCTAATCC

As reações de PCR foram montadas para um volume final de $25 \mu \mathrm{L}$ utilizando o kit KAPA HiFi HotStart READYMIX (Kapa Biosystems, Wilmington, EUA), $12,5 \mathrm{ng}$ de amostras de DNA e 200nM de cada um dos primers. A reação de PCR foi conduzida a $95^{\circ} \mathrm{C}$ durante 3 minutos, seguido de 25 ciclos de: 30 segundos a $95^{\circ} \mathrm{C}, 30$ segundos a $55^{\circ} \mathrm{C}$ e 30 segundos a $72^{\circ} \mathrm{C}$ e uma incubação final a $72^{\circ} \mathrm{C}$ durante 5 minutos. $O$ fragmento esperado da amplificação era de $\sim 550 \mathrm{pb}$ cujo tamanho foi avaliado por meio de eletroforese capilar com o DNA 1000 kit no 2100 BioAnalyzer (Agilent Technologies). 
Os produtos das reações de PCR foram purificados com AMPure XP beads (Beckman Coulter, Inc., Brea, EUA). Foi utilizado o Kit Nextera Índice XT (Illumina, Inc., San Diego, EUA) para a ligação dos pares de índices distintos nas extremidades dos amplicons das diferentes bibliotecas, seguido por uma nova etapa de purificação com AMPure XP beads. A confirmação da ligação dos índices aos amplicons das regiões V3 e V4 foi realizada por eletroforese no BioAnalyzer com High Sensitivity DNA kit. Nesta etapa, o tamanho esperado do fragmento era de $\sim 630 \mathrm{pb}$.

\subsection{Preparação de bibliotecas de cDNA para RNA-seq (Metatranscritômica)}

\subsubsection{Depleção de rRNA das amostras de RNA total}

O enriquecimento das preparações de RNA total na fração de mRNAs foi realizado pela depleção de rRNA utilizando o Ribo-Zero Magnetic Kit Bacteria (Epicentre). $O$ protocolo inicia-se com a preparação das beads magnéticas AMPure XP beads onde para cada amostra de RNA total foi utilizado um volume de $225 \mu \mathrm{L}$ da suspensão de beads adicionada a um tubo de $1,5 \mathrm{~mL}$, que foi inserido em um suporte magnético e o sobrenadante obtido foi descartado. As beads foram lavadas duas vezes com $225 \mu \mathrm{L}$ de água livre de RNAse com os tubos ainda no suporte. Em seguida, os tubos foram retirados do suporte e as beads ressuspendidas em $65 \mu \mathrm{L}$ de Magnetic bead resuspension solution, além da adição de $1 \mu \mathrm{L}$ de RiboGuard RNase Inhibitor. Os tubos de beads magnéticas foram mantidos em temperatura ambiente até o uso.

Para o tratamento de cada amostra de RNA total com a Ribo-Zero rRNA removal solution, foi montada a seguinte reação: $4 \mu \mathrm{L}$ de Ribo-Zero reaction buffer, $10 \mu \mathrm{L}$ de Ribo-Zero rRNA removal solution, $5 \mu \mathrm{g}$ de RNA total e água livre de RNAse para completar $40 \mu \mathrm{L}$ de volume final. A reação foi incubada por 10 minutos a $68^{\circ} \mathrm{C}$. Após esta etapa, o volume total do RNA tratado foi adicionado no tubo contendo as beads magnéticas, previamente preparadas. $O$ tubo foi vigorosamente agitado e deixado à temperatura ambiente por 5 minutos e, em seguida, deixado incubado a $50^{\circ} \mathrm{C}$ por 5 minutos e, então, adicionado ao suporte magnético por 1 minuto. Noventa microlitros do sobrenadante foi cuidadosamente removido e separado em um tubo de $1,5 \mathrm{~mL}$, e o RNA livre de 
rRNA foi purificado por precipitação com etanol, conforme descrito a seguir. Aos $90 \mu \mathrm{L}$ de amostra de RNA livre de rRNA foram adicionados $90 \mu \mathrm{L}$ de água livre de RNAse, $18 \mu \mathrm{L}$ de acetato de sódio $3 \mathrm{M}, 2 \mu \mathrm{L}$ de glicogênio $(10 \mathrm{mg} / \mathrm{mL})$ e $600 \mu \mathrm{L}$ de etanol $100 \%$ gelado. As amostras foram homogeneizadas vigorosamente e incubadas por 2 horas a $-20^{\circ} \mathrm{C}$. Após este período, foi realizada uma centrifugação a $16.000 \times$ x por 30 minutos. O sobrenadante foi descartado e o precipitado lavado duas vezes com etanol $70 \%$ gelado, com centrifugações de $16.000 \times$ por 5 minutos cada. Após a retirada do etanol na segunda lavagem, o precipitado foi secado a temperatura ambiente por 5 minutos previamente a preparação da biblioteca de cDNA.

\subsubsection{Preparação da biblioteca de cDNA}

Após a etapa de depleção do rRNA, o RNA foi utilizado para a preparação da biblioteca de cDNA utilizando o protocolo do TruSeq RNA sample preparation kit v2 (Illumina), com algumas adaptações. O RNA, após a etapa de depleção do rRNA, foi solubilizado em $18 \mu \mathrm{L}$ da solução Elute, Prime, Fragment Mix, seguido pela incubação a $94^{\circ} \mathrm{C}$ por 8 minutos (etapa de fragmentação) e imediata transferência para banho de gelo.

A partir desta etapa, todos os procedimentos foram realizados em placas de 96 poços. A síntese da primeira fita do cDNA foi realizada com $17 \mu \mathrm{L}$ da amostra de RNA em Elute, Prime, Fragment Mix, $8 \mu \mathrm{L}$ do First strand Master Mix e transcritase reversa ImProm I/ (Promega), na proporção de $1 \mu \mathrm{L}$ da enzima para $9 \mu \mathrm{L}$ da Master Mix. A placa foi colocada no termociclador com a seguinte programação: $25^{\circ} \mathrm{C}$ por 10 minutos, $42^{\circ} \mathrm{C}$ por 50 minutos, $70^{\circ} \mathrm{C}$ por 15 minutos, sendo a reação mantida a $4^{\circ} \mathrm{C}$ até a etapa de síntese da segunda fita do cDNA. A cada poço da placa foi então adicionado $25 \mu \mathrm{L}$ do Second strand Master Mix, seguindo-se incubação no termociclador por 1 hora a $16^{\circ} \mathrm{C}$. Após a síntese da segunda fita, foi realizada a purificação do cDNA dupla fita com o uso de AMPure XP beads. Para tal, cada amostra foi transferida para uma placa de 96 poços compatível com o suporte magnético, $90 \mu \mathrm{L}$ da suspensão de beads foram adicionados e a placa foi incubada por 15 minutos à temperatura ambiente fora do suporte. Posteriormente, a placa foi inserida no suporte e incubada por 5 minutos. O sobrenadante foi removido e o precipitado lavado 
duas vezes com $200 \mu \mathrm{L}$ de etanol $80 \%$. Após a retirada do etanol, no final da segunda lavagem, a placa foi deixada secando por 15 minutos no suporte magnético. Em seguida, a placa foi retirada do suporte e $52,5 \mu \mathrm{L}$ de Resuspension buffer foram adicionados, seguido pela incubação por 2 minutos. Novamente a placa foi incubada no suporte magnético por 5 minutos e $50 \mu \mathrm{L}$ do sobrenadante foi removido e transferido para uma placa compatível com 0 termociclador.

De posse das preparações do cDNA dupla fita, foram realizados procedimentos para a ligação dos adaptadores e dos índices a cada uma das bibliotecas, além de uma etapa de PCR para enriquecimento dos fragmentos gerados. Primeiramente, foi realizado o reparo das extremidades dos fragmentos adicionando 40 $\mu \mathrm{L}$ do End Repair Mix ao poço da placa contendo amostra. Foram adicionados 10 $\mu \mathrm{L}$ de uma diluição 1/100 do End Repair Control e a placa foi incubada em termociclador por 30 minutos a $30^{\circ} \mathrm{C}$. Em seguida, todo o volume da amostra foi transferido para uma placa compatível com o suporte magnético e foram adicionados $160 \mu \mathrm{L}$ das AMPure XP beads. Seguimos o mesmo procedimento de purificação citado acima, sendo que a ressuspensão das beads foi realizada com $17,5 \mu \mathrm{L}$ de Resuspension buffer $\mathrm{e}$ $15 \mu \mathrm{L}$ do sobrenadante foi coletado e transferido para a outra placa.

A etapa seguinte consistiu em adicionar um nucleotídeo de adenina na extremidade 3' dos fragmentos, de modo que possam especificamente se ligar aos adaptadores que apresentam um nucleotídeo com base timina na extremidade 3'. Desta forma, foram adicionados $12,5 \mu \mathrm{L}$ do A-Tailing Mix ao poço contendo a amostra. Foram adicionados $2,5 \mu \mathrm{L}$ de uma diluição 1/100 do A-Tailing Control. A placa foi inserida em um termociclador com a seguinte programação: $37^{\circ} \mathrm{C}$ por 30 minutos, $70^{\circ} \mathrm{C}$ por 5 minutos, sendo mantida a $4^{\circ} \mathrm{C}$. Imediatamente foi realizada a ligação dos adaptadores, com a adição de $2,5 \mu \mathrm{L}$

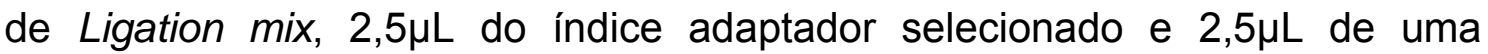
diluição 1/100 do Ligation Control. A placa foi incubada em um termociclador por 10 minutos a $30^{\circ} \mathrm{C}$. Feito isto, toda a amostra foi transferida para a placa compatível com o suporte magnético e foram adicionados $42 \mu \mathrm{L}$ das AMPure $X P$ beads. Seguimos o mesmo procedimento de purificação citado acima, sendo que a ressuspensão das beads foi feita com $52,5 \mu \mathrm{L}$ de Resuspension 
buffer. Foi então coletado $50 \mu \mathrm{L}$ do sobrenadante e transferido para outro poço da placa para uma purificação adicional com as beads. Para esta segunda purificação foi utilizado $50 \mu \mathrm{L}$ de AMPure XP beads e, ao final, as beads foram ressuspendidas em $22,5 \mu \mathrm{L}$ de Resuspension buffer e $20 \mu \mathrm{L}$ do sobrenadante foi coletado e transferido para outra placa.

A última parte do protocolo consistiu no enriquecimento dos fragmentos de cDNA por PCR. Para isto, foram adicionados $5 \mu \mathrm{L}$ do PCR primer cocktail e $25 \mu \mathrm{L}$ do PCR Master Mix ao poço da placa contendo a amostra. A placa foi inserida em termociclador com a seguinte programação: $98^{\circ} \mathrm{C}$ por 30 segundos e 15 ciclos de: $98^{\circ} \mathrm{C}$ por 10 segundos, $60^{\circ} \mathrm{C}$ por 30 segundos e $72^{\circ} \mathrm{C}$ por 30 segundos; com mais 5 minutos a $72^{\circ} \mathrm{C}$, sendo mantida a $10^{\circ} \mathrm{C}$. Finalmente, foi realizada uma última purificação com AMPure $X P$ beads, a amostra foi transferida para a placa compatível com o suporte magnético, sendo então adicionados $50 \mu \mathrm{L}$ das beads. Ao final, foram usados $32,5 \mu \mathrm{L}$ de Resuspension buffer para a ressuspensão das beads e $30 \mu \mathrm{L}$ do sobrenadante contendo a biblioteca de cDNA pronta foram transferidos para um tubo de $1,5 \mathrm{~mL}$ e armazenados a $-20^{\circ} \mathrm{C}$. As bibliotecas de cDNA foram quantificadas e sequenciadas nas plataformas llumina MiSeq e HiSeq como descrito a seguir (itens 3.8 e 3.9 ).

\subsection{Quantificação de bibliotecas de fragmentos de DNA e de cDNA}

A quantificação das bibliotecas de fragmentos DNA, bibliotecas de amplicons 165 e bibliotecas de cDNA foi realizada por ensaios de qPCR absoluto utilizando o Kapa Library Quantification kit para plataformas de sequenciamento Illumina. O kit dispõe de uma curva padrão de amostras de DNA com concentrações conhecidas que varia de $20 \mathrm{pM}$ a 0,0002pM. Para que as amostras pudessem apresentar concentrações dentro do intervalo da curva, foram realizadas estimativas com base nas quantificações por espectrofotômetro NanoDrop e no tamanho médio dos fragmentos obtidos por eletroforese capilar. As concentrações estimadas em $\mathrm{ng} / \mu \mathrm{L}$ foram convertidas para nM seguindo instruções do Nextera DNA Sample Preparation Guide.

Após a diluição das bibliotecas, a placa para o ensaio de qPCR foi montada em triplicata com $12 \mu \mathrm{L}$ do Kapa SYBR FastqPCR Master Mix, $4 \mu \mathrm{L}$ de 
água pré-tratada com DEPC mais $4 \mu \mathrm{L}$ da biblioteca diluída a ser quantificada ou $4 \mu \mathrm{L}$ da amostra com concentração conhecida (curva padrão) ou $4 \mu \mathrm{L}$ de água DEPC (branco).

Os ensaios de qPCR foram realizados no equipamento 7500 Real Time PCR System (Applied Biosystems) programado para $95^{\circ} \mathrm{C}$ por 5 minutos, 35 ciclos de: $95^{\circ} \mathrm{C}$ por 30 segundos e $60^{\circ} \mathrm{C}$ por 45 segundos. Os valores de CT (Cycle Threshold) foram obtidos das curvas de amplificação e utilizados para calcular as concentrações das bibliotecas com base na curva padrão (Tabelas 4 e 5). As concentrações das bibliotecas foram ajustadas, com base no tamanho médio dos fragmentos de cada biblioteca e na correção da diluição realizada antes da quantificação, para adequar a concentração necessária para o sequenciamento.

Tabela 4: Quantificação das bibliotecas de DNA da ZC3. Valores estimados da concentração das bibliotecas de DNA foram obtidos pela multiplicação da concentração das amostras (medida pelo NanoDrop) pelo fator de conversão do protocolo Nextera. A concentração estimada das bibliotecas foi utilizada como base para a quantificação por qPCR utilizando a curva padrão do kit Kappa.

\begin{tabular}{|c|c|c|c|c|c|}
\hline Amostra & $\begin{array}{c}\text { Concentração } \\
\text { (Nanodrop) } \\
\text { ng/uL }\end{array}$ & $\begin{array}{c}\text { Tamanho } \\
\text { médio } \\
\text { nt }\end{array}$ & $\begin{array}{c}\text { Fator de } \\
\text { Conversão }\end{array}$ & $\begin{array}{c}\text { Concentração } \\
\text { estimada } \\
\text { nM }\end{array}$ & $\begin{array}{c}\text { Concentração } \\
\text { obtida com o } \\
\text { qRT-PCR } \\
\text { nM }\end{array}$ \\
\hline & \multicolumn{7}{|c|}{} & \multicolumn{2}{|c|}{ Biblioteca de DNA total } \\
\hline D1 & 3,4 & 532 & 3,0 & 10,2 & 0,7 \\
\hline D30 & 4,8 & 531 & 3,0 & 14,4 & 1,4 \\
\hline D64 & 3,6 & 690 & 2,0 & 7,2 & 0,4 \\
\hline D78 & 3,6 & 641 & 2,5 & 9,0 & 0,5 \\
\hline D99 & 13,4 & 703 & 2,0 & 26,8 & 0,6 \\
\hline & & Biblioteca de Amplicon V3-V4 do rRNA16S & \\
\hline D1 & 133,0 & 611 & 2,5 & 332,5 & 156,0 \\
\hline D30 & 123,0 & 609 & 2,5 & 307,5 & 79,0 \\
\hline D64 & 120,0 & 611 & 2,5 & 300,0 & 99,0 \\
\hline D78 & 118,0 & 612 & 2,5 & 295,0 & 92,0 \\
\hline D99 & 108,0 & 612 & 2,5 & 270,0 & 75,0 \\
\hline
\end{tabular}


Tabela 5: Quantificação das bibliotecas da ZC4. Valores estimados da concentração das bibliotecas de DNA foram obtidos pela multiplicação da concentração das amostras (medida pelo NanoDrop) pelo fator de conversão do protocolo Nextera. A concentração estimada das bibliotecas foi utilizada como base para a quantificação por qPCR utilizando a curva padrão do kit Kappa.

\begin{tabular}{|c|c|c|c|c|c|}
\hline Amostra & $\begin{array}{c}\text { Concentração } \\
\text { (Nanodrop) } \\
\text { ng/uL }\end{array}$ & $\begin{array}{c}\text { Tamanho } \\
\text { médio } \\
\text { nt }\end{array}$ & $\begin{array}{l}\text { Fator de } \\
\text { Conversão }\end{array}$ & $\begin{array}{c}\text { Concentração } \\
\text { estimada } \\
\text { nM }\end{array}$ & $\begin{array}{c}\text { Concentração } \\
\text { determinada } \\
\text { por qPCR } \\
\text { nM }\end{array}$ \\
\hline \multicolumn{6}{|c|}{ Biblioteca de DNA (shotgun) } \\
\hline D01 & 4,5 & 558 & 2,5 & 11,2 & 2,5 \\
\hline D03 & 5,3 & 651 & 2,5 & 13,2 & 1,3 \\
\hline D07 & 5,5 & 502 & 3 & 16,5 & 2,5 \\
\hline D15 & 3,4 & 505 & 3 & 10,2 & 1,7 \\
\hline D30 & 7,6 & 595 & 2,5 & 19 & 2,5 \\
\hline D64 & 3,2 & 414 & 3 & 9,6 & 2,7 \\
\hline D67 & 3,2 & 367 & 4,5 & 14,4 & 3,8 \\
\hline D78 & 3,2 & 960 & 1,5 & 4,8 & 1,1 \\
\hline \multirow[t]{2}{*}{ D99 } & 4,9 & 810 & 2 & 9,8 & 3,0 \\
\hline & \multicolumn{5}{|c|}{ Biblioteca de Amplicon V3-V4 do rRNA 16S } \\
\hline D01 & 47,9 & 605 & 3,5 & 168 & 169 \\
\hline D03 & 95,5 & 601 & 3,5 & 334 & 190 \\
\hline D07 & 104,3 & 595 & 3,5 & 364 & 68 \\
\hline D15 & 112,7 & 594 & 3,5 & 394 & 100 \\
\hline D30 & 106,0 & 595 & 3,5 & 371 & 90 \\
\hline D64 & 62,8 & 595 & 3,5 & 220 & 118 \\
\hline D67 & 134,0 & 594 & 3,5 & 469 & 211 \\
\hline D78 & 88,0 & 589 & 3,5 & 308 & 160 \\
\hline \multirow[t]{2}{*}{ D99 } & 120,0 & 589 & 3,5 & 420 & 136 \\
\hline & \multicolumn{5}{|c|}{ Biblioteca de cDNA } \\
\hline D01 & 11,6 & 346 & 4,5 & 52,2 & 22,9 \\
\hline D03 & 22,7 & 453 & 3,5 & 79,4 & 41,4 \\
\hline D07 & 23,0 & 475 & 3 & 69,0 & 41,1 \\
\hline D15 & 31,0 & 435 & 3,5 & 108,5 & 66,0 \\
\hline D30 & 38,0 & 344 & 4,5 & 171,0 & 125,0 \\
\hline D64 & 31,8 & 434 & 3,5 & 111,3 & 47,4 \\
\hline D78 & 26,3 & 407 & 4,0 & 105,2 & 79,2 \\
\hline D99 & 22,0 & 337 & 4,5 & 99,0 & 83,0 \\
\hline
\end{tabular}

\subsection{Sequenciamento na plataforma Illumina/MiSeq}

Antes de iniciar o sequenciamento, as bibliotecas de fragmentos de DNA foram juntadas (obtenção de um pool de bibliotecas) em concentrações iguais de $300 \mathrm{pM}$. Importante ressaltar que somente foram reunidas em uma mesma corrida de sequenciamento bibliotecas que apresentavam índices distintos e compatíveis entre si. O pool de bibliotecas foi desnaturado por incubação a 
$98^{\circ} \mathrm{C}$ por 10 minutos e diluídos em tampão $H T 1$ (fornecido pelo kit de sequenciamento) para uma concentração final de $10 \mathrm{pM}$. No caso das bibliotecas de cDNA e de amplicons $16 \mathrm{~S}$ a desnaturação foi realizada com $\mathrm{NaOH}$, e não térmica. Para tal, a concentração das bibliotecas foi ajustada para $4 \mathrm{nM}$ e volumes iguais destas foram misturados, seguido pela adição de $\mathrm{NaOH}$ $0,2 \mathrm{~N}$ (na proporção 1:1), incubação por 5 minutos à temperatura ambiente $\mathrm{e}$ diluições em tampão $H T 1$ para concentração final de 10pM.

Seiscentos microlitros do pool diluído das bibliotecas desnaturadas foram aplicados no cartucho de sequenciamento que foi então inserido no equipamento Illumina/MiSeq (Illumina, Inc., CA) instalado no CATG do IQ-USP. Foram realizadas, no mínimo uma e no máximo três corridas de sequenciamento para cada biblioteca, utilizando o protocolo Paired-End (PE) e - Illumina/MiSeq Reagent kit v2 de 500 ciclos, que possibilita o sequenciamento de 250 bases de cada extremidade dos fragmentos de DNA. O workflow escolhido para a análise após a corrida foi o Generate FastQ para as bibliotecas de fragmentos de DNA e de cDNA e Amplicon para as bibliotecas de amplicons 16S. Ao final de cada corrida é gerado um arquivo de saída com as sequências (read1 e read2) acopladas a informações da qualidade de cada nucleotídeo sequenciado (arquivo FastQ). Em média, as corridas no MiSeq tiveram bom desempenho gerando $>75 \%$ das sequências com um índice de qualidade acima de 30 (Q30).

Foi realizada uma corrida de sequenciamento PE das bibliotecas de cDNA em uma lane no equipamento llumina/HiSeq2500 (instalado na ESALQUSP) utilizando o kit TruSeq SBS V3 200 ciclos. As sequências obtidas nesta plataforma foram juntadas com as sequências obtidas no Illumina/MiSeq.

As métricas dos sequenciamentos realizados nas plataformas Illumina para bibliotecas de amostras de ZC3 e ZC4 estão, respectivamente apresentadas nas Tabelas 3 e 6 . 


\section{PROCEDIMENTOS EXPERIMENTAIS}

Tabela 6: Métricas do sequenciamento e da montagem de sequências metagenômicas e metatranscritômicas das amostras da ZC4.

\begin{tabular}{|c|c|c|c|c|c|c|c|c|c|}
\hline \multicolumn{10}{|c|}{ Sequenciamento shotgun (Metagenômica shotgun) } \\
\hline Parâmetros & D01 & D03 & D07 & D15 & D30 & D64 & D67 & D78 & D99 \\
\hline Número total de reads $\mathrm{PE}^{*}$ & 8213864 & 9340402 & 9113124 & 14438720 & 9653864 & 14469070 & 8369838 & 22490204 & 16647048 \\
\hline $\begin{array}{l}\text { Tamanho médio dos reads } \\
\text { (pb) }\end{array}$ & 205 & 228 & 179 & 175 & 197 & 205 & 186 & 150 & 170 \\
\hline $\begin{array}{l}\text { Tamanho do Metagenoma } \\
\text { não montado }(\mathrm{pb})^{\star}\end{array}$ & 3385195302 & 4277689176 & 3279801076 & 5095916642 & 3822299536 & 5947512254 & 3133151522 & 6839411382 & 5690236784 \\
\hline $\begin{array}{l}\text { Tamanho do Metagenoma } \\
\text { montado }(\mathrm{pb})^{*}\end{array}$ & 243754413 & 219282386 & 151588766 & 177815419 & 190856909 & 382856416 & 161189624 & 237497447 & 269689437 \\
\hline Número de reads em contigs & 2576374 & 2807117 & 3220894 & 4271981 & 3077182 & 4775798 & 2191247 & 6596668 & 4861634 \\
\hline Número de contigst & 568660 & 487725 & 336757 & 391739 & 421533 & 883951 & 389331 & 517038 & 596836 \\
\hline Maior contig $(\mathrm{pb})$ & 7548 & 6098 & 7492 & 5534 & 10147 & 8897 & 4679 & 9038 & 8020 \\
\hline Tamanho médio do contig & 428 & 449 & 450 & 453 & 452 & 433 & 414 & 459 & 451 \\
\hline Tamanho do contig N50 & 408 & 428 & 424 & 430 & 429 & 412 & 396 & 436 & 431 \\
\hline Número de singletons & 5637490 & 6533285 & 5892230 & 10166739 & 6576682 & 9693272 & 6178591 & 15893536 & 11785414 \\
\hline \multicolumn{10}{|c|}{ Metatranscritômica (RNA-seq) } \\
\hline Parâmetros & D01 & D03 & D07 & D15 & D30 & D64 & D67 & D78 & D99 \\
\hline Número total de reads PE & 14937982 & 14873258 & 14524876 & 11978457 & 9245877 & 17514259 & - & 9564842 & 7416187 \\
\hline $\begin{array}{l}\text { Tamanho médio dos reads } \\
\text { (pb) }\end{array}$ & 113 & 114 & 116 & 113 & 141 & 114 & - & 112 & 139 \\
\hline $\begin{array}{l}\text { Tamanho do Metagenoma } \\
\text { não montado }(\mathrm{pb})^{*}\end{array}$ & 3405044922 & 3402767494 & 3385787392 & 2731899029 & 2617571479 & 4015710801 & - & 2162396674 & 2080659729 \\
\hline $\begin{array}{l}\text { Tamanho do Metagenoma } \\
\text { montado (pb) }\end{array}$ & 43615715 & 46631239 & 51298791 & 40471157 & 40860838 & 58172101 & - & 23091753 & 19965991 \\
\hline Número de reads em contigs & 3955349 & 4693257 & 5835118 & 6667988 & 3625900 & 5626057 & - & 3794053 & 1808358 \\
\hline Número de contigst & 79492 & 80281 & 80114 & 56979 & 80028 & 106273 & - & 44903 & 35669 \\
\hline Maior contig $(\mathrm{pb})$ & 12283 & 14247 & 13025 & 20141 & 15199 & 13323 & - & 7632 & 14074 \\
\hline $\begin{array}{l}\text { Tamanho médio do contig } \\
(\mathrm{pb})\end{array}$ & 548 & 580 & 640 & 710 & 510 & 547 & - & 514 & 559 \\
\hline Tamanho do contig N50 (pb) & 544 & 588 & 679 & 814 & 498 & 540 & - & 504 & 558 \\
\hline Número de singletons & 10982633 & 10180001 & 8689757 & 5310469 & 5619976 & 11888201 & - & 5770788 & 5607829 \\
\hline
\end{tabular}


PROCEDIMENTOS EXPERIMENTAIS

Tabela 6: continuação.

\begin{tabular}{|c|c|c|c|c|c|c|c|c|c|}
\hline \multicolumn{10}{|c|}{ Sequenciamento do amplicon das regiões V3-V4 do gene rRNA 16S (Metagenômica 16S) } \\
\hline Parâmetros & D01 & D03 & D07 & D15 & D30 & D64 & D67 & D78 & D99 \\
\hline Número total de reads $\mathrm{PE}^{*}$ & 1014282 & 2623129 & 1495244 & 2082961 & 784604 & 2376934 & 1364487 & 1862316 & 1285268 \\
\hline desvio padrão & $457 \pm 13$ & $456 \pm 17$ & $453 \pm 16$ & $454 \pm 16$ & $453 \pm 15$ & $456 \pm 17$ & $453 \pm 20$ & $452 \pm 25$ & $454 \pm 18$ \\
\hline
\end{tabular}




\subsection{Processamento e análise computacional das sequências obtidas}

\subsubsection{Pré-processamento e anotação de sequências de metagenomas e de metatranscritomas}

As sequências geradas (reads brutas não-montadas) pelo sequenciamento das bibliotecas de metagenômica shotgun e de cDNA foram submetidas a anotação automática na plataforma MG-RAST (Meyer et al., 2008; Glass et al., 2010) utilizando o processamento padrão de controle de qualidade das sequências desta plataforma (MG-RAST version 3.6).

A composição taxonômica a partir das reads não-montadas foi investigada com o auxílio da ferramenta de Best Hit Classification do MG-RAST contra a base de dados do M5NR (M5 non-redundant protein), utilizando os seguintes parâmetros: identidade mínima de $60 \%$, limite máximo de $p$-value de $1 \times 10^{-5}$ e alinhamento mínimo de 50pb.

As sequências foram também submetidas a montagem para geração de contigs. Para tal, as reads PE brutas triadas com o software Sickle (Joshi \& Fass, 2011) para remoção de reads com um índice de qualidade abaixo de 20 (Q20) e com tamanho <50pb. Após esta filtragem, 95\% do total inicial de reads foram recuperados. Após esta etapa, as sequências foram submetidas ao montador SOAPdenovo2 (sequências de metagenômica shotgun) ou SOAPdenovo-Trans (sequências de metatranscritômica) (Xie et al., 2011; Luo et al., 2012). Os parâmetros utilizados foram $-\mathrm{K} 23-\mathrm{L} 70-\mathrm{M} 3-\mathrm{u}-\mathrm{R}-\mathrm{F}-\mathrm{V}$ (Kultima et al., 2012). Os contigs obtidos foram submetidos a uma etapa de triagem, sendo excluídos contigs menores de $300 \mathrm{pb}$. Contigs $\geq 300 \mathrm{pb}$ foram submetidos a plataforma de anotação automática do IMG/M (Markowitz et al., 2008; Markowitz et al., 2012).

A anotação automática dos contigs no IMG/M permite sua classificação funcional com base no COG, o que possibilita a comparação dos contigs das diferentes amostras através da ferramenta de comparação funcional (Function Compare) disponível no próprio IMG/M. Contigs anotados com base no COG foram recuperados e confrontados contra a base de dados CAZY- dbCAN (Cantarel et al., 2009) através da ferramenta de comparação USEARCH (Edgar, 2013). Além disso, os contigs recuperados foram também submetidos a classificação taxonômica utilizando o programa MyTaxa (Luo et al., 2014). 
Os processamentos computacionais das sequências, tais como montagem de contigs e classificação taxonômica com o programa MyTaxa foram realizados por Gianluca Major Machado Silva, aluno de Mestrado do Programa Interunidades de Bioinformática sob orientação do Prof. Dr. João Carlos Setubal. Outras análises computacionais, como a 'recuperação de genomas bacterianos a partir dos metagenomas de ZC3 e ZC4, reconstruções filogenéticas destes genomas e comparações de sequências e contigs de metagenomas e metatranscritomas foram realizadas no laboratório de bioinformática do Prof. João Carlos Setubal.

\subsubsection{Processamento e análise de sequências de amplicons do gene rRNA16S}

As sequências PE das bibliotecas de amplicons das regiões V3-V4 do gene rRNA16S foram submetidas aos protocolos padrões do pacote QIIME (Caporaso et al., 2010b; Edgar, 2013). Inicialmente, sequências PE que apresentavam uma sobreposição mínima de 6 bp foram fundidas utilizando programa Fastq-join (Aronesty, 2013), seguido por: retirada de sequências dos índices, adaptadores e dos primers; filtragem de sequências com base no tamanho (eliminação de sequências fora do intervalo de 100-500pb) e eliminação de sequências com índice de qualidade abaixo de 20.

Após a filtragem, foi realizada a predição e agrupamento das OTUs utilizando identidade mínima de 97\% (OTU clustering), predição da abundância de cada OTU com base em um alinhamento global de todo o conjunto de dados contra um banco de dados de OTUs representativas de cada cluster. A correção do número de cópias do gene rRNA16S foi realizada utilizando a ferramenta CopyRighter (Angly et al., 2014).

A atribuição taxonômica das OTUs preditas foi determinada com o programa RDP Classifier (Wang et al., 2007; Cole et al., 2014) utilizando um mínimo de $80 \%$ de confiança. Para medidas de diversidade Unifrac, uma árvore filogenética foi construída pelo alinhamento de sequências representativas ao core set de sequências da base Greengenes (McDonald et al., 2012) usando os programas PyNAST (Caporaso et al., 2010a) e FastTree2 (Price et al., 2010). 
As análises comparativas da composição microbiana entre as amostras e/ou entre composteiras, com base em índices de riqueza, diversidade filogenética alfa e beta foram realizadas com o pacote QIIME versão 1.8. Para estas análises comparativas, o número de sequências foi normalizado em 517.210, num total de 10 interações. A diversidade alfa foi calculada usando 0 índice de diversidade filogenética (PD) (Faith et al., 2009) e a medida da riqueza de espécies e a diversidade beta foram calculadas utilizando as métricas UniFrac (Lozupone \& Knight, 2005) e Bray-Curtis.

As análises computacionais das sequências de amplicons do gene rRNA16S foram realizadas em colaboração com Andrew Maltez Thomas e Leandro Nascimento Lemos, pós-graduandos do Programa Interunidades de Bioinformática, sob orientação do Prof. Dr. João Carlos Setubal. 


\section{Resultados e Discussão}

Com o objetivo de investigar a composição e a diversidade taxonômica das comunidades microbianas do processo de compostagem, conhecer a dinâmica deste ecossistema e identificar as funções bioquímicas expressas por essas populações microbianas, principalmente aquelas relacionadas à degradação de biomassa lignocelulósica, empregamos abordagens de metagenômica shotgun, metagenômica $16 \mathrm{~S}$ e metatranscritômica na análise de amostras coletadas na Unidade de Compostagem do Parque Zoológico de São Paulo.

Foram coletadas amostras de duas composteiras denominadas ZC3 e ZC4, que foram montadas, respectivamente, em 27/06/2011 e 05/08/2013, como descrito no item 3.2. No caso de ZC3, realizamos coletas de amostras após 1, 30, 64, 78 e 99 dias de sua montagem e serão referidas como D01, D30, D64, D78 e D99 de ZC3. No caso da composteira ZC4, as coletas foram realizadas após $1,3,7,15,30,64,67,78$ e 99 dias de sua montagem (amostras D01, D03, D07, D15, D30, D64, D67, D78 e D99 de ZC4). O número maior de amostras coletadas para ZC4 foi guiado pelos resultados obtidos a partir das amostras de ZC3, que apontaram para a necessidade de explorar em mais detalhe os primeiros 30 dias do processo de compostagem. Além disso, cabe destacar que as amostras de ZC3 não foram avaliadas com a abordagem de metatranscritômica, a qual foi padronizada posteriormente a coleta dessas amostras. Apesar dessas diferenças, os resultados obtidos para ZC3 e ZC4 serão apresentados e discutidos conjuntamente.

Ressaltamos que as informações referentes as análises qualitativas e quantitativas do DNA total e do RNA total extraídos das amostras de compostagem, bem como das bibliotecas de DNA, cDNA e de amplicon do rRNA 16S (Tabelas 1, 2, 4 e 5) foram apresentadas na seção 3 (Procedimentos Experimentais). De modo geral, todas as amostras de DNA e RNA utilizadas neste trabalho apresentaram um grau de pureza exigido para a realização das etapas de preparação de bibliotecas e sequenciamento, tais como valor de RIN entre 6,9 e 7,8 para amostras de RNA total. Para a preparação da biblioteca de amplicons utilizamos um par de primers para a amplificação das regiões V3 e V4 do gene rRNA 16S, o qual apresentou a melhor cobertura de filos em um 
trabalho que avaliou 512 pares de primers. Embora tendo falhado apenas na detecção de sete filos bacterianos (Armatimonadetes, BHI80-139, Divisão candidata OP11, Cloroflexi, GOUTA4, Hyd24-12 e WS6), este par de primers permitiu a recuperação de alguns filos de Archaeas (Klindworth et al., 2013).

As estratégias e o fluxograma de trabalho que adotamos estão esquematizados na Figura 5, e os dados e métricas dos sequenciamentos realizados estão apresentados nas Tabelas 3, 6 e 7 .

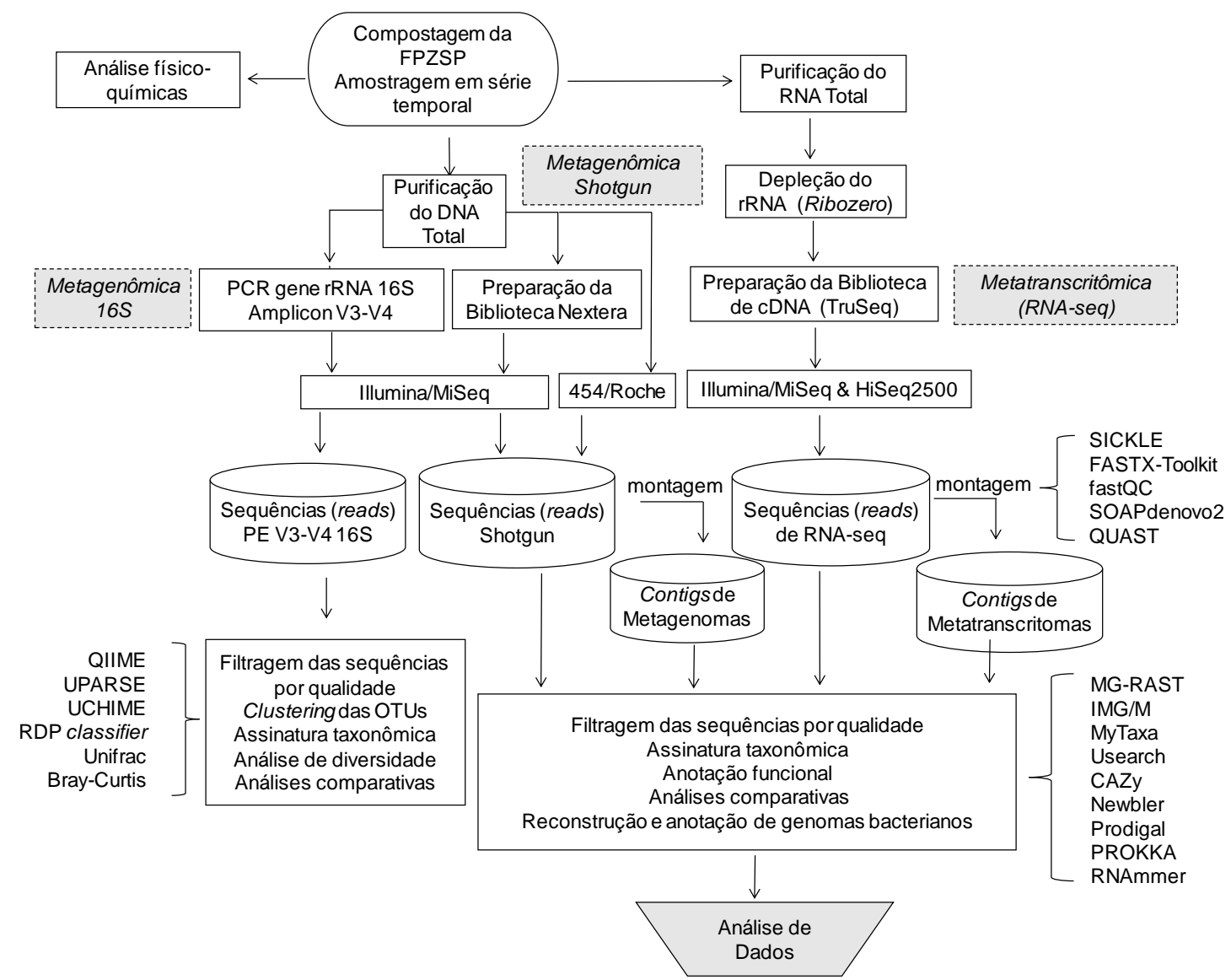

Figura 5: Fluxograma de trabalho para o processamento das amostras coletadas das composteiras ZC3 e ZC4. O esquema indica os passos realizados nas abordagens de metagenômica shotgun, metagenômica $16 \mathrm{~S}$ e metatranscritômica para geração das sequências (reads). As metodologias de sequenciamento de alto-desempenho e os principais programas de processamento e análise de sequências obtidas estão indicados. 
Tabela 7: Números de acesso das sequências depositadas nas plataformas MGRAST, IMG-M e SRA.

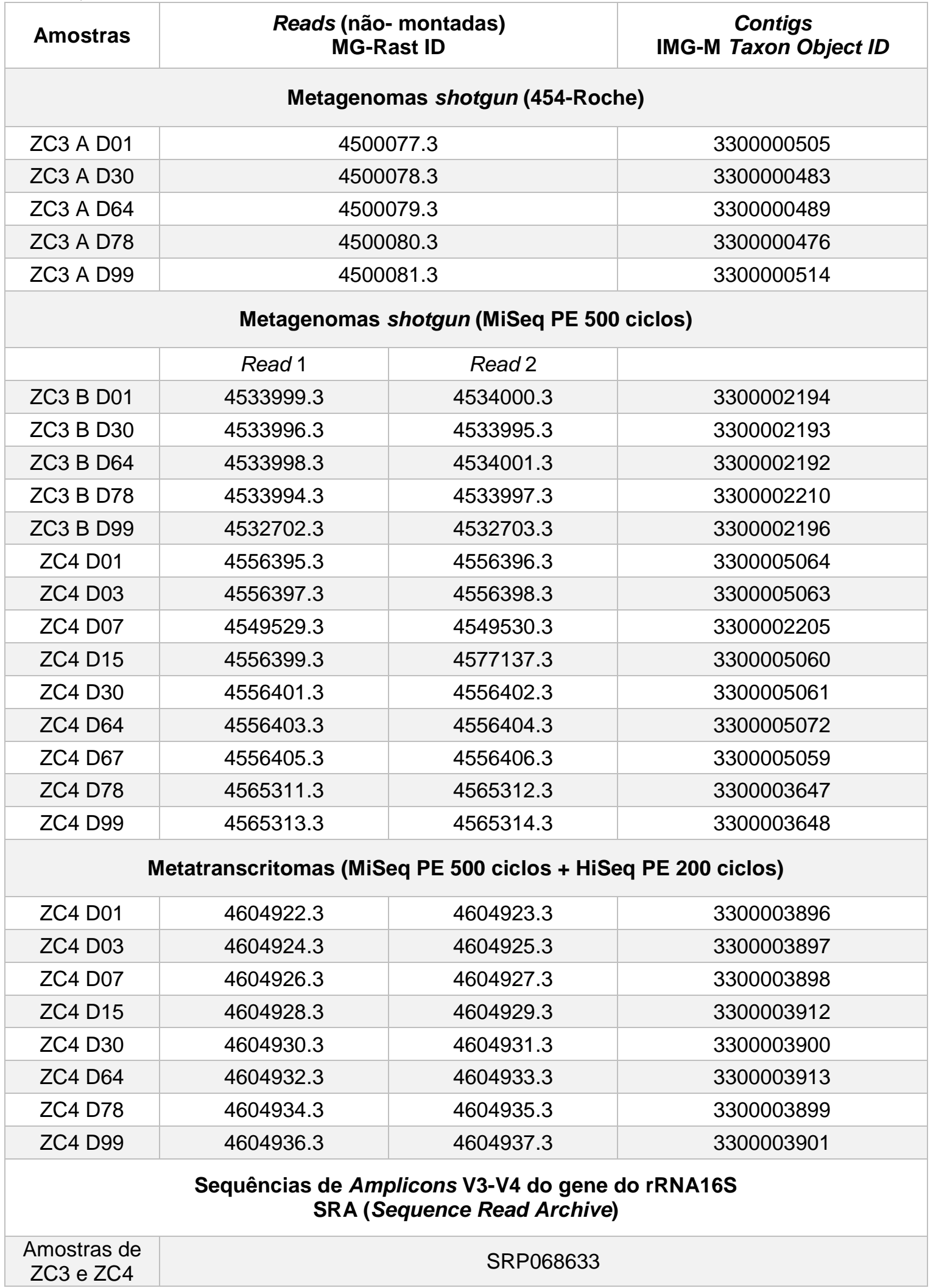




\subsection{Perfil de temperatura, $\mathrm{pH}$ e umidade e análise elementar das composteiras ZC3 e ZC4}

As composteiras ZC3 e ZC4 exibiram um perfil termofílico com temperaturas variando entre $50^{\circ} \mathrm{C}$ e $75^{\circ} \mathrm{C}$ (Figura 6 e Tabela 8). A amplitude da variação das temperaturas aferidas entre os pontos de medida atingiu $20^{\circ} \mathrm{C}$, em alguns dos dias amostrados, indicando que este processo de compostagem é heterogêneo. A diferença de temperatura nos pontos de medida, possivelmente, se deve a diferenças na compactação do material compostado e na aeração da pilha por ser esse um sistema de compostagem semi-estático.

Foram coletadas quatro amostras a mais da composteira ZC4, em relação ao realizado para ZC3, em particular na fase inicial do processo (entre dias 1 e 30). As temperaturas médias aferidas nos dias da coleta destas amostras estiveram acima dos $60^{\circ} \mathrm{C}$, sendo que a amostra do dia 07 (D07) apresentou a maior temperatura média $\left(71,2^{\circ} \mathrm{C}\right)$ e o dia 67 (D67) foi a o que apresentou o ponto em que foi medida a maior temperatura $\left(74^{\circ} \mathrm{C}\right)$ (Figura $6 \mathrm{e}$ Tabela 8).

Tabela 8. Medidas de temperatura, $\mathrm{pH}$ e umidade das amostras de ZC3 e ZC4.

\begin{tabular}{|c|c|c|c|c|c|}
\hline \multicolumn{6}{|c|}{ ZC4 } \\
\hline Amostra & Data da coleta & $\begin{array}{l}\text { Temperatura } \\
\text { médiaa }^{\mathrm{a}} \\
\left({ }^{\circ} \mathrm{C}\right)\end{array}$ & $\begin{array}{c}\operatorname{Temperatura}_{\mathbf{b}}^{\Delta} \\
\left({ }^{\circ} \mathrm{C}\right)\end{array}$ & pH & $\begin{array}{l}\text { Umidad } \\
\text { e } \\
(\%)\end{array}$ \\
\hline D01 & $06 / 08 / 2013$ & $66,2 \pm 7,5$ & 18 & 6.0 & 71,0 \\
\hline D03 & 08/08/2013 & $68,4 \pm 2,6$ & 6 & 5,5 & 67,0 \\
\hline D07 & $12 / 08 / 2013$ & $70,8 \pm 3,5$ & 9 & 6,4 & 70,3 \\
\hline D15 & $20 / 08 / 2013$ & $68,2 \pm 5,8$ & 14 & 6,9 & 63,8 \\
\hline D30 & $04 / 09 / 2013$ & $69,5 \pm 2,3$ & 6 & 6,9 & 61,8 \\
\hline $\mathrm{D} 64^{\mathrm{C}}$ & $08 / 10 / 2013$ & $57,9 \pm 8,9$ & 21 & 6,8 & 60,7 \\
\hline D67 & $11 / 10 / 2013$ & $70,5 \pm 4,8$ & 11 & 7,4 & n.d. \\
\hline D78 & $22 / 10 / 2013$ & $61,2 \pm 3,2$ & 8 & 7,8 & 58,6 \\
\hline D99 & $12 / 11 / 2013$ & $47,8 \pm 3,3$ & 8 & 7,9 & 58,7 \\
\hline \multicolumn{6}{|c|}{ ZC3 } \\
\hline D01 & $28 / 06 / 2011$ & $60,4 \pm 6,6$ & 14 & 5,0 & n.d. \\
\hline D30 & $27 / 07 / 2011$ & $58,0 \pm 6,5$ & 15 & 7,9 & n.d. \\
\hline$D 64^{d}$ & $30 / 08 / 2011$ & $53,2 \pm 6,5$ & 16 & 7,0 & n.d. \\
\hline D78 & $13 / 09 / 2011$ & $56,6 \pm 9,6$ & 24 & 7,0 & n.d. \\
\hline D99 & $04 / 10 / 2011$ & $49.4+10.3$ & 25 & 7.0 & n.d. \\
\hline \multicolumn{6}{|c|}{$\begin{array}{l}\text { a Média e o desvio padrão da variação de temperatura medida nos quatros pontos e } \\
\text { no centro da pilha de compostagem. b Variação entre a maior e a menor } \\
\text { temperatura media na pilha de compostagem. }{ }^{C} \text { revira realizada no dia } 63 .{ }^{d} \text { A revira } \\
\text { realizada no dia } 65 . \text { não determinado. }\end{array}$} \\
\hline
\end{tabular}




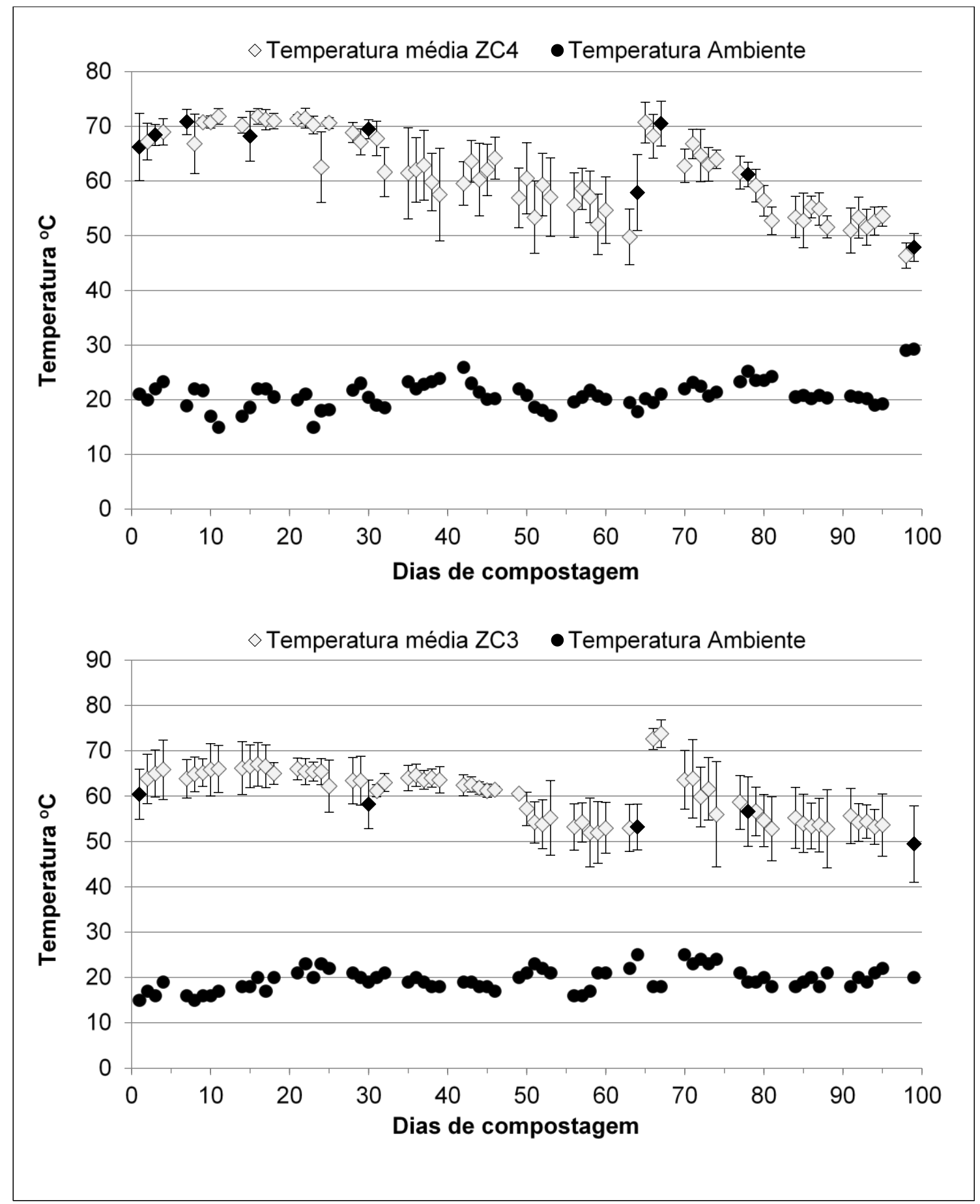

Figura 6: Perfil de temperatura ao longo do processo de compostagem. A temperatura ambiente e das composteiras ZC4 (A) e ZC3 (B) foram aferidas, sempre que possível, diariamente. As barras de erro representam o desvio padrão de medições feitas nas quatro bordas e no centro da pilha. Os losangos pretos indicam os dias de coleta de amostras. Em ZC4 a revira foi feita no dia 63 e em ZC3 no dia 65.

A medida de temperaturas acima dos $60^{\circ} \mathrm{C}$ já no primeiro dia após a montagem das composteiras, tanto em ZC3 como em ZC4 (Figura 6), é um indicativo de que o processo já havia se iniciado antes do preenchimento das pilhas. O início da compostagem pode ser atribuído principalmente a atuação 
de microrganismos presentes na pilha de material vegetal triturado, a qual permanece estocada por um período variável antes de ser utilizada na montagem de composteiras, a ação desta microbiota resulta na elevação da temperatura da pilha de material vegetal $\left(\sim 50^{\circ} \mathrm{C}\right)$. Portanto, uma composteira ao ser completada é constituída por materiais em diferentes estágios de decomposição e explica as temperaturas elevadas aferidas desde o primeiro dia.

Quando a temperatura caiu abaixo dos $55^{\circ} \mathrm{C}$ as composteiras foram reviradas de modo a permitir a oxigenação mais efetiva do composto e a restabelecer as condições termofílicas (Figura 6). O prolongamento da fase termofílica não é usual na maioria dos processos de compostagem, os quais com frequência apresentam fases bem definidas de temperaturas mesofílicas e termofílicas (Ryckeboer et al., 2003a; Kumar, 2011; Lopez-Gonzalez et al., 2015a). As temperaturas médias associadas a compostagem variam em torno de $30-50^{\circ} \mathrm{C}$ a $30-70^{\circ} \mathrm{C}$ dependendo do sistema de compostagem adotado, da revira e do tipo e disposição dos substratos (Adams \& Frostick, 2009; Chandna et al., 2013a; Lopez-Gonzalez et al., 2015a; Storey et al., 2015).

Os valores de $\mathrm{pH}$ variaram entre 5,0 e 7,9, de modo geral, os valores mais ácidos foram aferidos no início do processo, seguido por valores próximos a neutralidade e, no final, ligeiramente alcalinos $(\mathrm{pH}>7,0)$ (Tabela 8). Este resultado pode ser reflexo do grande aporte de material orgânico adicionado nas composteiras e da complexidade do mesmo (diferentes fontes). Trabalhos anteriores correlacionam a fase da compostagem com o $\mathrm{pH}$, a temperatura e a fonte de nutriente consumida, e relaciona $\mathrm{opH}$ mais baixo do início da compostagem com a intensa atividade de degradação de carboidratos cujos produtos de degradação são ácidos orgânicos, tais como, os ácidos acético e fórmico, seguido pela elevação do $\mathrm{pH}$ do composto para valores $\sim \mathrm{pH}$ 9,0 (Partanen et al., 2010; Hua et al., 2014).

A elevação do $\mathrm{pH}$ para valores alcalinos no final do processo pode ser associada a diminuição da disponibilidade de fontes de carboidratos mais simples e ao aumento concomitante da utilização de outras fontes de nutrientes mais complexas, como proteínas e compostos nitrogenados que promovem a 
liberação de amônia no meio em decorrência da sua degradação (Partanen et al., 2010; Hua et al., 2014).

A variação na umidade do composto foi medida apenas para ZC4 (Tabela 8) e encontrava-se dentro do intervalo de 40-65\% recomendado (Rynk et al., 1992), sendo que a média foi próxima de valores (50-60\%) anteriormente medidos em outras composteiras do Zoológico (Martins et al., 2013).

ZC4 e ZC3 apresentaram a razão C:N de 15:1 (Tabela 9), que é metade do valor recomendado (30:1) (Moreno et al., 2013) e empiricamente estimado quando as composteiras foram montadas. No entanto, a diminuição na razão C:N está dentro dos valores recomendados, refletindo uma perda aceitável de carbono como $\mathrm{CO}_{2}$ e da reciclagem de nitrogênio, em vez da perda de gás amônia ou por meio de lixiviação juntamente ao chorume produzido (Ryckeboer et al., 2003a; Kumar, 2011; Lopez-Gonzalez et al., 2013).

A análise elementar (Tabela 9) revelou que as amostras apresentavam concentrações de metais muito inferiores aos valores de referência orientadores de contaminação de solo, segundo normas técnicas do Conselho Nacional do Meio Ambiente (CONAMA) e da resolução CONAMA № 375 que dispõe sobre os limites estabelecidos para o emprego de lodo de esgoto em uso agrícola. Se por um lado, estes resultados indicaram a ausência de metais contaminantes no composto, eles mostraram que o composto possui uma baixa quantidade de micronutrientes como $\mathrm{K}, \mathrm{P}$ e N.

Foi realizada a medida da concentração de gases na composteira ZC4 (após 30 dias de seu início). Os resultados (Tabela 10), mostraram uma relativa baixa concentração de oxigênio na porção mais central na pilha de ZC4 (60-80 $\mathrm{cm}$ da superfície), indicando a presença de um microambiente de anaerobiose, porém com baixa concentração de metano, condição que deve favorecer 0 desenvolvimento de microrganismos anaeróbios, anaero-tolerantes e/ou facultativos capazes de promover a fermentação anaeróbica para a produção de ácidos orgânicos e obtenção de energia (Hua et al., 2014). Entretanto, não foi possível realizar medições ao longo de todo processo de compostagem e, portanto, correlações mais diretas entre concentração de gases e as características da comunidade microbiana ainda não puderam ser feitas. 
RESULTADOS E DISCUSSÃO

Tabela 9: Análises físico-químicas das composteiras ZC4 e ZC3.

\begin{tabular}{|c|c|c|c|c|c|c|c|c|c|c|c|c|c|c|c|c|c|}
\hline \multirow{2}{*}{$\begin{array}{c}\text { Amostras } \\
\text { ZC4 }\end{array}$} & \multirow{2}{*}{$\mathrm{C}: \mathrm{H}: \mathrm{N}$} & $\mathrm{C}$ & $\mathrm{H}$ & $\mathrm{N}$ & Al & $\mathrm{Fe}$ & $\mathrm{Mg}$ & $\mathrm{P}$ & As & $\mathrm{Cd}$ & $\mathrm{Cr}$ & $\mathrm{Cu}$ & $\mathrm{K}$ & $\mathrm{Ni}$ & $\mathrm{Pb}$ & $\mathrm{Se}$ & $\mathrm{Zn}$ \\
\hline & & \multicolumn{7}{|c|}{$\%($ peso seco) } & \multicolumn{9}{|c|}{$\mathrm{mg} / \mathrm{kg}$ (peso seco) } \\
\hline D01 & 16:02:01 & 37.6 & 5.6 & 2.4 & 1.5 & 1.1 & 0.2 & 0.4 & $<0.05$ & $<0.01$ & 14.9 & 19.0 & 1.0 & $<0.01$ & $<0.04$ & $<0.06$ & 2.4 \\
\hline D15 & 18:02:01 & 38.9 & 5.2 & 2.2 & 1.1 & 1.7 & 0.3 & 0.3 & $<0.05$ & $<0.01$ & 25.6 & 15.5 & 1.3 & $<0.01$ & $<0.04$ & $<0.06$ & 4.5 \\
\hline D30 & 14:02:01 & 33.9 & 4.4 & 2.4 & 1.2 & 1.8 & 0.3 & 0.5 & $<0.05$ & $<0.01$ & 23.4 & 23.4 & 1.4 & $<0.01$ & $<0.04$ & $<0.06$ & 8.5 \\
\hline D64 & $15: 02: 01$ & 35.1 & 4.5 & 2.3 & 1.2 & 1.3 & 0.3 & 0.4 & $<0.05$ & $<0.01$ & 20.2 & 24.5 & 1.4 & $<0.01$ & $<0.04$ & $<0.06$ & 9.4 \\
\hline D78 & $13: 02: 01$ & 29.0 & 3.8 & 2.3 & 1.3 & 1.1 & 0.3 & 0.5 & $<0.05$ & $<0.01$ & 13.3 & 31.9 & 1.8 & $<0.01$ & $<0.04$ & $<0.06$ & 20.4 \\
\hline D99 & 11:01:01 & 32.2 & 4.1 & 2.8 & 1.3 & 1.4 & 0.3 & 0.6 & $<0.05$ & $<0.01$ & 16.5 & 23.9 & 1.7 & $<0.01$ & $<0.04$ & $<0.06$ & 15.5 \\
\hline \multirow{2}{*}{$\begin{array}{c}\text { Amostras } \\
\text { ZC3 }\end{array}$} & \multirow{2}{*}{$\mathrm{C}: \mathrm{H}: \mathrm{N}$} & $\mathrm{C}$ & $\mathrm{H}$ & $\mathrm{N}$ & $\mathrm{Al}$ & $\mathrm{Fe}$ & $\mathrm{Mg}$ & $\mathrm{P}$ & As & $\mathrm{Cd}$ & & & $\mathrm{Ni}$ & $\mathrm{Pb}$ & $\mathrm{Se}$ & $\mathrm{Zn}$ & \\
\hline & & \multicolumn{7}{|c|}{$\%($ peso seco) } & \multicolumn{8}{|c|}{$\mathrm{mg} / \mathrm{kg}$ (peso seco) } & \\
\hline D01 & 14:02:01 & 35.45 & 5.2 & 2.5 & 13.2 & 1.1 & 0.5 & 0.6 & $<0.3$ & $<0.02$ & & & $<0.03$ & $<0.10$ & $<0.2$ & 207.3 & \\
\hline D30 & $15: 02: 01$ & 34.96 & 4.5 & 2.3 & 2.5 & 1.0 & 0.6 & 0.7 & $<0.3$ & $<0.02$ & & 03 & $<0.03$ & $<0.10$ & $<0.2$ & 211.4 & \\
\hline D64 & $15: 02: 01$ & 37.45 & 5.1 & 2.5 & 0.5 & 0.3 & 0.3 & 0.7 & $<0.01$ & $<0.03$ & & 02 & $<0.01$ & $<0.06$ & $<0.01$ & 91.5 & \\
\hline D78 & $14: 02: 01$ & 35.27 & 4.6 & 2.6 & 1.1 & 0.4 & 0.4 & 0.9 & $<0.02$ & 0.01 & & 004 & $<0.04$ & $<0.07$ & $<0.01$ & 191.8 & \\
\hline D99 & $12: 02: 01$ & 32.46 & 4.4 & 2.8 & 1.02 & 0.5 & 0.3 & 1.0 & $<0.03$ & $<0.01$ & & 04 & $<0.04$ & $<0.07$ & $<0.01$ & 173.7 & \\
\hline
\end{tabular}


Tabela 10: Medição da concentração de gases na compostagem. As medidas foram realizadas a partir de um mesmo ponto em diferentes profundidades do perfil vertical da composteira, utilizando o equipamento Landtec System Analyzer acoplado a uma sonda metálica de $1 \mathrm{~m}$ de comprimento, na composteira ZC4 após 30 dias da montagem.

\begin{tabular}{|c|c|c|c|c|c|c|c|}
\hline Profundidade & $\begin{array}{l}\mathrm{CH}_{4} \\
(\%)\end{array}$ & $\begin{array}{l}\mathrm{CO}_{2} \\
(\%)\end{array}$ & $\begin{array}{l}\mathrm{O}_{2} \\
(\%)\end{array}$ & $\begin{array}{c}\text { Baro. } \\
\text { Press. } \\
\text { (mb) }\end{array}$ & $\begin{array}{c}\text { CO } \\
(p p m)\end{array}$ & $\begin{array}{c}\mathbf{H}_{2} \\
(\mathrm{ppm})\end{array}$ & Data/horário \\
\hline \multicolumn{8}{|c|}{ ZC4 (D30) } \\
\hline Superfície & 0.1 & 4.5 & 16.8 & 917 & 206 & 479 & $\begin{array}{r}04 / 09 / 2013 \\
11: 09\end{array}$ \\
\hline $20 \mathrm{~cm}$ & 0.1 & 15.7 & 5.0 & 917 & 197 & 459 & $\begin{array}{r}04 / 09 / 2013 \\
11: 11\end{array}$ \\
\hline $40 \mathrm{~cm}$ & 0.3 & 18.9 & 1.9 & 917 & 195 & 467 & $\begin{array}{r}04 / 09 / 2013 \\
11: 13\end{array}$ \\
\hline $60 \mathrm{~cm}$ & 0.5 & 19.7 & 1.0 & 917 & 205 & 550 & $\begin{array}{r}04 / 09 / 2013 \\
11: 15\end{array}$ \\
\hline $80 \mathrm{~cm}$ & 0.8 & 19.8 & 1.0 & 917 & 210 & 674 & $\begin{array}{r}04 / 09 / 2013 \\
11: 17\end{array}$ \\
\hline $100 \mathrm{~cm}$ & 0.8 & 17.4 & 3.7 & 917 & 203 & 794 & $\begin{array}{r}04 / 09 / 2013 \\
11: 19\end{array}$ \\
\hline $120 \mathrm{~cm}$ & 0.3 & 3.5 & 17.8 & 917 & 189 & 805 & $\begin{array}{r}04 / 09 / 2013 \\
11: 21\end{array}$ \\
\hline
\end{tabular}

\subsection{Variação da estrutura e composição da comunidade microbiana durante a compostagem}

Em concordância com resultados prévios de caracterização da microbiota associada a compostagem (Martins et al., 2013), todas as amostras coletadas das composteiras ZC3 e ZC4 foram dominadas pelo DNA de bactérias, independentemente do avanço do processo, como demonstrado pela análise das sequências metagenômica shotgun no banco de dados do M5NR (M5 non-redundant protein) disponível na plataforma do MG-RAST (Glass et al., 2010). A tabela 11 mostra que o domínio Bacteria correspondeu a quase $100 \%$ de sequências classificadas, e a pelo menos $86 \%$ de todas as sequências obtidas, em todas as amostras. Considerando este resultado, o trabalho aqui apresentado focalizou especialmente a relação de bactérias no processo de compostagem.

A estrutura da comunidade bacteriana com base nos níveis taxonômicos de Filo e de Ordem foi investigada em maior detalhe combinando os dados de metagenômica shotgun e do sequenciamento do amplicon das regiões V3-V4 do gene rRNA16S, de modo a diluir as limitações inerentes a cada uma dessas abordagens. De modo geral, nossos resultados demonstraram uma 
concordância entre os dados obtidos com essas duas abordagens, como detalhado a seguir.

Os quatro Filos mais abundantes ao longo do processo de compostagem foram: Firmicutes, Proteobacteria, Bacteroidetes e Actinobacteria (Figura 7). Juntos representam $\geq 85 \%$ de todas as sequências classificadas em todas as amostras e apresentaram variações sutis ao longo do processo, sobretudo o filo Firmicutes. Esses quatro Filos já foram reportados como os dominantes em outros sistemas de compostagem ricos em lignocelulose (Partanen et al., 2010; de Gannes et al., 2013; Moreno et al., 2013; Neher et al., 2013; Jurado et al., 2014; Zainudin et al., 2014; Storey et al., 2015; Zhang et al., 2016).

Tabela 11: Distribuição de Domínios nas amostras das composteiras ZC3 e ZC4. Análise da abundância relativa das sequências shotgun não-montadas das amostras de ZC3 e ZC4, anotadas no MG-RAST utilizando o banco do M5NR com os seguintes parâmetros: identidade mínima de $60 \%$; e-value máximo de $1 \times 10^{-5}$ e comprimento mínimo de alinhamento de 50pb.

\begin{tabular}{|c|c|c|c|c|c|c|c|c|c|}
\hline \multicolumn{10}{|c|}{ ZC4 } \\
\hline $\begin{array}{l}\text { Domínio / } \\
\text { Amostra }\end{array}$ & $\begin{array}{c}\text { D01 } \\
\%\end{array}$ & $\begin{array}{c}\text { D03 } \\
\%\end{array}$ & $\begin{array}{c}\text { D07 } \\
\%\end{array}$ & $\begin{array}{c}\text { D15 } \\
\%\end{array}$ & $\begin{array}{c}\text { D30 } \\
\%\end{array}$ & $\begin{array}{c}\text { D64 } \\
\%\end{array}$ & $\begin{array}{c}\text { D67 } \\
\%\end{array}$ & $\begin{array}{c}\text { D78 } \\
\%\end{array}$ & $\begin{array}{c}\text { D99 } \\
\%\end{array}$ \\
\hline Bacteria & 90,47 & 90,50 & 88,44 & 89,19 & 89,72 & 86,80 & 87,70 & 88,35 & 87,60 \\
\hline Archaea & 0,27 & 0,29 & 0,48 & 0,39 & 0,28 & 0,46 & 0,37 & 0,69 & 0,35 \\
\hline Eukaryota & 0,31 & 0,27 & 0,15 & 0,19 & 0,31 & 0,31 & 0,12 & 0,13 & 0,12 \\
\hline Viruses & 0,17 & 0,13 & 0,07 & 0,05 & 0,08 & 0,09 & 0,09 & 0,21 & 0,11 \\
\hline Unclassified & 8,78 & 8,81 & 10,86 & 10,18 & 9,61 & 12,34 & 11,72 & 10,62 & 11,82 \\
\hline \multicolumn{10}{|c|}{ ZC3 } \\
\hline $\begin{array}{c}\text { Domínio / } \\
\text { Amostra }\end{array}$ & & $\begin{array}{c}\text { D01 } \\
\%\end{array}$ & \multicolumn{2}{|c|}{$\begin{array}{c}\text { D30 } \\
\%\end{array}$} & \multicolumn{2}{|l|}{$\begin{array}{c}\text { D64 } \\
\%\end{array}$} & $\begin{array}{c}\text { D78 } \\
\%\end{array}$ & \multicolumn{2}{|c|}{$\begin{array}{c}\text { D99 } \\
\%\end{array}$} \\
\hline Bacteria & & 84,86 & \multicolumn{2}{|c|}{89,62} & \multicolumn{2}{|c|}{88,54} & 87,79 & \multicolumn{2}{|c|}{89,18} \\
\hline Archaea & & 1,51 & \multicolumn{2}{|c|}{0,61} & \multicolumn{2}{|l|}{0,74} & 0,54 & \multicolumn{2}{|c|}{0,48} \\
\hline Eukaryota & & 0,17 & \multicolumn{2}{|c|}{0,53} & \multicolumn{2}{|l|}{0,31} & 0,28 & \multicolumn{2}{|c|}{0,28} \\
\hline Viruses & & 0,05 & \multicolumn{2}{|c|}{0,12} & \multicolumn{2}{|l|}{0,12} & 0,14 & \multicolumn{2}{|c|}{0,32} \\
\hline Unclassified & & 13,41 & \multicolumn{2}{|c|}{9,12} & \multicolumn{2}{|c|}{10,30} & 11,25 & \multicolumn{2}{|c|}{9,75} \\
\hline
\end{tabular}


i)

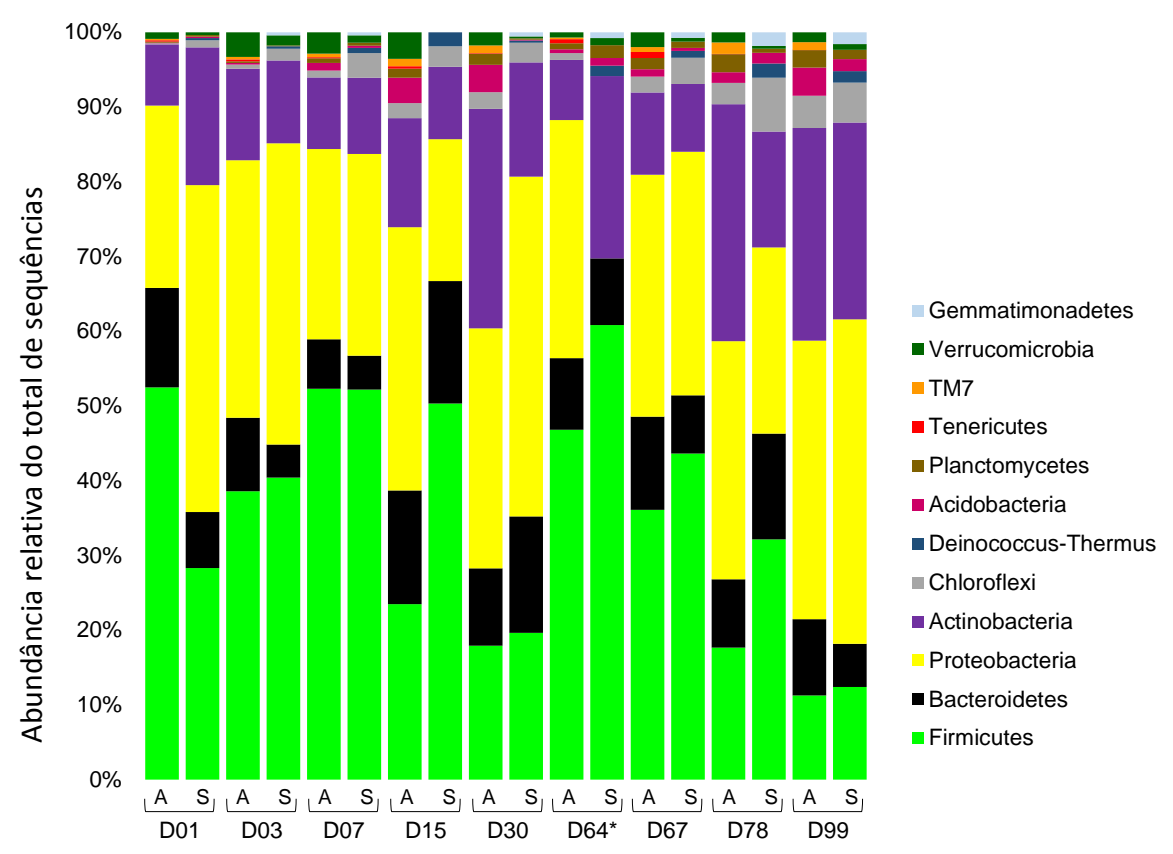

ii)

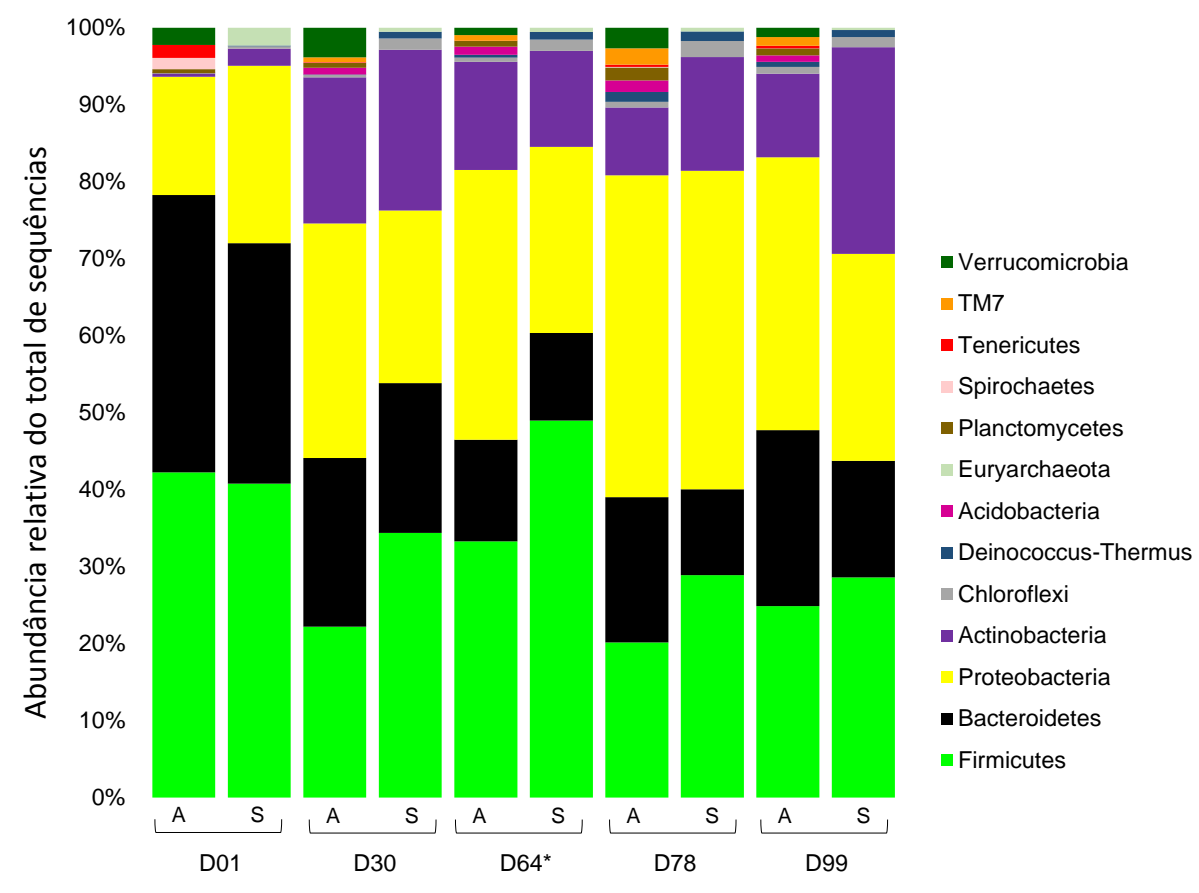

Figura 7: Abundância relativa de Filos bacterianos nas amostras da ZC4 (i) e ZC3 (ii). Análise baseada nas sequências classificadas do amplicon 16S (A) e da metagenômica shotgun (S). As sequências de amplicon 16S foram classificadas com RDP classifier e na figura estão representadas somente os Filos com abundância relativa $\geq 1 \%$. As sequências shotgun (reads não-montadas) foram analisadas na plataforma MG-RAST (base de dados M5NR). Foram excluídas da análise sequências não classificadas/ não anotadas no nível taxonômico de Filo, as quais representaram $\sim 16,7 \%$ (ZC4) e 1,9\% (ZC3) para o amplicon 16S e 11,9\% (ZC4) e 10,9\% (ZC3) para as sequências shotgun. $\mathrm{O}$ asterisco indica um dia após a revira em ZC4 ou um dia antes da revira em ZC3. 
A análise ao nível de Ordem revelou uma maior variação entre as amostras, refletindo de modo mais claro alterações na estrutura da comunidade, em decorrência do avanço do processo e da etapa de revira (Figura 8). Destaca-se a elevada abundância relativa das ordens Clostridiales, Bacillales e Actinomycetales na maioria das amostras, assim como verificado em outros sistemas de compostagem (Peters et al., 2000; Dees \& Ghiorse, 2001; Alfreider et al., 2002; Guo et al., 2007; Steger et al., 2007b; Klammer et al., 2008; Franke-Whittle et al., 2009; Partanen et al., 2010; Martins et al., 2013). Este resultado reforça as inferências propostas no nosso primeiro trabalho de investigação deste ambiente de que estas Ordens bacterianas seriam as principais responsáveis pela degradação de polímeros complexos, como a celulose e a lignina durante o processo de compostagem (Martins et al., 2013). Há evidências que sugerem que os membros de Actinomycetales e Bacillales, entre outras Ordens bacterianas, possuem a capacidade de degradar a celulose e de solubilizar a lignina combinado com a capacidade de tolerar altas temperaturas características da compostagem (Tuomela et al., 2000; Lynd et al., 2002; Ryckeboer et al., 2003b; Yu et al., 2007; Gu et al., 2010; Partanen et al., 2010; Rastogi et al., 2010; Bugg et al., 2011b).

A Ordem Clostridiales também é reconhecida como uma importante degradadora de biomassa vegetal por possuir um complexo multi-enzimático de desconstrução da celulose denominado celulossomo. A presença desta Ordem que incluem membros que são anaeróbicos ou microaerofílicos reforça a indicação de que a degradação da biomassa na compostagem seria realizada por sistemas aeróbios e anaeróbios de forma complementar e/ou sincronizada (Kato et al., 2004; Guo et al., 2007; Yi et al., 2012). 
i)

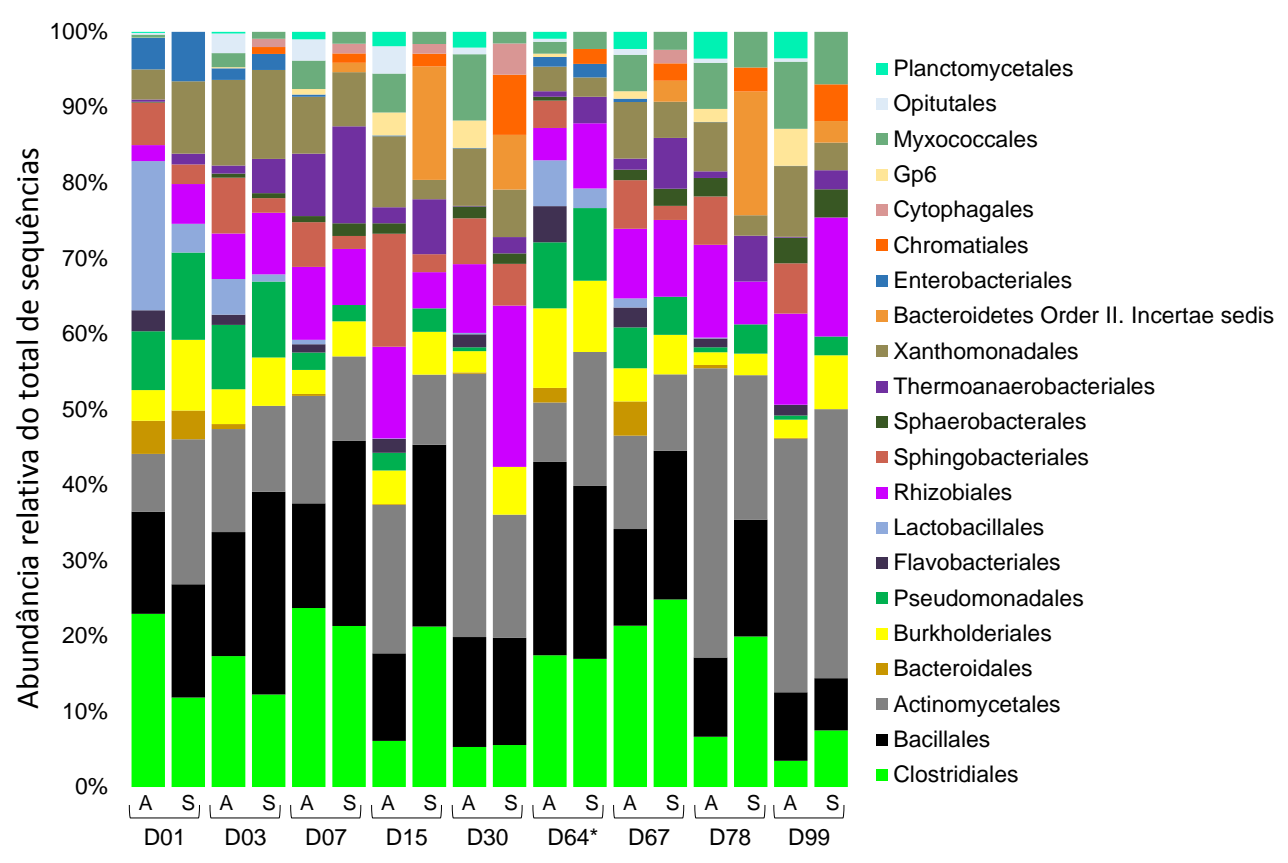

ii)

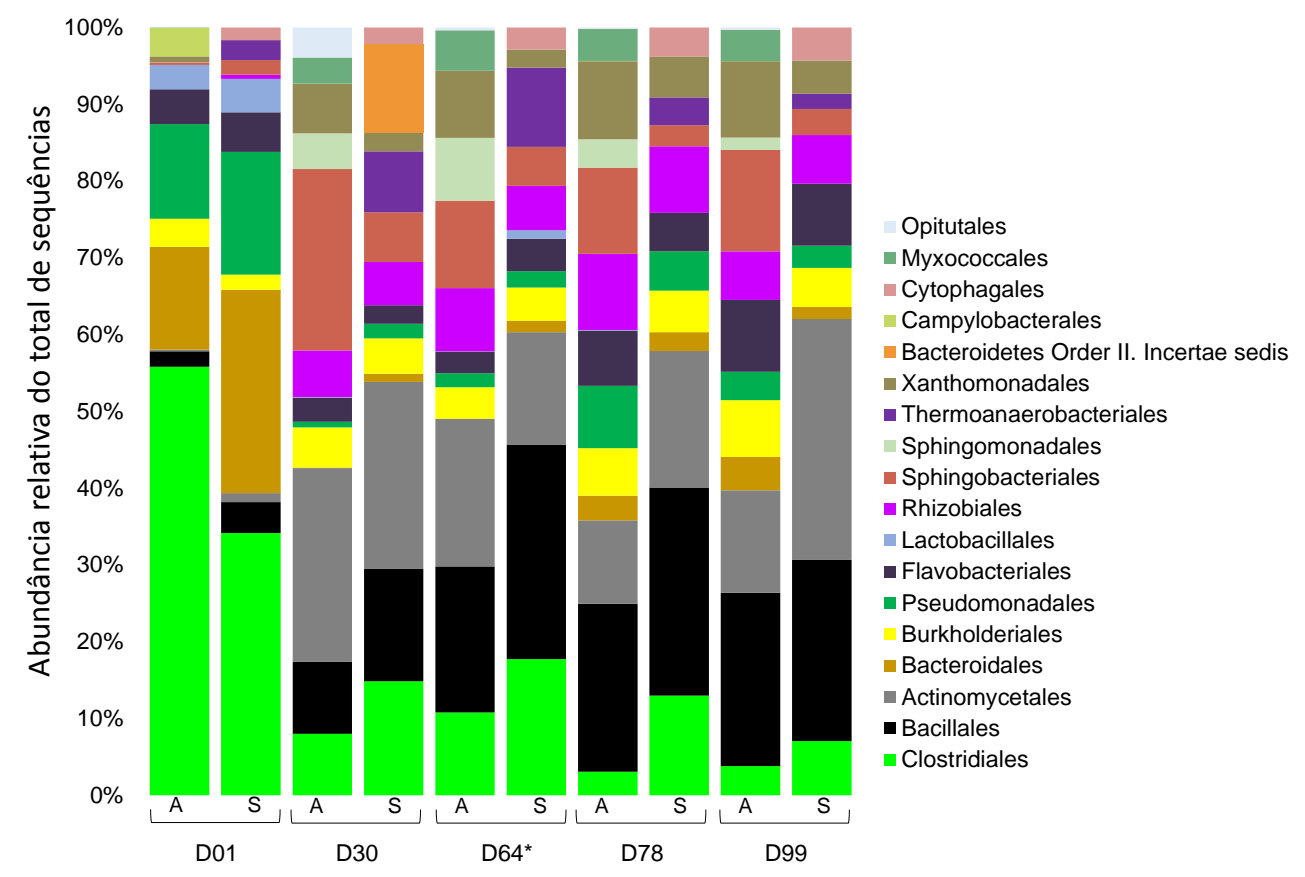

Figura 8: Abundância relativa de Ordens bacterianas nas amostras da ZC4 (i) e ZC3 (ii). Análise baseada nas sequências classificadas do amplicon 16S (A) e da metagenômica shotgun (S). As sequências de amplicon 16S foram classificadas com RDP classifier e na figura estão representadas somente as Ordens com abundância relativa $\geq 2 \%$. As sequências shotgun (reads não-montadas) foram analisadas na plataforma MG-RAST (base de dados M5NR). Foram excluídas da análise sequências não classificadas/ não anotadas no nível taxonômico de Ordem, as quais representaram 10-30\% (ZC4) e 16-29\% (ZC3) para o amplicon 16S e 10,1-14,6\% (ZC4) e 8,2-12,9\% (ZC3) para as sequências shotgun. $\mathrm{O}$ asterisco indica um dia após a revira em ZC4 ou um dia antes da revira em ZC3. 
A caracterização da microbiota associada a série temporal permitiu também verificar a ocorrência de variações na abundância de alguns grupos entre as composteiras, como de Clostridiales que na ZC3 apresentou maior abundância em D01 enquanto na ZC4 foi abundante em todo o processo. Estes resultados sugerem que ZC4 e ZC3 compartilham grupos de microrganismos das mesmas Ordens, ainda que suas abundâncias variem entre as composteiras. Por outro lado, análises de distância com diferentes métricas (Figura 9) demonstraram uma variação significativa dos grupos mais abundantes entre as amostras coletadas em série temporal de uma mesma composteira, indicando a natureza altamente dinâmica do processo de compostagem estudado, como detalhado a seguir.

\subsection{Análises de riqueza e diversidade da microbiota da compostagem}

Examinamos a comunidade microbiana da compostagem a partir dos dados de sequenciamento do amplicon 16S utilizando as métricas Bray Curtis e Unifrac (qualitativa e quantitativa). Os resultados obtidos com a comparação de amostras coletadas em dias equivalentes de ZC3 e ZC4 demonstraram que ambas as composteiras compartilham um conjunto de microrganismos, no qual devem estar presentes membros que conduzem o processo de degradação da matéria orgânica. Contudo, estas análises revelaram uma variação significativa entre os grupos mais abundantes entre as amostras das séries-temporais, demonstrando a natureza dinâmica do processo de compostagem (Figura 9).

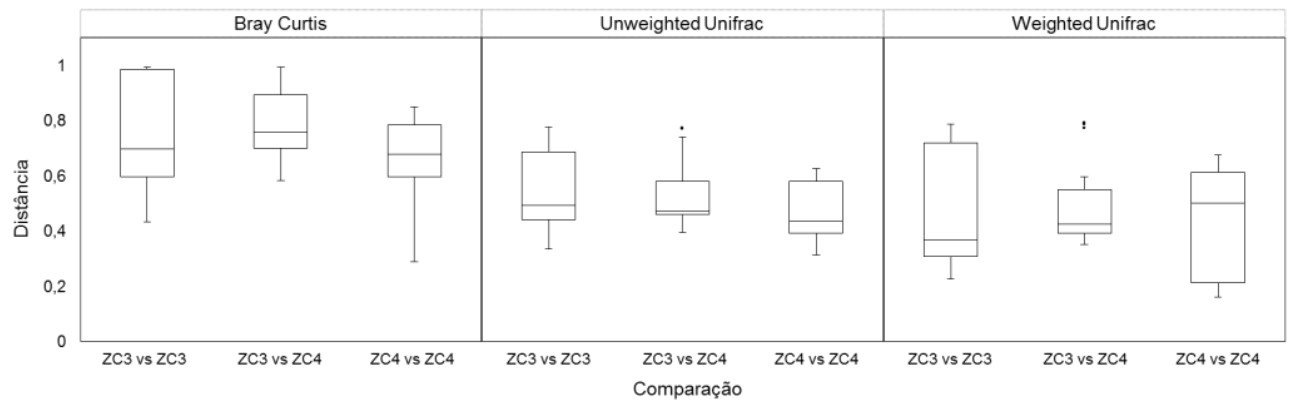

Figura 9. Comparação filogenética entre as comunidades bacterianas da ZC3 e ZC4. As OTUs foram classificadas com base no sequenciamento de amplicons V3-V4 do 16S, sendo a comparação feita entre amostras equivalentes de ZC3 e ZC4 (D01, D30, D78 e D99) utilizando-se as métricas Bray Curtis, Unifraq não ponderada e Unifraq ponderada (Unweighted e Weighted, respectivamente). Os box plots representam comparações de amostras dentro da mesma célula (ZC3 contra ZC3 ou ZC4 contra ZC4) ou entre amostras de células distintas (ZC3 contra ZC4). Os pontos indicam valores outliers. 
A dinâmica do processo pode ser visualizada com mais clareza na Figura 10, que apresenta a variação do número de unidades taxonômicas operacionais (OTUs) e do índice de diversidade filogenética alfa ao longo do tempo. Os dados mostram que o início do processo apresentou a maior diversidade (D01), assim como as amostras após a etapa de revira (D64 e D67). Uma maior diversidade filogenética associada ao começo da compostagem era esperada como já reportado anteriormente (Partanen et al., 2010). Mas foi surpreendente verificar a clara retomada da diversidade alfa após a revira. Nossa interpretação é que revira restabelece momentaneamente determinadas condições prevalentes no início da compostagem. Estas condições favoreceriam organismos aeróbicos que podem utilizar mais eficientemente os nutrientes disponíveis, tais como os membros da ordem Lactobacillales encontrada nas amostras de D01 e D64 (Alfreider et al., 2002; Ishii \& Takii, 2003; Partanen et al., 2010; Chandna et al., 2013a).

Acreditamos que com 0 avanço do processo de degradação, a concentração de oxigênio e de nutrientes facilmente degradáveis se tornaria progressivamente mais escassa, especialmente em regiões mais internas na pilha da composteira. Tais ambientes provavelmente restringem a comunidade microbiana e favorecem a seleção de populações microbianas mais especializadas para a degradação dos materiais recalcitrantes como a lignocelulose. Com a revira, o oxigênio e nutrientes facilmente degradáveis, confinados em outras regiões da pilha, se tornariam novamente abundantes para a maior parte da microbiota da compostagem, diminuindo assim a restrição seletiva por fontes de nutrientes acessíveis. Com base nestes resultados, nossa hipótese é que os nutrientes e disponibilidade de oxigênio são os principais determinantes das mudanças na composição de microbiota ao longo do processo de compostagem. 


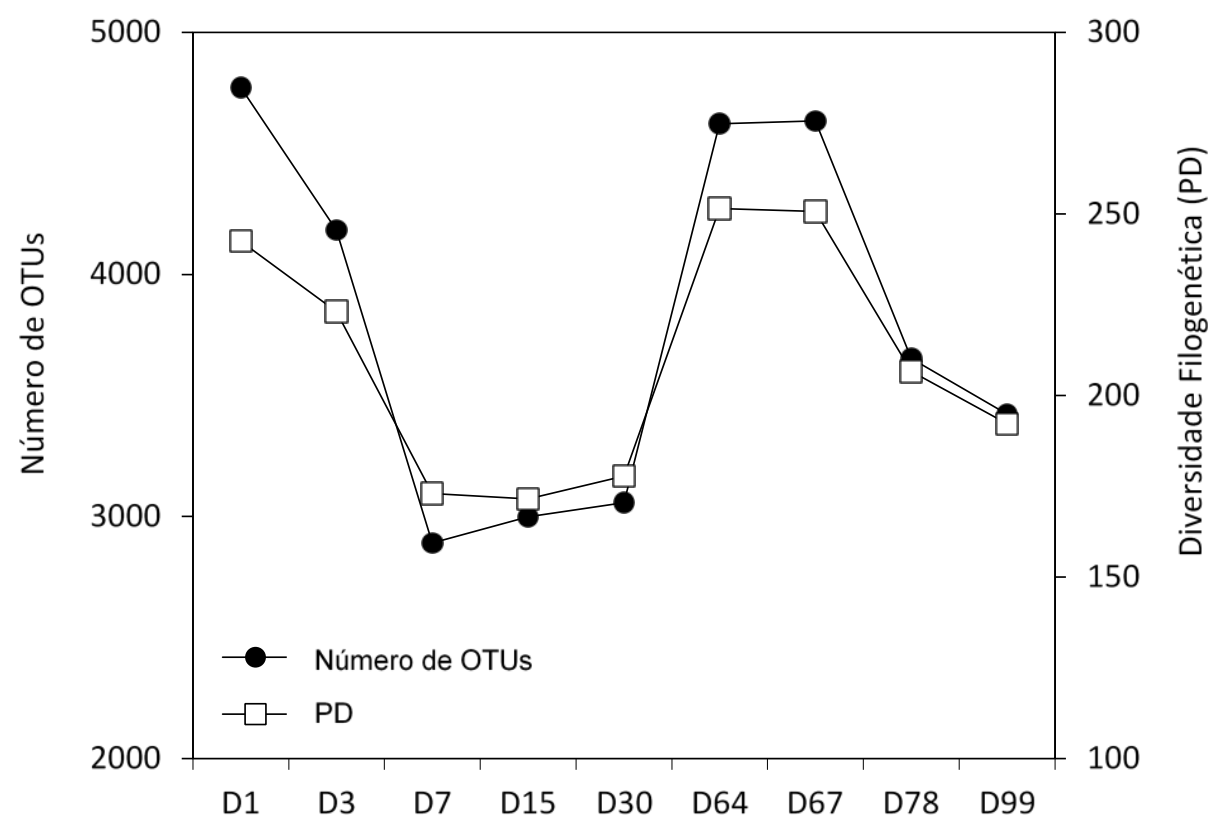

Figura 10: Variação da riqueza e da diversidade filogenética nas amostras de ZC4. Perfil do número de OTUs estimadas com base nos dados de sequenciamento do amplicon 16S e do índice de diversidade filogenética (diversidade alfa) das amostras. Intervalos no eixo horizontal não estão em escala cronológica.

\subsection{Espécies de bactérias mais abundantes na compostagem e reconstrução do genoma de um provável novo gênero bacteriano}

A riqueza e a diversidade de espécies (OTUs) encontrada nas amostras da compostagem foi, ao nosso ver, surpreendente, considerando que é um ambiente engenheirado. Como mostrado na Figura 10, o número de OTUs variou de 3000-5000 nas amostras de ZC4, o que supera resultados anteriores (Martins et al., 2013) que apontaram como 2200-2600 o número de espécies bacterianas preditas para amostras de duas composteiras (ZC1 e ZC2). Embora tenha sido possível classificar significativa fração $(>70 \%)$ das sequências geradas até o nível taxonômico de Ordem, dependendo da amostra ou da abordagem metagenômica utilizada (Figura 8), a classificação em níveis taxonômicos mais baixos, como gênero e espécie, nem sempre é possível, dado que a disponibilidade de sequências genômicas presentes nos bancos de dados estar restrita, principalmente, a bactérias que são cultiváveis.

Com objetivo de refinar a análise da diversidade bacteriana no nível das espécies presentes na compostagem, buscamos primeiramente identificar aquelas mais abundantes cuja classificação fosse confiável. Para tal, foi 
utilizado o programa MyTaxa (Luo et al., 2014) para a classificação taxonômica de sequências e contigs obtidos a partir dos dados de metagenômica shotgun. As cinco espécies identificadas como mais abundantes reunindo todos os metagenomas da ZC4 combinados foram: Rhodothermus marinus, Thermobispora bispora, Symbiobacterium thermophilum, Sphaerobacter thermophilus e Thermobifida fusca (Tabela 12). Todas essas espécies já foram isoladas ou detectadas em ambientes de degradação de biomassa (Demharter et al., 1989; Ohno et al., 2000; Ueda et al., 2004; Lykidis et al., 2007; Steger et al., 2007a; Liolios et al., 2010; Pati et al., 2010; Gladden et al., 2011; D'Haeseleer et al., 2013; Toth et al., 2013; Yabe et al., 2013). Além disso, T. fusca já foi amplamente identificada em sistemas compostagens de material vegetal e é conhecida por ser capaz de degradar celulose e lignina (Rahmanpour et al., 2016).

Tabela 12: Espécies de bactérias mais abundantes nos metagenomas da ZC4 classificadas pelo programa MyTaxa. A identificação destas espécies foi confirmada com identidade média de nucleotídeo de 96-99\% para sete genes marcadores filogenéticos, cujas sequências foram recuperadas dos respectivos genomas reconstruídos.

\begin{tabular}{|c|c|c|}
\hline Espécie & Ordem & $\begin{array}{l}\% \text { de reads } \\
\text { classificadas }\end{array}$ \\
\hline Rhodothermus marinus & $\begin{array}{l}\text { Bacteroidetes Order II. Incertae } \\
\text { sedis }\end{array}$ & 2,48 \\
\hline Thermobispora bispora & Actinobacteria incertae sedis & 2,15 \\
\hline $\begin{array}{l}\text { Symbiobacterium } \\
\text { thermophilum }\end{array}$ & Clostridiales & 1,5 \\
\hline Sphaerobacter thermophilus & Sphaerobacterales & 1,08 \\
\hline Thermobifida fusca & Streptosporangiales & 0,75 \\
\hline
\end{tabular}

O genoma de cada uma das cinco espécies mais abundantes foi reconstruído a partir das sequências metagenômicas de ZC4 e alinhado contra genomas referências dessas espécies. Foram identificadas variações pontuais entre os genomas reconstruídos quando comparados aos genomas de referência, as quais sugerem que podem se tratar de novas cepas. Além disso, os genomas reconstruídos conservam as características funcionais descritas para estas espécies bacterianas quando ao conteúdo de genes codificadores de glicosil hidrolases (Lemos, 2015). 
Várias das espécies identificadas como mais abundantes nos metagenomas de ZC4 também foram identificadas como mais abundantes a quando mesma análise foi realizada utilizando-se os dados de metatranscritômica de ZC4 (Tabela S1). No caso de $R$. marinus, a variação em abundância na série temporal é muito semelhante se comparados dados de metagenômica shotgun e dados de metatranscritômica (Figura 11). O conjunto dessas observações indica que as espécies mais abundantes que foram passíveis de identificação estão ativas no processo de compostagem, e também mostra que os resultados da metagenômica shotgun refletem, com boa acurácia, a efetiva atividade microbiana nesse processo.

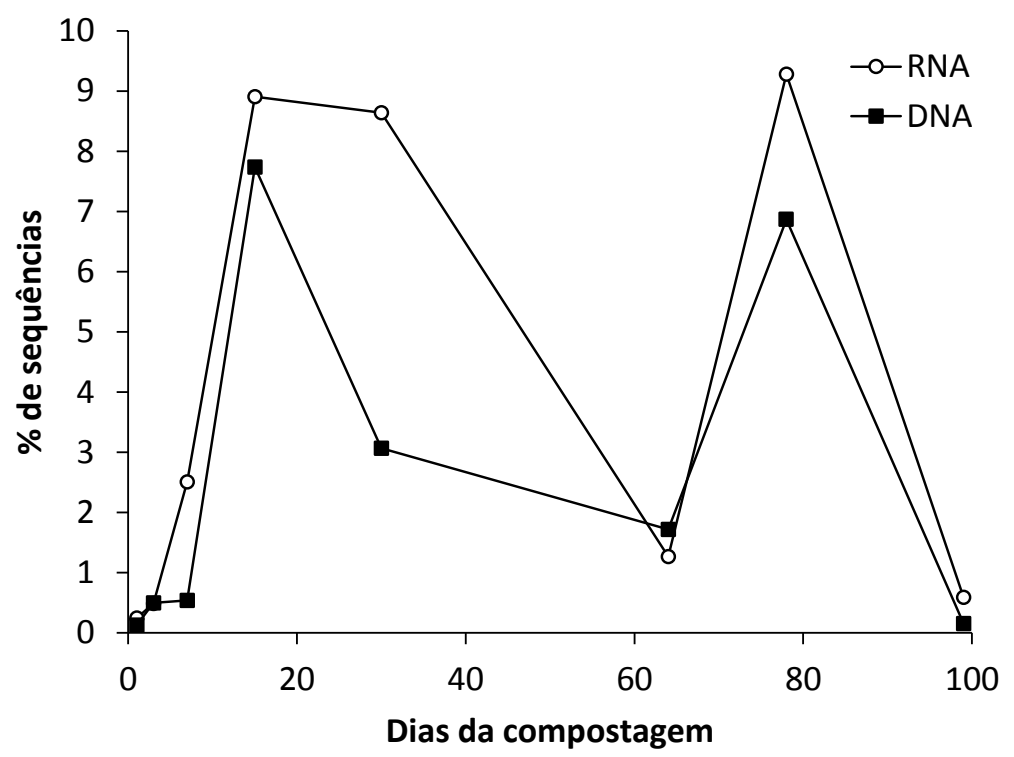

Figura 11: Variação na abundância relativa de reads classificadas como Rhodothermus marinus pelo MyTaxa nos metagenomas (DNA) e metatranscritomas (RNA) da ZC4. Os percentuais de reads classificadas foram normalizadas pelo total de reads de todas as amostras da ZC4.

Tabela 13: Lista da cinco OTUs mais abundantes nos metagenomas 16S de ZC4. O BLAST foi realizado com o GenBank (NT) em Novembro/2015. Todos os hits mostraram $100 \%$ de identidade e $\sim 100 \%$ de cobertura contra o fragmento do gene do rRNA 16S.

\begin{tabular}{|c|c|c|c|}
\hline Classificação & OTU & Melhor hit do BLAST & $\begin{array}{c}\text { Número de acesso no } \\
\text { GenBank do melhor hit }\end{array}$ \\
\hline 1 & 537822506 & $\begin{array}{c}\text { Calditerricola } \\
\text { yamamurae }\end{array}$ & AB308475.1 \\
\hline 2 & 576372771 & Bactéria não-cultivável & KF911139.1 \\
\hline 3 & 574661859 & Bactéria não-cultivável & FN667161.1 \\
\hline 4 & 723870961 & Bactéria não-cultivável & KF911257.1 \\
\hline 5 & 6102000 & Bactéria não-cultivável & HE804952.1 \\
\hline
\end{tabular}


Por outro lado, a classificação taxonômica até o nível de gênero realizada a partir dos dados do sequenciamento de amplicons do rRNA16S revelou uma estrutura microbiana diferente da descrita a partir da classificação dos dados de metagenômica shotgun com o programa MyTaxa, descrita acima. Observamos que nenhuma das cinco OTUs mais abundantes (Tabela 13) corresponde às espécies mais abundantes classificadas pelo programa MyTaxa (Tabela 12). Uma explicação para esta discrepância é que a classificação das sequências shotgun foi inteiramente baseada em genomas completos de referência, como já mencionado. Estas observações, são um forte indicativo que há bactérias presentes na compostagem para as quais não existem genomas completos disponíveis e tão pouco são cultiváveis, e fazem, portanto parte da microbial dark matter. No caso das cinco OTUs mais abundantes listadas na Tabela 13, quatro correspondem a bactérias nãocultiváveis identificadas em estudos metagenômicos publicamente disponíveis.

Com base nessas evidências, foi realizada a montagem apenas do conjunto de sequências atribuídas a OTU537822506 o que possibilitou a recuperação $~ 685 \mathrm{Kbp}$ que parece corresponder ao genoma desta OTU. Dados adicionais ampliaram a recuperação virtualmente completa deste novo genoma, com 2,7 Mpb. A análise filogenética com base em 23 genes ortólogos sugere que OTU537822506 é um novo gênero na família Bacillaceae (Figura 12).

Observamos ainda que o metatranscritoma contém sequências correspondentes ao genoma da OTU537822506, sugerindo que se trata, como esperado, de uma espécie ativa no processo de compostagem. Entretanto, uma análise detalhada do repertório das suas respectivas CDSs anotadas como CAZy sugere que esta bactéria, embora abundante na microbiota da compostagem, não parece ser um potente degradador de lignocelulose comparativamente a Clostridium clariflavum 4-2a (Firmicutes), Rhodothermus marinus DSM 4252 (Bacteroidetes) ou Thermobispora bispora DSM 43833 (Actinobateria) cujos genomas são enriquecidos em CDSs de variadas famílias do CAZy (R.V.Pereira \& L.F.Martins, comunicação pessoal). 


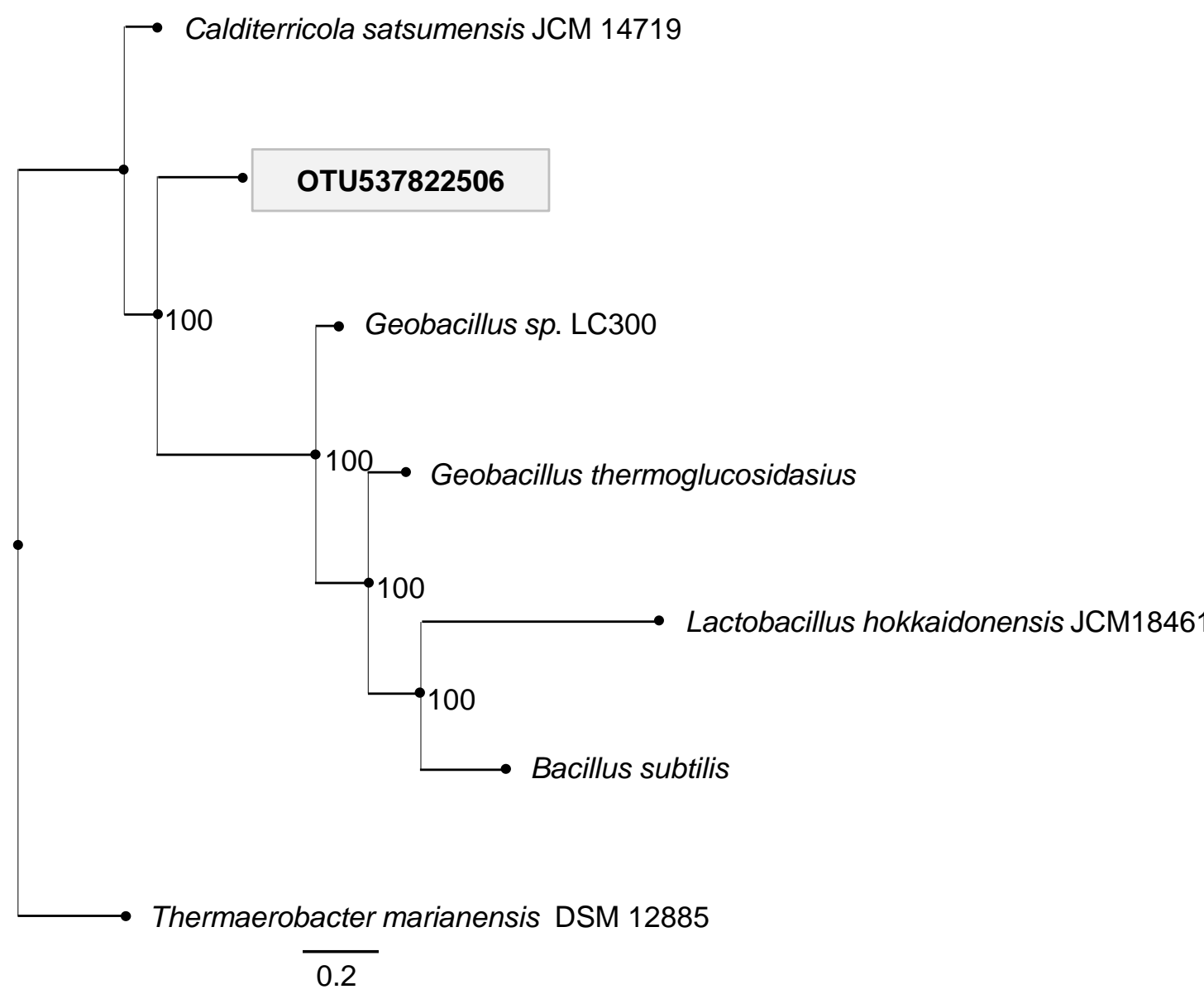

Figura 12: Árvore filogenética obtida por máxima verossimilhança baseada na sequência de nucleotídeos de 23 genes ortólogos. Os valores de nó representam o suporte de bootstrap. A escala demonstra o número de substituições por sítio. Thermaerobacter marianensis (Clostridiales) foi escolhida como grupo externo. Todas as outras espécies são membros da família Bacillaceae.

Análises adicionais serão futuramente realizadas na tentativa de se elucidar a identidade das outras OTUs abundantes e potencialmente correspondentes a espécies ainda desconhecidas bem como para compreender o papel ecofisiológico destas espécies no processo de compostagem.

\subsection{Potencial metabólico da microbiota da compostagem}

O perfil geral das funções metabólicas das comunidades microbianas presentes no processo de compostagem foi obtido através da análise de sequências codificadoras (CDS) anotadas nos contigs montados a partir das sequências metagenômicas e classificadas utilizando a base de dados do COG (Galperin et al., 2015). Entre as 15 funções mais abundantes em todas as 
amostras de metagenoma, encontramos COGs associados com a manutenção básica da célula (housekeeping): proliferação celular (carbohydrate and aminoacid transport and metabolism and DNA replication), comunicação (response and transcriptional regulators) e de defesa (bacterial efflux pumps) (Tabela 14). Tais funções são normalmente encontradas em ecossistemas lignocelulolíticos (Martins et al., 2013; Mhuantong et al., 2015; Wang et al., 2016). Avaliamos também, a abundância de CDS de enzimas envolvidas no processo de degradação da biomassa vegetal (Tabela 15). Constatamos que os metagenomas das amostras da série temporal tanto de ZC3 como de ZC4 codificam o potencial enzimático necessário para a metabolização da biomassa vegetal. Perfil similar foi observado para os metagenomas das composteiras ZC1 e ZC2, estudados anteriormente (Martins et al., 2013).

Com os dados do metatranscritoma das amostras da ZC4 foi possível, ir além da avaliação do potencial metabólico predito nos metagenomas, para uma avaliação do potencial metabólico ativo e da sua dinâmica ao longo do processo. Primeiramente, realizamos o mapeamento das sequências obtidas do metatranscritoma nos contigs do metagenoma e, como esperado, verificamos que a vasta maioria das sequências dos metatranscritomas de ZC4 representa um subconjunto dos metagenomas de ZC4 (dados não mostrados).

Os contigs oriundos da montagem das sequências do metatranscritoma para as amostras de ZC4 tiveram suas CDSs classificadas com base em categorias de COG, sendo que o agrupamento hierárquico baseado na abundância relativa dessas categorias de COG permitiu dividir o processo de compostagem em três grupos: início ou retomada (D01, D03 e D64), meio (D07, D15 e D30) e final (D78 e D99) (Figura 13A). 
RESULTADOS E DISCUSSÃO

Tabela 14: Análise comparativa das 15 funções do COG mais abundantes nos metagenomas da ZC3 e ZC4. Os valores representam a abundância relativas de sequências (1/1000) obtidas a partir da anotação de COGs utilizando o pipeline do IMG/M.

Metagenomas

D01

D30

D64

D78

D99

\begin{tabular}{|c|c|c|c|c|c|c|c|c|c|c|c|c|}
\hline $\begin{array}{l}\text { Categoria } \\
\text { COG }^{*}\end{array}$ & $\begin{array}{l}\text { Função } \\
\text { COG }\end{array}$ & Nome da Função & ZC3 & ZC4 & ZC3 & ZC4 & ZC3 & ZC4 & ZC3 & ZC4 & ZC3 & ZC4 \\
\hline $\mathrm{L}$ & COG0178 & $\begin{array}{l}\text { Excinuclease UvrABC } \\
\text { ATPase subunit }\end{array}$ & 2,64 & 1,65 & 1,43 & 1,36 & 1,45 & 1,34 & 1,69 & 1,23 & 1,91 & 1,13 \\
\hline $\mathrm{L}$ & COG0187 & $\begin{array}{l}\text { DNA gyrase/topoisomerase } \\
\text { IV, subunit B }\end{array}$ & 2,72 & 1,27 & 1,19 & 0,81 & 1,17 & 1,09 & 1,22 & 0,88 & 1,19 & 0,78 \\
\hline $\mathrm{L}$ & COG0188 & $\begin{array}{l}\text { DNA gyrase/topoisomerase } \\
\text { IV, subunit A }\end{array}$ & 2,67 & 1,63 & 1,23 & 1,22 & 1,32 & 1,48 & 1,61 & 1,16 & 1,62 & 1,08 \\
\hline $\mathrm{I}, \mathrm{Q}$ & COG0318 & $\begin{array}{l}\text { Acyl-CoA synthetase (AMP- } \\
\text { forming)/AMP-acid ligase II }\end{array}$ & 2,86 & 3,53 & 3,53 & 3,99 & 3,60 & 3,61 & 3,68 & 3,57 & 3,26 & 4,15 \\
\hline $\mathrm{G}$ & COG0395 & $\begin{array}{l}\text { ABC-type glycerol-3- } \\
\text { phosphate transport system, } \\
\text { permease component }\end{array}$ & 1,65 & 2,91 & 3,38 & 2,54 & 2,83 & 2,77 & 2,29 & 2,64 & 2,28 & 2,78 \\
\hline $\mathrm{M}$ & COG0438 & $\begin{array}{l}\text { Glycosyltransferase involved } \\
\text { in cell wall biosynthesis }\end{array}$ & 2,65 & 2,56 & 3,26 & 4,80 & 3,40 & 3,72 & 3,89 & 4,43 & 3,05 & 5,06 \\
\hline$J$ & COG0480 & $\begin{array}{l}\text { Translation elongation factor } \\
\text { EF-G, a GTPase }\end{array}$ & 2,79 & 1,16 & 1,16 & 0,98 & 1,28 & 1,16 & 1,27 & 1,08 & 1,12 & 0,95 \\
\hline $\mathrm{K}, \mathrm{L}, \mathrm{R}, \mathrm{T}$ & COG0515 & $\begin{array}{l}\text { Serine/threonine protein } \\
\text { kinase }\end{array}$ & 1,25 & 1,52 & 2,43 & 3,54 & 1,74 & 2,08 & 2,92 & 2,89 & 2,01 & 3,53 \\
\hline V & COG0534 & $\begin{array}{l}\text { Na+-driven multidrug efflux } \\
\text { pump }\end{array}$ & 5,17 & 2,58 & 1,59 & 1,03 & 1,34 & 1,60 & 1,18 & 1,32 & 1,17 & 1,09 \\
\hline
\end{tabular}


RESULTADOS E DISCUSSÃO

\begin{tabular}{|c|c|c|c|c|c|c|c|c|c|c|c|c|}
\hline E,P & COG0601 & $\begin{array}{l}\text { ABC-type } \\
\text { dipeptide/oligopeptide/nickel } \\
\text { transport system, permease } \\
\text { component }\end{array}$ & 1,20 & 2,05 & 2,95 & 2,38 & 3,11 & 2,30 & 2,47 & 2,67 & 2,38 & 2,75 \\
\hline$J$ & COG0621 & $\begin{array}{l}\text { tRNA A37 } \\
\text { methylthiotransferase MiaB }\end{array}$ & 2,59 & 1,14 & 1,13 & 1,11 & 1,08 & 1,13 & 1,06 & 0,97 & 1,14 & 0,94 \\
\hline $\mathrm{T}$ & COG0642 & $\begin{array}{l}\text { Signal transduction histidine } \\
\text { kinase }\end{array}$ & 4,15 & 3,45 & 3,11 & 3,87 & 2,92 & 3,64 & 3,29 & 3,41 & 3,51 & 3,86 \\
\hline $\mathrm{R}$ & COG0673 & Predicted dehydrogenase & 2,34 & 2,70 & 3,44 & 3,15 & 2,91 & 2,71 & 2,85 & 3,17 & 2,92 & 3,44 \\
\hline $\mathrm{K}, \mathrm{T}$ & COG0745 & $\begin{array}{l}\text { DNA-binding response } \\
\text { regulator, OmpR family, } \\
\text { contains } R E C \text { and winged- } \\
\text { helix (wHTH) domain }\end{array}$ & 3,47 & 3,36 & 3,58 & 3,67 & 2,93 & 3,57 & 3,38 & 3,21 & 3,27 & 3,13 \\
\hline$E$ & COG0747 & $\begin{array}{l}\text { ABC-type transport system, } \\
\text { periplasmic component }\end{array}$ & 1,17 & 2,76 & 4,10 & 3,45 & 3,66 & 3,12 & 3,52 & 3,78 & 3,08 & 3,71 \\
\hline V & COG0841 & $\begin{array}{l}\text { Multidrug efflux pump subunit } \\
\text { AcrB }\end{array}$ & 2,80 & 3,57 & 3,90 & 3,74 & 3,83 & 3,56 & 3,89 & 3,55 & 4,63 & 3,72 \\
\hline C & COG1012 & $\begin{array}{l}\text { Acyl-CoA reductase or other } \\
\text { NAD-dependent aldehyde } \\
\text { dehydrogenase }\end{array}$ & 1,43 & 4,26 & 4,16 & 4,19 & 4,02 & 3,87 & 4,04 & 3,56 & 4,33 & 3,72 \\
\hline $\mathrm{I}, \mathrm{Q}, \mathrm{R}$ & COG1028 & $\begin{array}{l}N A D(P) \text {-dependent } \\
\text { dehydrogenase, short-chain } \\
\text { alcohol dehydrogenase family }\end{array}$ & 2,06 & 4,05 & 4,22 & 4,32 & 3,71 & 4,14 & 3,98 & 4,06 & 4,10 & 4,60 \\
\hline V & COG1131 & $\begin{array}{l}\text { ABC-type multidrug transport } \\
\text { system, ATPase component }\end{array}$ & 1,73 & 2,52 & 2,78 & 2,85 & 3,10 & 2,98 & 3,29 & 2,93 & 2,76 & 2,63 \\
\hline
\end{tabular}


RESULTADOS E DISCUSSÃO

\begin{tabular}{|c|c|c|c|c|c|c|c|c|c|c|c|c|}
\hline V & COG1132 & $\begin{array}{l}\text { ABC-type multidrug transport } \\
\text { system, ATPase and } \\
\text { permease component }\end{array}$ & 4,62 & 3,75 & 3,61 & 2,79 & 2,99 & 3,64 & 3,16 & 2,98 & 2,90 & 2,72 \\
\hline G & COG1175 & $\begin{array}{l}\text { ABC-type sugar transport } \\
\text { system, permease component }\end{array}$ & 1,47 & 2,68 & 3,42 & 2,66 & 2,80 & 2,71 & 2,45 & 2,65 & 2,42 & 2,87 \\
\hline $\mathrm{R}$ & COG1373 & $\begin{array}{l}\text { Predicted ATPase, AAA+ } \\
\text { superfamily }\end{array}$ & 2,76 & 0,55 & 0,24 & 0,19 & 0,24 & 0,17 & 0,20 & 0,17 & 0,25 & 0,24 \\
\hline $\mathrm{K}$ & COG1595 & $\begin{array}{l}\text { DNA-directed RNA } \\
\text { polymerase specialized sigma } \\
\text { subunit, sigma24 family }\end{array}$ & 2,91 & 2,94 & 3,25 & 3,57 & 2,92 & 3,15 & 2,95 & 3,16 & 2,70 & 3,87 \\
\hline K & COG1609 & $\begin{array}{l}\text { DNA-binding transcriptional } \\
\text { regulator, Lacl/PurR family }\end{array}$ & 1,92 & 3,68 & 3,35 & 2,74 & 2,65 & 3,18 & 2,70 & 2,59 & 2,35 & 2,74 \\
\hline G & COG1653 & $\begin{array}{l}\text { ABC-type glycerol-3- } \\
\text { phosphate transport system, } \\
\text { periplasmic component }\end{array}$ & 1,36 & 2,69 & 4,68 & 2,93 & 3,70 & 3,17 & 3,04 & 4,22 & 2,95 & 3,39 \\
\hline I & COG1960 & $\begin{array}{l}\text { Acyl-CoA dehydrogenase } \\
\text { related to the alkylation } \\
\text { response protein AidB }\end{array}$ & 1,14 & 3,30 & 3,63 & 4,10 & 3,88 & 3,41 & 4,06 & 3,68 & 3,70 & 3,76 \\
\hline $\mathrm{T}$ & COG2204 & $\begin{array}{l}\text { DNA-binding transcriptional } \\
\text { response regulator, NtrC } \\
\text { family, contains REC, AAA- } \\
\text { type ATPase, and a Fis-type } \\
\text { DNA-binding domains }\end{array}$ & 1,45 & 2,13 & 2,50 & 3,71 & 2,61 & 2,82 & 3,37 & 3,24 & 3,26 & 3,77 \\
\hline $\mathrm{P}$ & COG2217 & Cation transport ATPase & 2,38 & 2,50 & 2,62 & 2,27 & 2,86 & 2,47 & 2,74 & 2,33 & 2,81 & 2,09 \\
\hline
\end{tabular}




\section{RESULTADOS E DISCUSSÃO}

\begin{tabular}{|c|c|c|c|c|c|c|c|c|c|c|c|c|}
\hline L & COG4974 & $\begin{array}{l}\text { Site-specific recombinase } \\
\text { XerD }\end{array}$ & 3,46 & 2,45 & 1,96 & 2,08 & 2,36 & 2,15 & 2,37 & 2,55 & 2,40 & 2,36 \\
\hline $\mathrm{K}$ & COG0583 & $\begin{array}{l}\text { DNA-binding transcriptional } \\
\text { regulator, LysR family }\end{array}$ & 1,82 & 4,84 & 2,49 & 2,43 & 1,99 & 3,21 & 1,81 & 1,98 & 1,99 & 2,25 \\
\hline $\mathrm{K}, \mathrm{T}$ & COG2197 & $\begin{array}{l}\text { DNA-binding response } \\
\text { regulator, NarL/FixJ family, } \\
\text { contains REC and HTH } \\
\text { domains }\end{array}$ & 1,04 & 2,26 & 2,91 & 2,74 & 2,65 & 2,41 & 2,76 & 2,67 & 2,41 & 3,00 \\
\hline $\mathrm{G}$ & COG2814 & $\begin{array}{l}\text { Predicted arabinose efflux } \\
\text { permease, MFS family }\end{array}$ & 1,11 & 3,67 & 2,79 & 2,65 & 2,18 & 2,76 & 2,08 & 2,42 & 2,33 & 2,49 \\
\hline
\end{tabular}

* Categorias COG: C: Produção e conversão de energia; E: Metabolismo e transporte de aminoácidos; G: Metabolismo e transporte de carboidratos; I: : Metabolismo e transporte de lipídios; J: Tradução, estrutura e biogênese de ribosomal; K: Trancrição; L: Replicação, recombinação e reparo; M: biogênese de parede/membrane e envelope cellular; P: Metabolismo e transporte de íons inorgânicos; Q: Biossíntese, transporte e catabolismo de metabólitos secundários; R: Função geral predita; T: Mecanismos de transdução de sinais; V: Mecanismos de defesa. 
RESULTADOS E DISCUSSÃO

Tabela 15: Análise comparativa das funções do COG relacionadas com a degradação da biomassa vegetal nos metagenomas da ZC3 e ZC4. Os valores representam a abundância relativas de sequências (1/1000) obtidas a partir da anotação de COGs utilizando o pipeline do IMG/M.

\begin{tabular}{|c|c|c|c|c|c|c|c|c|c|c|c|c|}
\hline \multicolumn{3}{|c|}{ Metagenomas } & \multicolumn{2}{|c|}{ D01 } & \multicolumn{2}{|c|}{ D30 } & \multicolumn{2}{|c|}{ D64 } & \multicolumn{2}{|c|}{ D78 } & \multicolumn{2}{|c|}{ D99 } \\
\hline Enzimas & $\begin{array}{l}\text { Função } \\
\text { COG }\end{array}$ & Nome da Função & ZC3 & ZC4 & ZC3 & ZC4 & ZC3 & ZC4 & ZC3 & ZC4 & ZC3 & ZC4 \\
\hline \multirow{3}{*}{ Celulase } & COG2723 & $\begin{array}{l}\text { Beta-glucosidase/6-phospho-beta- } \\
\text { glucosidase/beta-galactosidase }\end{array}$ & 0,55 & 0,70 & 0,59 & 0,61 & 0,47 & 0,61 & 0,49 & 0,53 & 0,47 & 0,57 \\
\hline & COG3405 & Endo-1,4-beta-D-glucanase $Y$ & 0,05 & 0,10 & 0,04 & 0,10 & 0,06 & 0,10 & 0,09 & 0,09 & 0,10 & 0,07 \\
\hline & COG5297 & Cellulase/cellobiase CelA1 & 0,02 & 0,14 & 0,20 & 0,18 & 0,13 & 0,12 & 0,19 & 0,22 & 0,13 & 0,28 \\
\hline \multirow{9}{*}{ Hemicelulases } & COG3693 & Endo-1,4-beta-xylanase, GH35 family & 0,30 & 0,29 & 0,44 & 0,41 & 0,43 & 0,30 & 0,46 & 0,40 & 0,45 & 0,34 \\
\hline & COG3507 & Beta-xylosidase & 0,93 & 0,70 & 0,74 & 0,51 & 0,63 & 0,57 & 0,60 & 0,53 & 0,58 & 0,46 \\
\hline & COG3534 & Alpha-L-arabinofuranosidase & 0,50 & 0,45 & 0,41 & 0,36 & 0,38 & 0,43 & 0,32 & 0,40 & 0,45 & 0,38 \\
\hline & COG3661 & Alpha-glucuronidase & 0,16 & 0,18 & 0,19 & 0,21 & 0,22 & 0,19 & 0,23 & 0,17 & 0,28 & 0,18 \\
\hline & COG3934 & Endo-1,4-beta-mannosidase & 0,06 & 0,08 & 0,07 & 0,12 & 0,04 & 0,07 & 0,08 & 0,08 & 0,07 & 0,07 \\
\hline & COG3345 & Alpha-galactosidase & 0,65 & 0,44 & 0,20 & 0,11 & 0,17 & 0,19 & 0,10 & 0,15 & 0,07 & 0,14 \\
\hline & COG2723 & $\begin{array}{l}\text { Beta-glucosidase/6-phospho-beta- } \\
\text { glucosidase/beta-galactosidase }\end{array}$ & 0,55 & 0,70 & 0,59 & 0,61 & 0,47 & 0,61 & 0,49 & 0,53 & 0,47 & 0,57 \\
\hline & COG3867 & Arabinogalactan endo-1,4-beta-galactosidase & 0,23 & 0,14 & 0,08 & 0,10 & 0,08 & 0,10 & 0,09 & 0,08 & 0,09 & 0,10 \\
\hline & COG3250 & Beta-galactosidase/beta-glucuronidase & 2,51 & 1,54 & 0,96 & 0,72 & 0,79 & 0,79 & 0,50 & 0,56 & 0,62 & 0,71 \\
\hline \multirow{4}{*}{ Ligninases } & COG1496 & Copper oxidase (laccase) domain & 0,24 & 0,32 & 0,28 & 0,29 & 0,33 & 0,28 & 0,27 & 0,24 & 0,28 & 0,31 \\
\hline & COG2303 & Choline dehydrogenase or related flavoprotein & 0,09 & 0,92 & 1,02 & 1,25 & 1,06 & 0,96 & 1,03 & 0,95 & 0,94 & 1,24 \\
\hline & COG2837 & Periplasmic deferrochelatase/peroxidase EfeB & 0,09 & 0,17 & 0,09 & 0,12 & 0,06 & 0,11 & 0,09 & 0,08 & 0,06 & 0,09 \\
\hline & COG2132 & $\begin{array}{l}\text { Multicopper oxidase with three cupredoxin } \\
\text { domains (includes cell division protein FtsP } \\
\text { and spore coat protein CotA) }\end{array}$ & 0,11 & 0,52 & 0,57 & 0,55 & 0,63 & 0,57 & 0,58 & 0,55 & 0,65 & 0,57 \\
\hline \multirow{3}{*}{ Pectinases } & COG4677 & $\begin{array}{l}\text { Pectin methylesterase and related acyl-CoA } \\
\text { thioesterases }\end{array}$ & 0,11 & 0,11 & 0,10 & 0,06 & 0,02 & 0,09 & 0,07 & 0,07 & 0,06 & 0,05 \\
\hline & COG5434 & Polygalacturonase & 0,65 & 0,31 & 0,31 & 0,14 & 0,22 & 0,18 & 0,13 & 0,19 & 0,20 & 0,24 \\
\hline & COG3866 & Pectate lyase & 0,07 & 0,10 & 0,14 & 0,08 & 0,09 & 0,09 & 0,04 & 0,09 & 0,10 & 0,09 \\
\hline
\end{tabular}



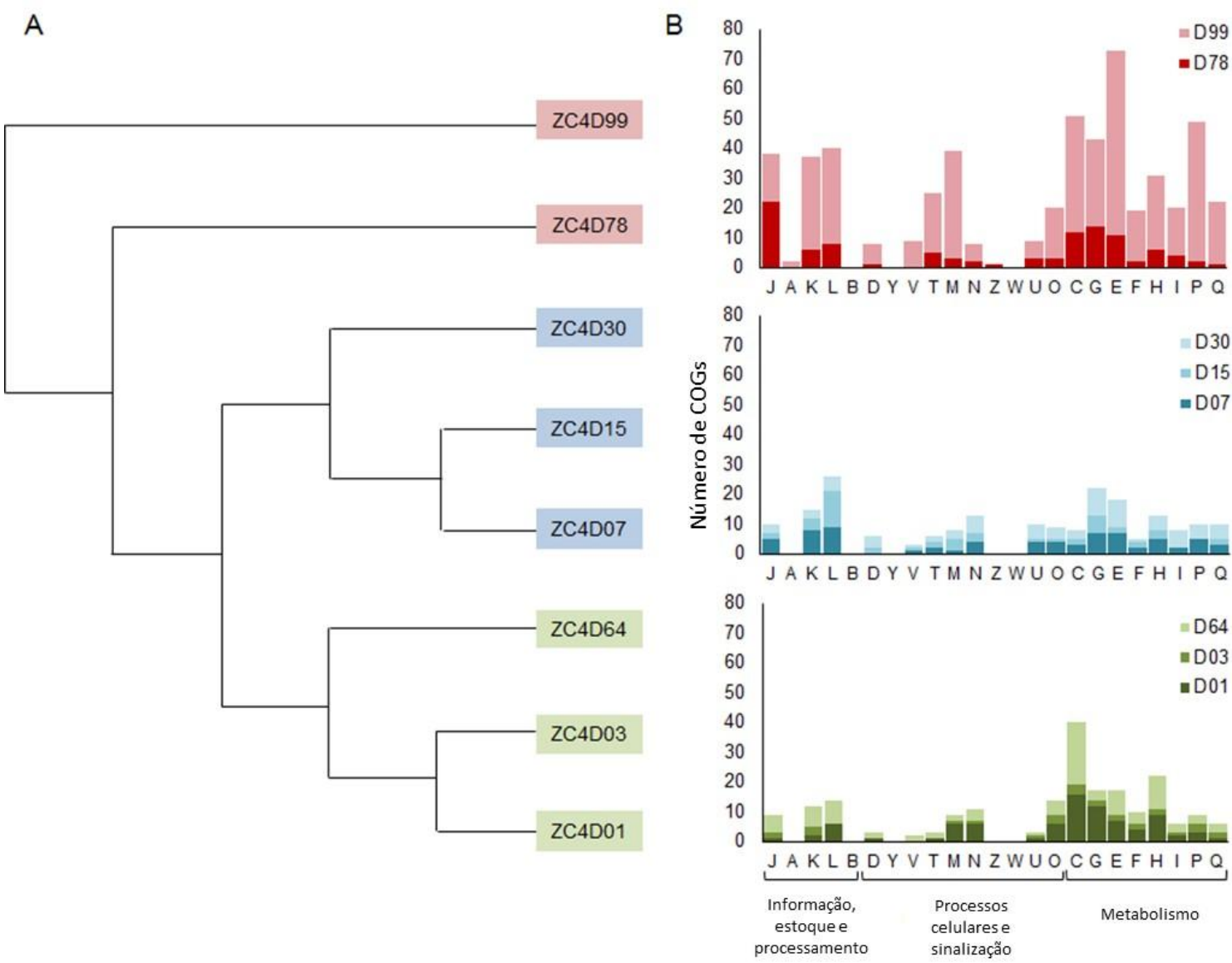

Figura 13: Perfil funcional dos metatranscritomas de ZC4 e análise de agrupamentos com base nas categorias de COGs. (A) Agrupamento hierárquico das CDSs dos metatranscritomas. A árvore foi gerada usando a ferramenta cluster compare com a base de dados das vias de COG, disponíveis no IMG/M. (B) Análise de abundância de CDSs. Número de COGs (eixo y) de cada categoria funcional (eixo x) que teve uma representação diferencial, baseada na análise de abundância de CDSs. Uma categoria de COG foi considerada diferencialmente representada se o seu valor de abundância relativa em uma determinada amostra foi $\geq 1,5$ vezes 0 intervalo interquartil para 0 terceiro quartil (ou seja, somente valores outliers super-representados foram considerados), considerando os valores de abundância relativa para essa categoria de COG em todas as amostras. Cada histograma corresponde ao mesmo grupo de amostras de cores da árvore. Categorias COG: C: Produção e conversão de energia; E: Metabolismo e transporte de aminoácidos; G: Metabolismo e transporte de carboidratos; I: : Metabolismo e transporte de lipídios; J: Tradução, estrutura e biogênese de ribosomal; K: Trancrição; L: Replicação, recombinação e reparo; M: biogênese de parede/membrane e envelope cellular; P: Metabolismo e transporte de íons inorgânicos; Q: Biossíntese, transporte e catabolismo de metabólitos secundários; R: Função geral predita; T: Mecanismos de transdução de sinais; V: Mecanismos de defesa. 
Avaliamos também, quais funções das categorias do COG poderiam contribuir para os agrupamentos obtidos, por meio da análise de expressão diferencial. Para isso, consideramos relevantes valores discrepantes de abundância relativa (outliers) como quaisquer valores acima de 1,5 x distância interquartil (Figura 13B). O grupo que reúne D01, D03 e D64 representa o início ou a retomada do processo após a revira e é caracterizado pela expressão de CDSs de COGs de funções relacionadas com o metabolismo de manutenção celular e com a degradação de fontes menos complexas de nutrientes, as quais estariam abundantes para este grupo, como produção e conversão de energia (Categoria $\mathrm{C}$ ), transporte e metabolização de coenzimas $(\mathrm{H})$ e metabolismo de aminoácidos (E).

O grupo que reúne D7, D15 e D30, representa o meio do processo (Figura 13B), que é caracterizado pela diminuição da disponibilidade de fontes menos complexas de carbono e de fácil degradação e a substituição dos membros da microbiota. Assim, verifica-se um aumento na abundância de microrganismos capazes de degradar polímeros mais complexos. A mudança na estrutura da microbiota ativa neste grupo é indicada pelos altos níveis de expressão de genes envolvido com os processos de replicação, recombinação e reparo (L), além de ser enriquecido nas funções de transporte e metabolização de carboidratos $(G)$ e do metabolismo de aminoácidos $(E)$.

O grupo que representa o final da compostagem (amostras D78 e D99) cujo substrato é o composto maduro. Estaria sob condições de restrição de oxigênio e nutrientes, uma condição que favorece a microbiota capaz de degradar materiais recalcitrantes, como a lignina. Destacamos que entre os transcritos mais abundantes da categoria $\mathrm{P}$ existem CDSs que codificam para a enzima superóxido dismutase (SOD) cuja função além de estar relacionada com defesa celular, também está associada a oxidação da lignina, como foi demonstrado recentemente (Rashid et al., 2015). Este grupo é enriquecido em COGs relacionadas com metabolismo de aminoácido $(E)$, produção e conversão de energia $(C)$, transporte e metabolismo de íons inorgânicos $(P)$, transporte e metabolismo de carboidratos $(G)$, além dos processos de transcrição, tradução, replicação, recombinação, reparo e a biogênese de parede e membranas celulares (J, K, L e M). 
O agrupamento de D64 a amostras do início da compostagem reforça os resultados obtidos pela análise de sucessão de táxons verificada no metagenoma (Figura 10), isto é, a revira propicia uma mudança da abundância de grupos taxonômicos e das funções executadas, semelhante a uma reinicialização do processo. Vale lembrar, que o substrato desta fase se encontra parcialmente processado e, portanto, não apresenta as mesmas características encontradas no começo da compostagem, o que é reforçado pela D78 não se agrupar com amostras do início e nem do meio do processo (Figura 13).

\subsection{Transcritos relacionados a degradação de biomassa vegetal em ZC4}

A desconstrução da lignocelulose pode ser realizada por diversos mecanismos e o repertório de enzimas conhecidas e espécies microbianas capazes de degradar este material recalcitrante tem aumentado rapidamente (Cragg et al., 2015; Hemsworth et al., 2015). Nós investigamos a presença e a variação de abundância das enzimas-chaves de degradação da lignocelulose como base na classificação por COG nos metatranscritomas de ZC4. A expressão de hemicelulases, celulases, pectinases e ligninases foram detectadas em todas as amostras (Figura 14 e Tabela 16). A variação de suas abundâncias relativas ao longo do processo de compostagem indicou que a hemicelulose, celulose, pectina e lignina são degradados durante todo 0 processo de compostagem e que a revira diminuiu temporariamente esta degradação (Figura 14). 
RESULTADOS E DISCUSSÃO

Tabela 16: Análise de COGs relacionados com a degradação da biomassa vegetal nos metatranscritomas ZC4. Os valores representam a abundância relativas de CDSs (\%) obtidas a partir da anotação de COGs utilizando o pipeline do IMG/M.

\begin{tabular}{|c|c|c|c|c|c|c|c|c|c|c|c|}
\hline \\
\hline Enzima & $\begin{array}{l}\text { Número } \\
\text { EC }\end{array}$ & $\begin{array}{l}\text { Função } \\
\text { COG }\end{array}$ & Nome da função & D01 & D03 & D07 & D15 & D30 & D64 & D78 & D99 \\
\hline \multirow{3}{*}{ Celulases } & 3.2.1.21 & COG2723 & $\begin{array}{l}\text { Beta-glucosidase/6-phospho- } \\
\text { beta-glucosidase/beta- } \\
\text { galactosidase }\end{array}$ & 0,0545 & 0,0560 & 0,0705 & 0,0701 & 0,0656 & 0,0222 & 0,0567 & 0,1136 \\
\hline & 3.2.1.91 & COG3405 & Endo-1,4-beta-D-glucanase $Y$ & 0,0063 & 0,0031 & 0,0038 & 0,0091 & 0,0159 & 0,0016 & 0,0038 & 0,0159 \\
\hline & 3.2.1.4 & COG5297 & Cellulase/cellobiase CelA1 & 0,0524 & 0,0448 & 0,0534 & 0,0584 & 0,1069 & 0,0135 & 0,1662 & 0,0681 \\
\hline \multirow{9}{*}{ Hemicelulases } & 3.2.1.8 & COG3693 & $\begin{array}{l}\text { Endo-1,4-beta-xylanase, } \\
\text { GH35 family }\end{array}$ & 0,0440 & 0,0468 & 0,0610 & 0,0935 & 0,1090 & 0,0421 & 0,1058 & 0,0273 \\
\hline & 3.2.1.37 & COG3507 & Beta-xylosidase & 0,0545 & 0,0244 & 0,0486 & 0,0597 & 0,0593 & 0,0349 & 0,0378 & 0,0409 \\
\hline & 3.2 .1 .55 & COG3534 & Alpha-L-arabinofuranosidase & 0,0346 & 0,0407 & 0,0410 & 0,0428 & 0,0519 & 0,0238 & 0,0397 & 0,0023 \\
\hline & 3.2.1.139 & COG3661 & Alpha-glucuronidase & 0,0105 & 0,0132 & 0,0200 & 0,0130 & 0,0159 & 0,0103 & 0,0019 & 0,0045 \\
\hline & 3.2.1.78 & COG3934 & Endo-1,4-beta-mannosidase & 0,0000 & 0,0031 & 0,0010 & 0,0052 & 0,0000 & 0,0000 & 0,0019 & 0,0068 \\
\hline & 3.2.1.22 & COG3345 & Alpha-galactosidase & 0,0147 & 0,0143 & 0,0076 & 0,0065 & 0,0042 & 0,0095 & 0,0019 & 0,0114 \\
\hline & 3.2.1.21 & COG2723 & $\begin{array}{l}\text { Beta-glucosidase/6-phospho- } \\
\text { beta-glucosidase/beta- } \\
\text { galactosidase }\end{array}$ & 0,0545 & 0,0560 & 0,0705 & 0,0701 & 0,0656 & 0,0222 & 0,0567 & 0,1136 \\
\hline & 3.2.1.89 & COG3867 & $\begin{array}{l}\text { Arabinogalactan endo-1,4- } \\
\text { beta-galactosidase }\end{array}$ & 0,0031 & 0,0010 & 0,0029 & 0,0026 & 0,0053 & 0,0024 & 0,0057 & 0,0045 \\
\hline & 3.2 .1 .23 & COG3250 & $\begin{array}{l}\text { Beta-galactosidase/beta- } \\
\text { glucuronidase }\end{array}$ & 0,0482 & 0,0295 & 0,0858 & 0,0662 & 0,0614 & 0,0206 & 0,0283 & 0,0204 \\
\hline Ligninases & 1.10.3.2 & COG1496 & $\begin{array}{l}\text { Copper oxidase (laccase) } \\
\text { domain }\end{array}$ & 0,0210 & 0,0326 & 0,0343 & 0,0363 & 0,0328 & 0,0206 & 0,0113 & 0,0273 \\
\hline
\end{tabular}


RESULTADOS E DISCUSSÃO

\begin{tabular}{|c|c|c|c|c|c|c|c|c|c|c|c|}
\hline & 1.1.99.18 & COG2303 & $\begin{array}{l}\text { Choline dehydrogenase or } \\
\text { related flavoprotein }\end{array}$ & 0,0157 & 0,0153 & 0,0229 & 0,0441 & 0,0476 & 0,0183 & 0,0321 & 0,0863 \\
\hline & 1.11.1.19 & COG2837 & $\begin{array}{l}\text { Periplasmic } \\
\text { deferrochelatase/peroxidase } \\
\text { EfeB }\end{array}$ & 0,0105 & 0,0061 & 0,0057 & 0,0013 & 0,0042 & 0,0087 & 0,0019 & 0,0204 \\
\hline & 1.3.3.5. & COG2132 & $\begin{array}{l}\text { Multicopper oxidase with } \\
\text { three cupredoxin domains } \\
\text { (includes cell division protein } \\
\text { FtsP and spore coat protein } \\
\text { CotA) }\end{array}$ & 0,0262 & 0,0346 & 0,0686 & 0,0973 & 0,0656 & 0,0714 & 0,1077 & 0,2090 \\
\hline \multirow{3}{*}{ Pectinases } & 3.1 .1 .11 & COG4677 & $\begin{array}{l}\text { Pectin methylesterase and } \\
\text { related acyl-CoA } \\
\text { thioesterases }\end{array}$ & 0,0021 & 0,0031 & 0,0038 & 0,0039 & 0,0032 & 0,0000 & 0,0038 & 0,0091 \\
\hline & 3.2.1.82 & COG5434 & Polygalacturonase & 0,0136 & 0,0051 & 0,0095 & 0,0052 & 0,0106 & 0,0056 & 0,0076 & 0,0091 \\
\hline & 4.2.2.2 & COG3866 & Pectate lyase & 0,0178 & 0,0071 & 0,0038 & 0,0065 & 0,0127 & 0,0008 & 0,0057 & 0,0068 \\
\hline
\end{tabular}




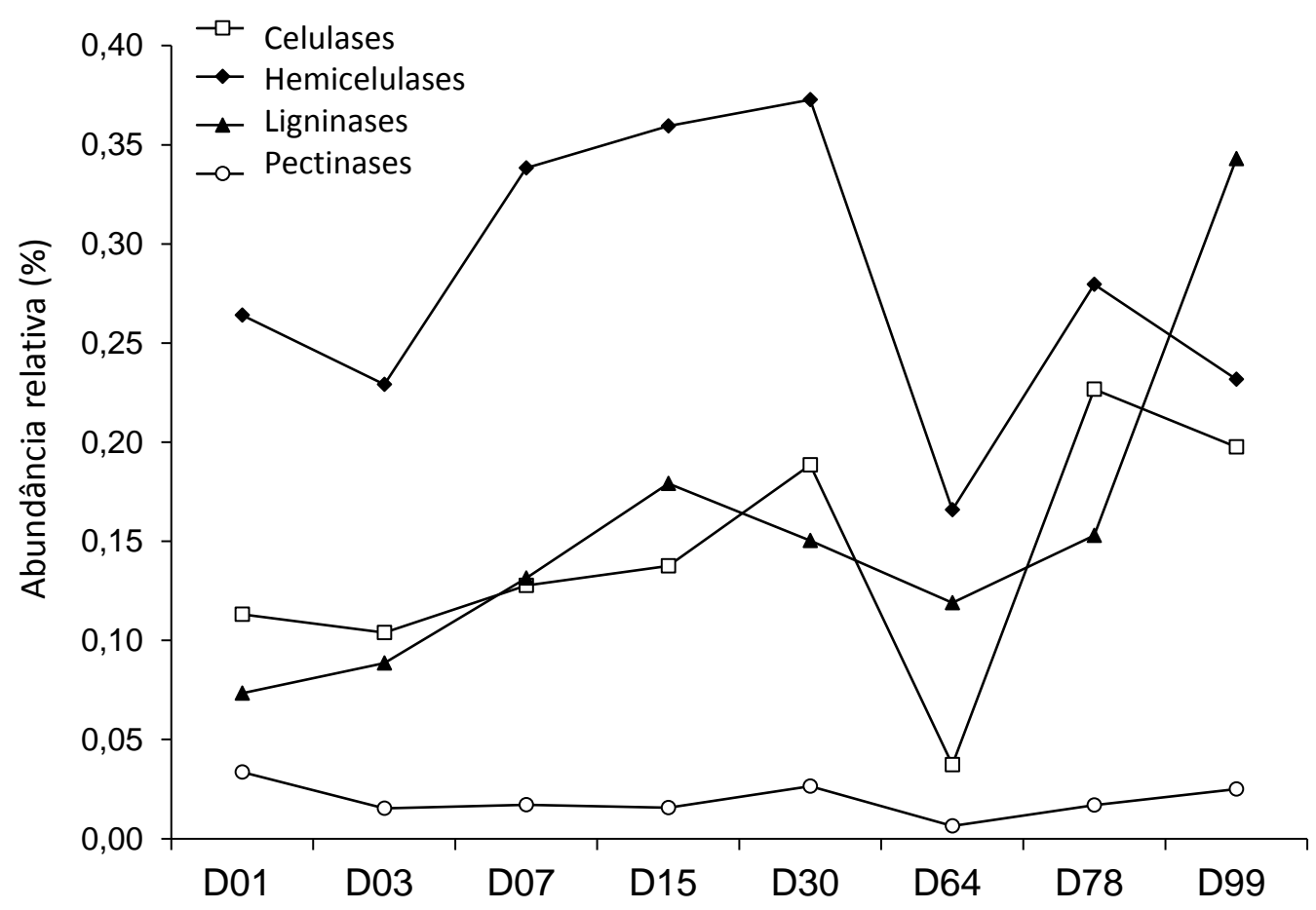

Figura 14: Análise de CDSs envolvidas na degradação da lignocelulose durante o processo de compostagem da ZC4. Abundância relativa (\%) das CDSs anotadas de COGs de celulases, hemicelulases, ligninases e pectinases nos metatranscritomas da série temporal, utilizando o pipeline do IMG-M. Os intervalos no eixo horizontal não estão em escala cronológica.

Verificamos que a abundância de ligninases atinge um pico apenas no final (D99). Estes resultados indicam que a desconstrução da biomassa lignocelulósica ocorre sinergicamente e sequencialmente, com hemicelulose sendo degradada, preferencialmente, em relação a celulose e a lignina, corroborando outros estudos anteriores (Cragg et al., 2015; Lopez-Gonzalez et al., 2015a; Mhuantong et al., 2015).

Para complementar a análise feita com base em COG e explorar 0 repertório de enzimas de degradação da lignocelulose em maior detalhe, realizamos um alinhamento das CDSs codificadas nos metatranscritomas de ZC4 com o banco de dados do dbCan, o qual utiliza a base de dados do CAZy (Cantarel et al., 2009). Detectamos a expressão das famílias de enzimas/módulos envolvidas na degradação deste material: módulos não catalíticos de ligação a carboidratos (CBMs), glicosil hidrolases (GHs), glicosil transferases (GTs), Carboxilesterases (CE), polissacarídeos liases (PLs) e 
atividades auxiliares (Aas) (Figura 15) (Beguin \& Aubert, 1994; Cantarel et al., 2009).
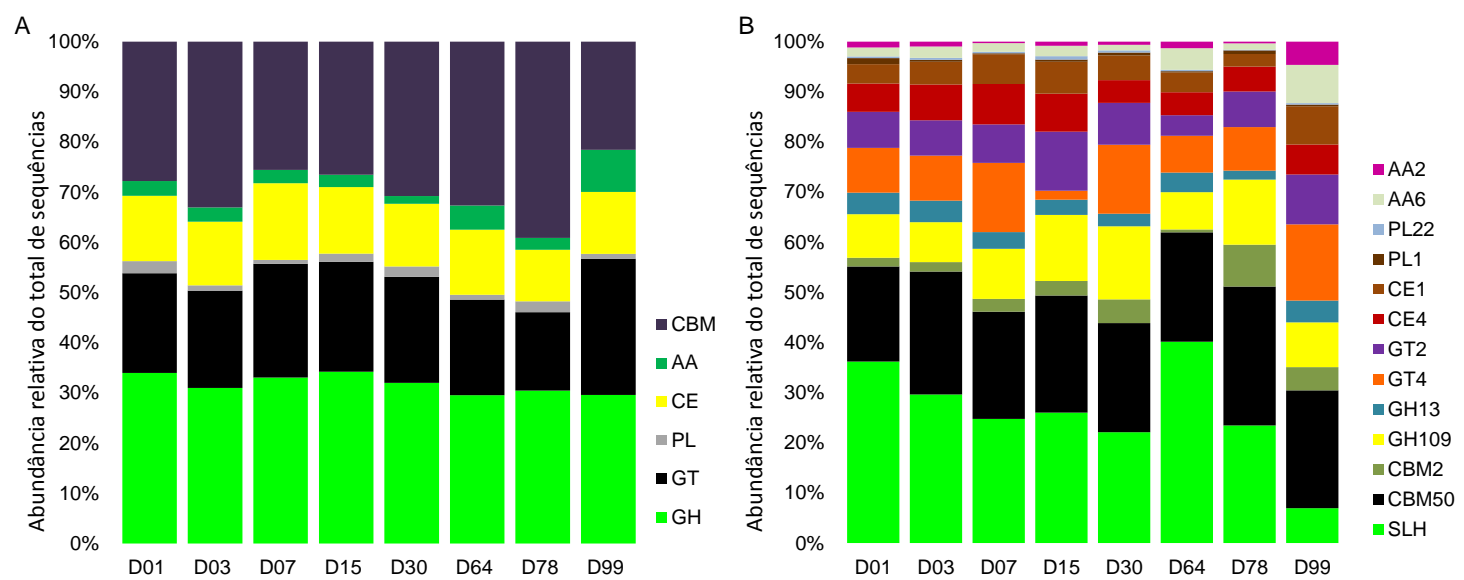

Figura 15: Perfil funcional de enzimas envolvidas na degradação de carboidratos presentes nos metatranscritomas de ZC4 com base na classificação do CAZy. (A) abundância relativa das classes/módulos do CAZy em cada metatranscritoma. (B) abundância relativa das famílias mais abundantes das classes/módulos classificadas pelo CAZy.

Entre as enzimas e domínios mais abundantes, destacamos os domínios SLH e CBM50. O domínio SLH está presente no complexo do celulossomo de bactérias anaeróbicas (Clostridiales) e em algumas celulases (tais como xynb39 e endo1,4 $\beta$ glucanase CelD) e liga as bactérias com o complexo enzimático de degradação, formando um complexo de proteínas do lado de fora da parede celular (Hyeon et al., 2013; Velikodvorskaya et al., 2013; Zhao et al., 2013). O domínio CBM50 facilita a degradação de celulose pela aproximação dos substratos, tornando as enzimas de degradação mais eficientes. Este domínio está presente em proteínas das famílias GH18, GH19, GH23, GH24, GH25 e GH73 (Cantarel et al., 2009). Todas estas famílias são representadas em nosso conjunto de dados, incluindo os endoglucanases (GH5 e GH9) e exo-celobiohidrolases (GH6, GH48 e GH7) necessárias para a hidrólise completa de celulose (Tabela S2). Celulases hipotéticas também foram encontradas nos transcritos da $\mathrm{ZC} 4$, sendo a maioria pertencente as famílias GH5 e GH9, as quais já foram relatadas em outros sistemas de degradação, como por exemplo, consórcios microbianos para degradação de palha de arroz e de switchgrass (Allgaier et al., 2010; Mhuantong et al., 2015; Wang et al., 2016). 
Entre as CDSs expressas também detectamos sequencias codificadoras de enzimas conhecidas por Atividades Auxiliares (AAs), sendo oito famílias de enzimas com atividade lignocelulolítica e três famílias de mono-oxigenases. A maioria das encontradas nas amostras de ZC4 pertencem às classes AA2 (7$28 \%$ de todos os AAs) e AA6 (32-66\%), seguido de quantidades moderadas de AA3, 4, 7, 9 e 10 (Figura 15 e Tabela S2). A amostra do final da compostagem (D99) foi a que apresentou o maior número de CDSs atribuídas a essa classe. Não encontramos nenhuma CDS atribuídas a fungos tais como: lacases, manganês-peroxidases, peroxidases-versáteis e peroxidases de lignina. A ausências de AAs de fungos também foi relatada por um estudo de consórcio de degradação da biomassa de compostagem (Wang et al., 2016). Esta é uma evidência adicional de que a degradação da lignocelulose em um processo de compostagem termofílica é principalmente ou exclusivamente o resultado de atividades enzimáticas bacterianas. Assim, as enzimas lignocelulolíticas de origem bacteriana despertam um interesse especial para aplicações biotecnológicas, em que as enzimas de fungos não podem ser usadas (Chandra et al., 2007; Bugg et al., 2011a; Wang et al., 2016).

\subsection{Classificação taxonômica de CDSs expressas nos metatranscritomas}

Para determinar quais microrganismos presentes no processo de compostagem de ZC4 estavam ativos e contribuindo para o avanço do processo de transformação da matéria orgânica em adubo, as sequências/contigs dos metatranscritomas foram submetidas a classificação taxonômica com o programa MyTaxa (Luo et al., 2014). Também submetemos a classificação taxonômica as CDS atribuídas aos COGs relacionados com a degradação da biomassa vegetal. Os resultados demonstram (Figura 16) que, exceto para a amostra D99, as ordens mais ativas durante toda a compostagem foram: Bacillales, Clostridiales, Actinomycetales e Thermoanaerobacteriales. Estas ordens também parecem ser as principais responsáveis pela degradação da biomassa vegetal. Como já mencionado Actinomycetales são comumente encontrados em compostagem, especialmente nas fases termófilas e de maturação (Takaku et al., 2006; de Gannes et al., 2013; Simmons et al., 2014; Zhang et al., 2014; Wang et al., 
2016). Os resultados de abundância relativa de CDSs atribuídas a degradação da biomassa vegetal indicam que esta ordem tem maior abundância em D30 e D78 (34,4\% e 49\%, respectivamente). Além disso, membros das Ordens Clostridiales e Bacillales, sabidamente possuem genes codificadores de enzimas envolvidas na degradação da celulose e da hemicelulose e tem sido reconhecido como os principais responsáveis pela degradação da biomassa vegetal da microbiota associada a florestas pantanosas (Kanokratana et al., 2011; Ventorino et al., 2015).

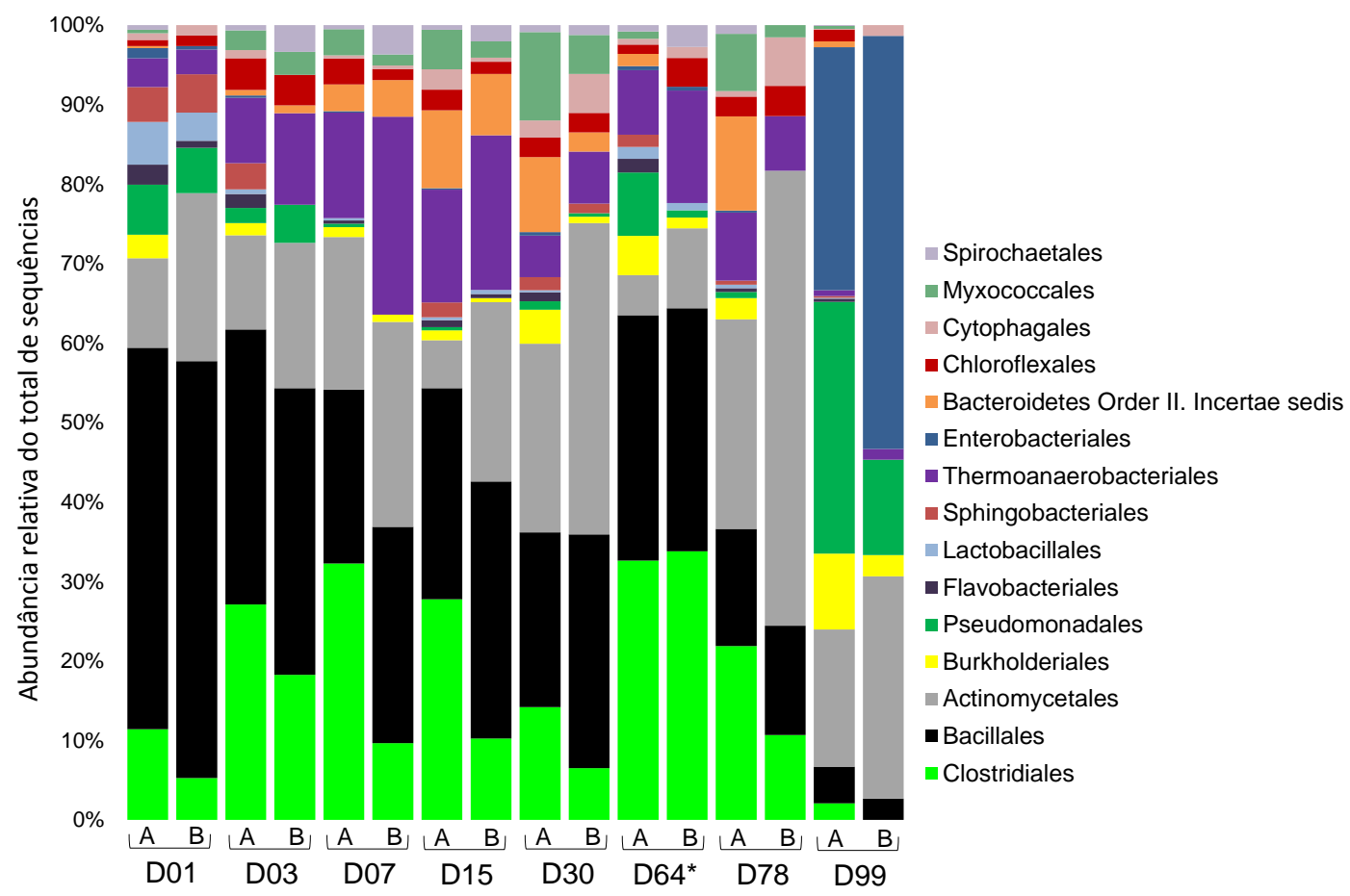

Figura 16: Perfil taxonômico dos metatranscritomas da ZC4. As CDSs anotadas utilizando a base do COG foram recuperadas do IMG-M e submetidas a classificação taxonômica o programa MyTaxa. Colunas marcadas com A apresentam perfis taxonômicos considerando todas as CDSs anotadas com COGs. Colunas marcadas por B apresentam perfis taxonômicos considerando somente as CDSs anotadas com COGs relacionados com a degradação biomassa vegetal (lignocelulose e pectina). $O$ asterisco indica um dia após a revira.

Os metatranscritomas de ZC4 possuem CDSs classificadas como pertencentes a outras Ordens que atuam na degradação da biomassa vegetal, como Bacteroidetes Order II incertae sedis que estão presentes na primeira fase (de D03 a D30) e depois desaparecem. A Ordem Lactobacillales parece ser mais ativa no início (D01) e após a revira (D64). Enquanto que no final do processo (D99), além da Ordem Actinomycetales, membros das Ordens 
Enterobacteriales e Pseudomonadales também estão ativos e parecem contribuir para a degradação continua da biomassa lignocelulósica remanescente (Mhuantong et al., 2015).

Enterobacter spp. são comumente descritos nas fases iniciais de compostagem e estão associados a temperaturas mais baixas $\left(<60^{\circ} \mathrm{C}\right)$ (Gbolagade, 2006; Chandna et al., 2013a). Interessantemente, verificamos que abundância de CDS atribuídas para esta ordem torna-se mais expressiva quando a temperatura diminui para valores menores $<50^{\circ} \mathrm{C}$ (aferida em alguns dos pontos de coleta da amostra D99). Além disso, em D99 a maioria das CDSs $(69,2 \%)$ anotadas como da Ordem Enterobacteriales foram atribuídas a uma única espécie, Klebsiella pneumoniae, que é conhecida por realizar a degradação de celulose, hemicelulose e fixar nitrogênio e já foi encontrada na microbiota associada a decomposição de madeira, a cupins e a compostagem (Droffner et al., 1995; Doolittle et al., 2008). Outros estudos também registraram a presença marcante dos membros da ordem Enterobacteriales, especialmente de espécies de Klebsiella, em um consórcio de microrganismos de degradação palha de trigo (Jimenez et al., 2015). 


\section{Conclusões e Perspectivas}

A vasta quantidade de dados de sequências metagenômicas e metatranscritômicas gerada neste trabalho possibilitou investigar a composição e a diversidade taxonômica durante o processo de compostagem termofílica bem como as funções metabólicas das comunidades microbianas, principalmente aquelas relacionadas à degradação de biomassa lignocelulósica.

O processo de compostagem conhecidamente abriga uma grande riqueza microbiológica, englobando populações com distintos requerimentos/tolerâncias. Este processo ocorre de maneira dinâmica e apresenta condições que podem ser consideradas "extremas", como temperatura de até $80^{\circ} \mathrm{C}$. Diante disto, e dada a composição peculiar da unidade de compostagem implantada no Parque Zoológico, era razoável supor que este sistema de compostagem sediasse uma grande diversidade microbiana, combinando a riqueza filogenética de comunidades do solo e florestais da Mata Atlântica, bem como da microbiota associada aos dejetos de animais do Zoológico. Essa hipótese foi verificada em um estudo anterior (Martins et al., 2013) e totalmente reafirmada pelos resultados descritos nesse trabalho. Os dados aqui reportados indicam que a compostagem do Parque Zoológico abriga de 3000 a 5000 OTUs, dependendo do estágio do processo, sendo que até $~ 16,7 \%$ das sequências de rRNA 16 S não foram passíveis de identificação considerando o nível de Filo cujas espécies bacterianas compõem a chamada microbial dark matter, ainda que seja um ambiente engeinharado e com propósito bem definido, que é transformar a matéria orgânica em adubo. As análises aqui descritas apenas pincelaram estas possibilidades, e há muito a ser explorado no vasto conjunto de sequências que geramos. Até o momento fomos capazes de recuperar cinco genomas abundantes de espécies já conhecidas e também de reconstruir um genoma de um suposto novo gênero bacteriano. Trabalhos futuros irão expandir estas análises bem como avaliar a contribuição destas espécies abundantes para o processo de transformação da biomassa vegetal que ocorre na compostagem.

Verificamos que o sistema de compostagem que foi estudado é inteiramente termofílico e é conduzido por Bactérias. A amostragem em série 
temporal e a utilização de abordagens independentes de cultivo associadas ao sequenciamento de alto desempenho nos permitiu determinar a composição da comunidade bacteriana associada a cada amostra e acompanhar ao longo do processo as variações ocorridas, bem como das variações nas funções por meio da análise dos genes expressos. Os resultados aqui descritos, em conjunto com outros estudos sobre a microbiota da compostagem nos permitiram propor um conjunto das principais bactérias e funções metabólicas responsáveis pela degradação da biomassa lignocelulósica na compostagem, que está esquematizado na Figura 17.

Uma das observações que destacamos é a importância do processo de revira na modulação da estrutura da comunidade microbiana e das funções expressas (Figuras 10 e 13).

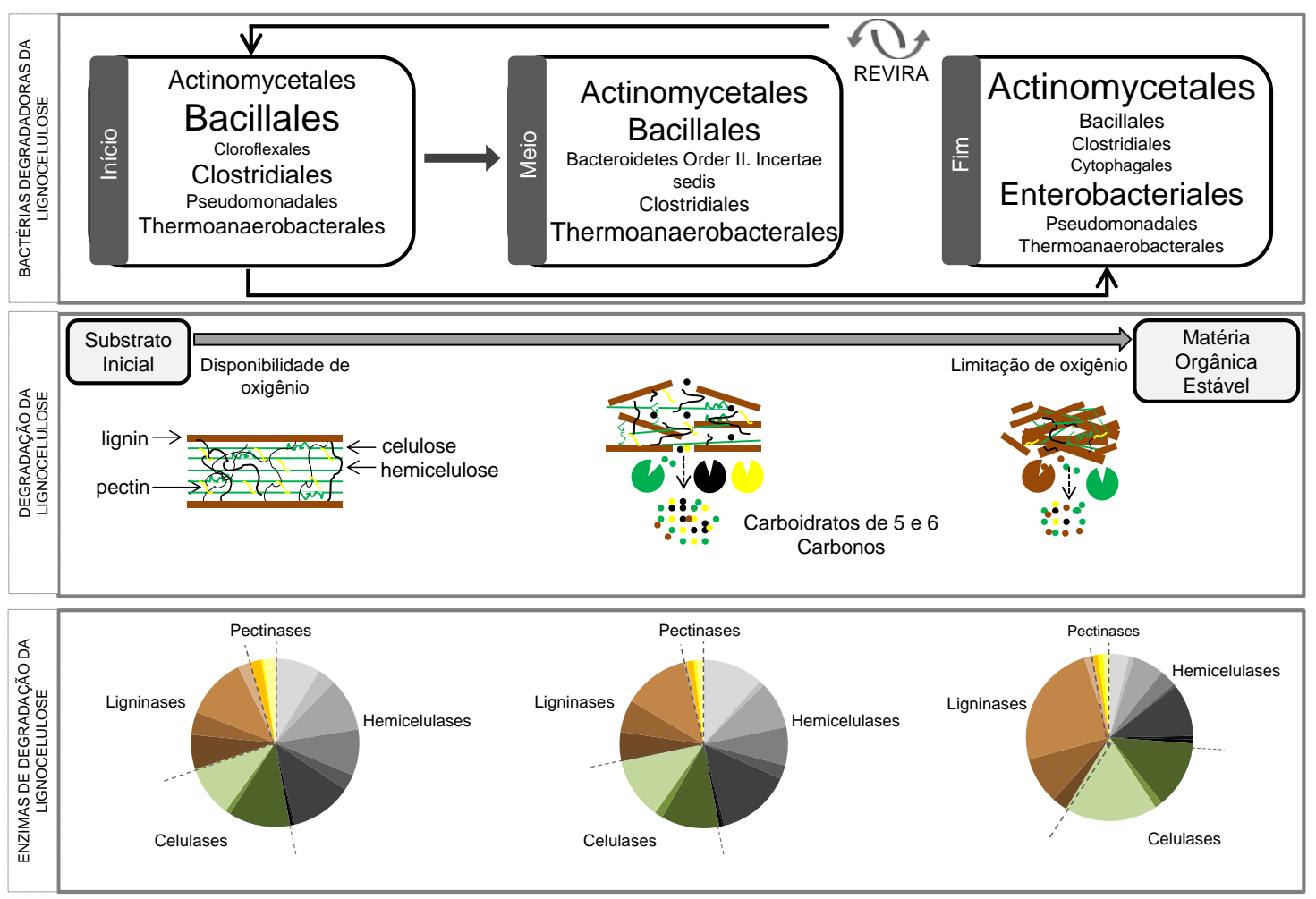

Figura 17: Visão geral do processo termofílico da compostagem. Os resultados mostrados são baseados nos dados dos metatranscritomas da ZC4. O painel superior representa as três fases identificadas no processo: Inicio (D01, D03 e D64), meio (D07, D15 e D30) e fim (D78 e D99). A composição da microbiota no nível de Ordem para cada fase do processo está indicada. A abundância relativa de micro-organismos é aproximadamente proporcional ao tamanho da fonte e apenas Ordens com abundância relativa $\geq 2,5 \%$ são mostradas. O painel do meio mostra o processo de degradação, com correspondência vertical para as etapas mostradas no painel do topo. O painel de baixo mostra a abundância relativa de COGs de enzimas de degradação da biomassa vegetal (lignocelulose e pectina), também com correspondência vertical para as etapas mostradas no painel do topo. 
A nossa interpretação é que revira permite a restauração momentânea de algumas das condições prevalentes no início do processo, como da disponibilidade de nutrientes (biomassa) e oxigênio, aliviando a restrição seletiva e permitindo a "reativação" de microrganismos que estariam inativos.

A variedade de microrganismos e de funções metabólicas ativas na compostagem termofílica reforça a sua capacidade de ser uma fonte promissora de bactérias e enzimas termoresistentes potencialmente úteis em processos industriais. Nesse sentido, está em andamento em nosso grupo tanto o estudo mais detalhado de sequências de glicosil hidrolases identificadas a partir de sequências metagenômicas e metatranscritômicas, como um esforço para caracterizar com maior precisão os genomas de bactérias ainda não-cultiváveis e que correspondem as OTUs mais abundantes identificadas nos metagenomas da compostagem.

Vale destacar que o conjunto de sequências que geramos neste trabalho constitui um material que poderá ser explorado sobre diversos outros aspectos. Por exemplo, há uma fração pequena, mas não desprezível, de sequências dos metagenomas shotgun e dos metatranscritomas que não foram classificadas nos domínios Bacteria, Archaea e Eukaryota. Uma possibilidade é que sejam sequências relativas a vírus e bacteriófagos, além do conjunto de sequências efetivamente classificadas nesta categoria, e merece uma análise mais especializada para tentar elucidar o metaviroma da compostagem termofilica. Outro aspecto que merece um estudo mais detalhado é a investigação das interações ecofisiológicas entre organismos das comunidades microbianas que se sucedem ao longo da compostagem com o propósito de conhecer suas respectivas funções na manutenção da estrutura bem estabelecida destas microbiotas. 


\section{Referências Bibliográficas}

1. Adams, J. D. W. \& Frostick, L. E. 2009. Analysis of bacterial activity, biomass and diversity during windrow composting. Waste Management 29:598-605.

2. Aguiar-Pulido, V., Huang, W., Suarez-Ulloa, V., Cickovski, T., Mathee, K. \& Narasimhan, G. 2016a. Metagenomics, Metatranscriptomics, and Metabolomics Approaches for Microbiome Analysis. Evolutionary Bioinformatics

3. Aguiar-Pulido, V., Huang, W., Suarez-Ulloa, V., Cickovski, T., Mathee, K. \& Narasimhan, G. 2016b. Metagenomics, Metatranscriptomics, and Metabolomics Approaches for Microbiome Analysis. Evol Bioinform Online 12:5-16.

4. Ahmadian, A., Ehn, M. \& Hober, S. 2006. Pyrosequencing: history, biochemistry and future. Clinica Chimica Acta; International Journal of Clinical Chemistry 363:83-94.

5. Alfreider, A., Peters, S., Tebbe, C. C., Rangger, A. \& Insam, H. 2002. Microbial community dynamics during composting of organic matter as determined by $16 \mathrm{~S}$ ribosomal DNA analysis. Compost Science \& Utilization 10:303-312.

6. Allgaier, M., Reddy, A., Park, J. I., Ivanova, N., D'haeseleer, P., Lowry, S., Sapra, R., Hazen, T. C., Simmons, B. A., VanderGheynst, J. S. \& Hugenholtz, P. 2010. Targeted Discovery of Glycoside Hydrolases from a Switchgrass-Adapted Compost Community. PloS one 5.

7. Anastasi, A., Varese, G. C. \& Marchisio, V. F. 2005. Isolation and identification of fungal communities in compost and vermicompost. Mycologia 97:33-44.

8. Angly, F. E., Dennis, P. G., Skarshewski, A., Vanwonterghem, I., Hugenholtz, P. \& Tyson, G. W. 2014. CopyRighter: a rapid tool for improving the accuracy of microbial community profiles through lineage-specific gene copy number correction. Microbiome 2:11.

9. Aronesty, E. 2013. Comparison of Sequencing Utility Programs. The Open Bioinformatics Journal 7:1-8.

10. Bapteste, E. \& Boucher, Y. 2008. Lateral gene transfer challenges principles of microbial systematics. Trends in Microbiology 16:200-207.

11. Barton, L. L. \& Northup, D. E. 2011. Microbial Ecology. Wiley-Blackwell, United States of America.

12. Beguin, P. \& Aubert, J. P. 1994. THE BIOLOGICAL DEGRADATION OF CELLULOSE. Fems Microbiology Reviews 13:25-58.

13. Bent, S. J. \& Forney, L. J. 2008. The tragedy of the uncommon: understanding limitations in the analysis of microbial diversity. ISME Journal 2:689-695.

14. Bhattacharya, S. S., Kim, K.-H., Das, S., Uchimiya, M., Jeon, B. H., Kwon, E. \& Szulejko, J. E. 2016. A review on the role of organic inputs in maintaining 
the soil carbon pool of the terrestrial ecosystem. Journal of Environmental Management 167:214-227.

15. Binnewies, T. T., Motro, Y., Hallin, P. F., Lund, O., Dunn, D., La, T., Hampson, D. J., Bellgard, M., Wassenaar, T. M. \& Ussery, D. W. 2006. Ten years of bacterial genome sequencing: comparative-genomics-based discoveries. Funct Integr Genomics 6:165-85.

16. Bitencourt, A. L. V., Vallim, M. A., Maia, D., Spinelli, R., Angeloni, R., Principal, L., Souza, E. \& Pascon, R. C. 2010. Core sampling test in largescale compost cells for microorganism isolation. African Journal of Microbiology Research 4:1631-1634.

17. Blanc, M., Marilley, L., Beffa, T. \& Aragno, M. 1999. Thermophilic bacterial communities in hot composts as revealed by most probable number counts and molecular (16S rDNA) methods. Fems Microbiology Ecology 28:141-149.

18. Blumer-Schuette, S. E., Brown, S. D., Sander, K. B., Bayer, E. A., Kataeva, I., Zurawski, J. V., Conway, J. M., Adams, M. W. W. \& Kelly, R. M. 2014. Thermophilic lignocellulose deconstruction. Fems Microbiology Reviews 38:393-448.

19. Botero, L. M., D'Imperio, S., Burr, M., McDermott, T. R., Young, M. \& Hassett, D. J. 2005. Poly(A) polymerase modification and reverse transcriptase PCR amplification of environmental RNA. Applied and Environmental Microbiology $71: 1267-1275$.

20. Brown, C. T., Hug, L. A., Thomas, B. C., Sharon, I., Castelle, C. J., Singh, A., Wilkins, M. J., Wrighton, K. C., Williams, K. H. \& Banfield, J. F. 2015. Unusual biology across a group comprising more than $15 \%$ of domain Bacteria. Nature 523:208-U173.

21. Brown, S., Kruger, C. \& Subler, S. 2008. Greenhouse gas balance for composting operations. Journal of Environmental Quality 37:1396-1410.

22. Bugg, T. D. H., Ahmad, M., Hardiman, E. M. \& Rahmanpour, R. 2011a. Pathways for degradation of lignin in bacteria and fungi. Natural Product Reports 28:1883-1896.

23. Bugg, T. D. H., Ahmad, M., Hardiman, E. M. \& Singh, R. 2011b. The emerging role for bacteria in lignin degradation and bio-product formation. Current Opinion in Biotechnology 22:394-400.

24. Cantarel, B. L., Coutinho, P. M., Rancurel, C., Bernard, T., Lombard, V. \& Henrissat, B. 2009. The Carbohydrate-Active EnZymes database (CAZy): an expert resource for Glycogenomics. Nucleic Acids Research 37:D233-D238.

25. Caporaso, J. G., Bittinger, K., Bushman, F. D., DeSantis, T. Z., Andersen, G. L. \& Knight, R. 2010a. PyNAST: a flexible tool for aligning sequences to a template alignment. Bioinformatics 26:266-7.

26. Caporaso, J. G., Kuczynski, J., Stombaugh, J., Bittinger, K., Bushman, F. D. et al. 2010b. QIIME allows analysis of high-throughput community sequencing data. Nat Methods 7:335-6. 
27. Caporaso, J. G., Lauber, C. L., Walters, W. A., Berg-Lyons, D., Huntley, J., Fierer, N., Owens, S. M., Betley, J., Fraser, L., Bauer, M., Gormley, N., Gilbert, J. A., Smith, G. \& Knight, R. 2012. Ultra-high-throughput microbial community analysis on the Illumina HiSeq and MiSeq platforms. The ISME journal 6:1621-4.

28. Carvalhais, L. C., Dennis, P. G., Tyson, G. W. \& Schenk, P. M. 2012. Application of metatranscriptomics to soil environments. Journal of Microbiological Methods 91:246-251.

29. Castelle, C. J., Wrighton, K. C., Thomas, B. C., Hug, L. A., Brown, C. T., Wilkins, M. J., Frischkorn, K. R., Tringe, S. G., Singh, A., Markillie, L. M., Taylor, R. C., Williams, K. H. \& Banfield, J. F. 2015. Genomic Expansion of Domain Archaea Highlights Roles for Organisms from New Phyla in Anaerobic Carbon Cycling. Current Biology 25:690-701.

30. Chandna, P., Mayilraj, S. \& Kuhad, R. C. 2013a. Bacillus paraflexus sp nov., isolated from compost. International Journal of Systematic and Evolutionary Microbiology 63:4735-4743.

31. Chandna, P., Nain, L., Singh, S. \& Kuhad, R. C. 2013b. Assessment of bacterial diversity during composting of agricultural byproducts. BMC Microbiol 13:99.

32. Chandra, R., Raj, A., Purohit, H. J. \& Kapley, A. 2007. Characterisation and optimisation of three potential aerobic bacterial strains for kraft lignin degradation from pulp paper waste. Chemosphere 67:839-846.

33. Cole, J. R., Wang, Q., Fish, J. A., Chai, B., McGarrell, D. M., Sun, Y., Brown, C. T., Porras-Alfaro, A., Kuske, C. R. \& Tiedje, J. M. 2014. Ribosomal Database Project: data and tools for high throughput rRNA analysis. Nucleic Acids Res 42:D633-42.

34. Cragg, S. M., Beckham, G. T., Bruce, N. C., Bugg, T. D. H., Distel, D. L., Dupree, P., Etxabe, A. G., Goodell, B. S., Jellison, J., McGeehan, J. E., McQueen-Mason, S. J., Schnorr, K., Walton, P. H., Watts, J. E. M. \& Zimmer, M. 2015. Lignocellulose degradation mechanisms across the Tree of Life. Current Opinion in Chemical Biology 29:108-119.

35. D'Haeseleer, P., Gladden, J. M., Allgaier, M., Chain, P. S. G., Tringe, S. G., Malfatti, S. A., Aldrich, J. T., Nicora, C. D., Robinson, E. W., Pasa-Tolic, L., Hugenholtz, P., Simmons, B. A. \& Singer, S. W. 2013. Proteogenomic Analysis of a Thermophilic Bacterial Consortium Adapted to Deconstruct Switchgrass. Plos One 8.

36. Da Cruz, J. B. 2004. O processo de compostagem como instrumento de preservação ambiental na Fundação Parque Zoológico de São Paulo. Presented at the I Simpósio sobre compostagem, ciência e tecnologia, UNESP - Botucatu.

37. de Gannes, V., Eudoxie, G. \& Hickey, W. J. 2013. Prokaryotic successions and diversity in composts as revealed by 454 -pyrosequencing. Bioresource Technology 133:573-580. 
38. DeAngelis, K. M., Gladden, J. M., Allgaier, M., D'haeseleer, P., Fortney, J. L., Reddy, A., Hugenholtz, P., Singer, S. W., Vander Gheynst, J. S., Silver, W. L., Simmons, B. A. \& Hazen, T. C. 2010. Strategies for Enhancing the Effectiveness of Metagenomic-based Enzyme Discovery in Lignocellulolytic Microbial Communities. Bioenergy Research 3:146-158.

39. Dees, P. M. \& Ghiorse, W. C. 2001. Microbial diversity in hot synthetic compost as revealed by PCR-amplified rRNA sequences from cultivated isolates and extracted DNA. FEMS microbiology ecology 35:207-216.

40. DeLong, E. E. \& Pace, N. R. 2001. Environmental diversity of Bacteria and Archaea. Systematic Biology 50:470-478.

41. Demharter, W., Hensel, R., Smida, J. \& Stackebrandt, E. 1989. SPHAEROBACTER-THERMOPHILUS GEN-NOV, SP-NOV - A DEEPLY ROOTING MEMBER OF THE ACTINOMYCETES SUBDIVISION ISOLATED FROM THERMOPHILICALLY TREATED SEWAGE-SLUDGE. Systematic and Applied Microbiology 11:261-266.

42. Diaz, L. F., Savage, G. M., Eggerth, L. L. \& Chiumenti, A. 2007. Systems Used in Composting, p. 67-87. In L. F. Diaz, M. de Bertoldi, W. Bidlingmaier \& E. Stentiford (ed.), Compost Science and Technology, vol. 1. Elsevier, Amsterdam, The Netherlands.

43. Dinsdale, E. A., Edwards, R. A., Hall, D., Angly, F., Breitbart, M. et al. 2008. Functional metagenomic profiling of nine biomes. Nature 452:629-630.

44. Doolittle, M., Raina, A., Lax, A. \& Boopathy, R. 2008. Presence of nitrogen fixing Klebsiella pneumoniae in the gut of the Formosan subterranean termite (Coptotermes formosanus). Bioresource Technology 99:3297-3300.

45. Dougherty, M. J., D'Haeseleer, P., Hazen, T. C., Simmons, B. A., Adams, P. D. \& Hadi, M. Z. 2012. Glycoside hydrolases from a targeted compost metagenome, activity-screening and functional characterization. BMC biotechnology 12:38.

46. Droffner, M. L., Brinton, W. F. \& Evans, E. 1995. EVIDENCE FOR THE PROMINENCE OF WELL CHARACTERIZED MESOPHILIC BACTERIA IN THERMOPHILIC (50-70-DEGREES-C) COMPOSTING ENVIRONMENTS. Biomass \& Bioenergy 8:191-195.

47. Edgar, R. C. 2013. UPARSE: highly accurate OTU sequences from microbial amplicon reads. Nat Methods 10:996-8.

48. Eichorst, S. A., Varanasi, P., Stavila, V., Zemla, M., Auer, M., Singh, S., Simmons, B. A. \& Singer, S. W. 2013. Community dynamics of celluloseadapted thermophilic bacterial consortia. Environmental Microbiology 15:25732587.

49. Eloe-Fadrosh, E. A., Ivanova, N. N., Woyke, T. \& Kyrpides, N. C. 2016a. Metagenomics uncovers gaps in amplicon-based detection of microbial diversity. Nature Microbiology 1:15032.

50. Eloe-Fadrosh, E. A., Paez-Espino, D., Jarett, J., Dunfield, P. F., Hedlund, B. P., Dekas, A. E., Grasby, S. E., Brady, A. L., Dong, H., Briggs, B. R., Li, W. 
J., Goudeau, D., Malmstrom, R., Pati, A., Pett-Ridge, J., Rubin, E. M., Woyke, T., Kyrpides, N. C. \& Ivanova, N. N. 2016b. Global metagenomic survey reveals a new bacterial candidate phylum in geothermal springs. Nat Commun 7:10476.

51. Faith, D. P., Lozupone, C. A., Nipperess, D. \& Knight, R. 2009. The cladistic basis for the phylogenetic diversity (PD) measure links evolutionary features to environmental gradients and supports broad applications of microbial ecology's "phylogenetic beta diversity" framework. Int J Mol Sci 10:4723-41.

52. Federici, E., Pepi, M., Esposito, A., Scargetta, S., Fidati, L., Gasperini, S., Cenci, G. \& Altieri, R. 2011. Two-phase olive mill waste composting: Community dynamics and functional role of the resident microbiota. Bioresource Technology 102:10965-10972.

53. Fitzpatrick, G. E., Worden, E. C. \& Vendrame, W. A. 2005. Historical development of composting technology during the 20th century. Horttechnology 15:48-51.

54. Franke-Whittle, I. H., Knapp, B. A., Fuchs, J., Kaufmann, R. \& Insam, H. 2009. Application of COMPOCHIP microarray to investigate the bacterial communities of different composts. Microbial ecology 57:510-21.

55. Franzosa, E. A., Hsu, T., Sirota-Madi, A., Shafquat, A., Abu-Ali, G., Morgan, X. C. \& Huttenhower, C. 2015. Sequencing and beyond: integrating molecular 'omics' for microbial community profiling. Nature Reviews Microbiology 13:360372.

56. Franzosa, E. A., Morgan, X. C., Segata, N., Waldron, L., Reyes, J., Earl, A. M., Giannoukos, G., Boylan, M. R., Ciulla, D., Gevers, D., Izard, J., Garrett, W. S., Chan, A. T. \& Huttenhower, C. 2014. Relating the metatranscriptome and metagenome of the human gut. Proceedings of the National Academy of Sciences of the United States of America 111:E2329-E2338.

57. Gajalakshmi, S. \& Abbasi, S. A. 2008. Solid Waste Management by Composting: State of the Art. Critical Reviews in Environmental Science and Technology 38:311-400.

58. Galperin, M. Y., Makarova, K. S., Wolf, Y. I. \& Koonin, E. V. 2015. Expanded microbial genome coverage and improved protein family annotation in the COG database. Nucleic Acids Research 43:D261-D269.

59. Gbolagade, J. S. 2006. Bacteria associated with compost used for cultivation of Nigerian edible mushrooms Pleurotus tuber-regium ( Fr.) Singer, and Lentinus squarrosulus ( Berk.). African Journal of Biotechnology 5:338-342.

60. Gies, E. A., Konwar, K. M., Beatty, J. T. \& Hallam, S. J. 2014. Illuminating Microbial dark matter in Meromictic Sakinaw Lake. Applied and Environmental Microbiology 80:6807-6818.

61. Gladden, J. M., Allgaier, M., Miller, C. S., Hazen, T. C., VanderGheynst, J. S., Hugenholtz, P., Simmons, B. A. \& Singer, S. W. 2011. Glycoside hydrolase activities of thermophilic bacterial consortia adapted to switchgrass. Applied and environmental microbiology 77:5804-12. 
62. Glass, E. M., Wilkening, J., Wilke, A., Antonopoulos, D. \& Meyer, F. 2010. Using the metagenomics RAST server (MG-RAST) for analyzing shotgun metagenomes. Cold Spring Harbor protocols 2010:pdb prot5368.

63. Golueke, C. G. 1992. Bacteriology of Composting. Biocycle 33:55-57.

64. Gonzalez, J. M., Portillo, M. C., Belda-Ferre, P. \& Mira, A. 2012. Amplification by PCR Artificially Reduces the Proportion of the Rare Biosphere in Microbial Communities. PloS one 7.

65. Goyal, S., Dhull, S. K. \& Kapoor, K. K. 2005. Chemical and biological changes during composting of different organic wastes and assessment of compost maturity. Bioresource Technology 96:1584-1591.

66. Gu, Y., Ding, Y., Ren, C., Sun, Z., Rodionov, D. A., Zhang, W. W., Yang, S., Yang, C. \& Jiang, W. H. 2010. Reconstruction of xylose utilization pathway and regulons in Firmicutes. BMC Genomics 11.

67. Guo, Y., Zhu, N., Zhu, S. \& Deng, C. 2007. Molecular phylogenetic diversity of bacteria and its spatial distribution in composts. Journal of Applied Microbiology 103:1344-54.

68. Habbeche, A., Saoudi, B., Jaouadi, B., Haberra, S., Kerouaz, B., Boudelaa, M., Badis, A. \& Ladjama, A. 2014. Purification and biochemical characterization of a detergent-stable keratinase from a newly thermophilic actinomycete Actinomadura keratinilytica strain Cpt29 isolated from poultry compost. Journal of Bioscience and Bioengineering 117:413-421.

69. Handelsman , J., Rondon, M., Brady, S., Clardy, J. \& Goodman, R. 1998. Molecular biological access to the chemistry of unknown soil microbes: A new frontier for natural products. Chemistry \& Biology 5:R245-R249.

70. Hansgate, A. M., Schloss, P. D., Hay, A. G. \& Walker, L. P. 2005. Molecular characterization of fungal community dynamics in the initial stages of composting. FEMS microbiology ecology 51:209-14.

71. Hassen, A., Belguith, K., Jedidi, N., Cherif, A., Cherif, M. \& Boudabous, A. 2001. Microbial characterization during composting of municipal solid waste. Bioresource Technology 80:217-225.

72. Haug, R. T. 1993. Practical Handbook of Compost Engineering. Lewis Publisher, London.

73. Hedlund, B. P., Dodsworth, J. A., Murugapiran, S. K., Rinke, C. \& Woyke, T. 2014. Impact of single-cell genomics and metagenomics on the emerging view of extremophile "microbial dark matter". Extremophiles 18:865-875.

74. Hemsworth, G. R., Johnston, E. M., Davies, G. J. \& Walton, P. H. 2015. Lytic Polysaccharide Monooxygenases in Biomass Conversion. Trends in Biotechnology 33:747-761.

75. Hess, M., Sczyrba, A., Egan, R., Kim, T. W., Chokhawala, H., Schroth, G., Luo, S. J., Clark, D. S., Chen, F., Zhang, T., Mackie, R. I., Pennacchio, L. A., Tringe, S. G., Visel, A., Woyke, T., Wang, Z. \& Rubin, E. M. 2011. 
Metagenomic Discovery of Biomass-Degrading Genes and Genomes from Cow Rumen. Science 331:463-467.

76. Hiergeist, A., Glasner, J., Reischl, U., Gessner, A. 2015. ILar Journal 2,228210.

77. Hong, S. H., Bunge, J., Leslin, C., Jeon, S. \& Epstein, S. S. 2009. Polymerase chain reaction primers miss half of rRNA microbial diversity. Isme Journal 3:1365-1373.

78. Hua, B., Lu, Y.,Wang, J., Wen, B., Cao, Y., Wang, X., Cui, Z. 2014. Dynamic changes in the composite microbial system MC1 during and following its rapid degradation of lignocellulose. Appl. Biochem. Biotechnol. 172:951-961.

79. Huang, D. L., Zeng, G. M., Feng, C. L., Hu, S., Lai, C., Zhao, M. H., Su, F. F., Tang, L. \& Liu, H. L. 2010. Changes of microbial population structure related to lignin degradation during lignocellulosic waste composting. Bioresource Technology 101:4062-4067.

80. Hultman, J., Vasara, T., Partanen, P., Kurola, J., Kontro, M. H., Paulin, L., Auvinen, P. \& Romantschuk, M. 2010. Determination of fungal succession during municipal solid waste composting using a cloning-based analysis. Journal of applied microbiology 108:472-87.

81. Hyeon, J. E., Jeon, S. D. \& Han, S. O. 2013. Cellulosome-based, Clostridiumderived multi-functional enzyme complexes for advanced biotechnology tool development: Advances and applications. Biotechnology Advances 31:936-944.

82. Inácio, C. \& Miller, P. 2009. Compostagem ciência e prática para a gestão de residuos orgânicos, vol. Capítulo 2. Embrapa solos

83. Ingelmo, F., Molina, M. J., Soriano, M. D., Gallardo, A. \& Lapena, L. 2012. Influence of organic matter transformations on the bioavailability of heavy metals in a sludge based compost. Journal of Environmental Management 95:S104-S109.

84. Insam, H. \& de Bertoldi, M. 2007. Microbiology of the composting process, p. 26-48. In L. F. Diaz, M. de Bertoldi, W. Bidlingmaier \& E. Stentiford (ed.), Compost Science and Technology, vol. 1. Elsevier, Amsterdam, The Netherlands.

85. Ishii, K. \& Takii, S. 2003. Comparison of microbial communities in four different composting processes as evaluated by denaturing gradient gel electrophoresis analysis. Journal of applied microbiology 95:109-119.

86. Izquierdo, J. A., Sizova, M. V. \& Lynd, L. R. 2010. Diversity of Bacteria and Glycosyl Hydrolase Family 48 Genes in Cellulolytic Consortia Enriched from Thermophilic Biocompost. Applied and Environmental Microbiology 76:35453553.

87. Jimenez, D. J., Chaves-Moreno, D. \& van Elsas, J. D. 2015. Unveiling the metabolic potential of two soil-derived microbial consortia selected on wheat straw. Scientific Reports 5:16. 
88. Joshi, N. A. \& Fass, J. N. 2011. Sickle: A sliding-window, adaptive, qualitybased trimming tool for FastQ files Version 1.33 ed, Available at https://github.com/najoshi/sickle.

89. Jurado, M., Lopez, M. J., Suarez-Estrella, F., Vargas-Garcia, M. C., LopezGonzalez, J. A. \& Moreno, J. 2014. Exploiting composting biodiversity: Study of the persistent and biotechnologically relevant microorganisms from lignocellulose-based composting. Bioresource Technology 162:283-293.

90. Kanokratana, P., Uengwetwanit, T., Rattanachomsri, U., Bunterngsook, B., Nimchua, T., Tangphatsornruang, S., Plengvidhya, V., Champreda, V. \& Eurwilaichitr, L. 2011. Insights into the Phylogeny and Metabolic Potential of a Primary Tropical Peat Swamp Forest Microbial Community by Metagenomic Analysis. Microbial Ecology 61:518-528.

91. Kato, S., Haruta, S., Cui, Z. J., Ishii, M. \& Igarashi, Y. 2004. Effective cellulose degradation by a mixed-culture system composed of a cellulolytic Clostridium and aerobic non-cellulolytic bacteria. FEMS microbiology ecology 51:133-142.

92. Klammer, S., Knapp, B., Insam, H., Dell'Abate, M. T. \& Ros, M. 2008. Bacterial community patterns and thermal analyses of composts of various origins. Waste Management \& Research 26:173-187.

93. Klindworth, A., Pruesse, E., Schweer, T., Peplies, J., Quast, C., Horn, M. \& Glockner, F. O. 2013. Evaluation of general 16S ribosomal RNA gene PCR primers for classical and next-generation sequencing-based diversity studies. Nucleic Acids Res 41:e1.

94. Kuczynski, J., Stombaugh, J., Walters, W., González, A., Caporaso, J. \& Knight, R. 2011. Using QIIME to analyze 16S rRNA gene sequences from microbial communities, Current protocols in bioinformatics

95. Kultima, J. R., Sunagawa, S., Li, J. H., Chen, W. N., Chen, H., Mende, D. R., Arumugam, M., Pan, Q., Liu, B. H., Qin, J. J., Wang, J. \& Bork, P. 2012. MOCAT: A Metagenomics Assembly and Gene Prediction Toolkit. Plos One 7:6.

96. Kumar, S. 2011. Composting of municipal solid waste. Critical reviews in biotechnology 31:112-36.

97. Lauber, C. L., Ramirez, K. S., Aanderud, Z., Lennon, J. \& Fierer, N. 2013. Temporal variability in soil microbial communities across land-use types. Isme Journal 7:1641-1650.

98. Ledford, H. 2015. Plant denizens get the big-science treatment. Nature 523:137-8.

99. Lemos, L. N. 2015. Reconstrução e análise de genomas de bactérias de compostagem a partir de dados metagenômicos. Dissertação de Mestrado. Programa Interunidades de Bioinformática, Universidade de São Paulo, São Paulo. 59 pág.

100. Ley, R. E., Peterson, D. A. \& Gordon, J. I. 2006. Ecological and evolutionary forces shaping microbial diversity in the human intestine. Cell 124:837-848. 
101. Liang, C., Das, K. C. \& McClendon, R. W. 2003. The influence of temperature and moisture contents regimes on the aerobic microbial activity of a biosolids composting blend. Bioresource Technology 86:131-137.

102. Liolios, K., Sikorski, J., Jando, M., Lapidus, A., Copeland, A. et al. 2010. Complete genome sequence of Thermobispora bispora type strain (R51). Stand Genomic Sci 2:318-26.

103. Logares, R., Sunagawa, S., Salazar, G., Cornejo-Castillo, F. M., Ferrera, I., Sarmento, H., Hingamp, P., Ogata, H., de Vargas, C., Lima-Mendez, G., Raes, J., Poulain, J., Jaillon, O., Wincker, P., Kandels-Lewis, S., Karsenti, E., Bork, P. \& Acinas, S. G. 2014. Metagenomic 16S rDNA Illumina tags are a powerful alternative to amplicon sequencing to explore diversity and structure of microbial communities. Environmental Microbiology 16:2659-2671.

104. Lombard, N., Prestat, E., van Elsas, J. D. \& Simonet, P. 2011. Soil-specific limitations for access and analysis of soil microbial communities by metagenomics. FEMS microbiology ecology 78:31-49.

105. Lopez-Gonzalez, J. A., Lopez, M. J., Vargas-Garcia, M. C., Suarez-Estrella, F., Jurado, M. \& Moreno, J. 2013. Tracking organic matter and microbiota dynamics during the stages of lignocellulosic waste composting. Bioresource Technology 146:574-584.

106. Lopez-Gonzalez, J. A., Suarez-Estrella, F., Vargas-Garcia, M. C., Lopez, M. J., Jurado, M. M. \& Moreno, J. 2015a. Dynamics of bacterial microbiota during lignocellulosic waste composting: Studies upon its structure, functionality and biodiversity. Bioresource Technology 175:406-416.

107. Lopez-Gonzalez, J. A., Vargas-Garcia, M. D., Lopez, M. J., Suarez-Estrella, F., Jurado, M. D. \& Moreno, J. 2015b. Biodiversity and succession of mycobiota associated to agricultural lignocellulosic waste-based composting. Bioresource Technology 187:305-313.

108. Lozupone, C. \& Knight, R. 2005. UniFrac: a new phylogenetic method for comparing microbial communities. Appl Environ Microbiol 71:8228-35.

109. Luo, C., Rodriguez, R. L. \& Konstantinidis, K. T. 2014. MyTaxa: an advanced taxonomic classifier for genomic and metagenomic sequences. Nucleic Acids Res 42:e73.

110. Luo, R., Liu, B., Xie, Y., Li, Z., Huang, W. et al. 2012. SOAPdenovo2: an empirically improved memory-efficient short-read de novo assembler. Gigascience 1:18.

111. Lykidis, A., Mavromatis, K., Ivanova, N., Anderson, I., Land, M., DiBartolo, G., Martinez, M., Lapidus, A., Lucas, S., Copeland, A., Richardson, P., Wilson, D. B. \& Kyrpides, N. 2007. Genome sequence and analysis of the soil cellulolytic actinomycete Thermobifida fusca YX. J Bacteriol 189:2477-86.

112. Lynd, L. R., Weimer, P. J., van Zyl, W. H. \& Pretorius, I. S. 2002. Microbial cellulose utilization: Fundamentals and biotechnology. Microbiology and Molecular Biology Reviews 66:506-577. 
113. Mardis, E. R. 2013. Next-Generation Sequencing Platforms. Annual Review of Analytical Chemistry 6:287-303.

114. Markowitz, V. M., Chen, I. M., Chu, K., Szeto, E., Palaniappan, K., Grechkin, Y., Ratner, A., Jacob, B., Pati, A., Huntemann, M., Liolios, K., Pagani, I., Anderson, I., Mavromatis, K., Ivanova, N. N. \& Kyrpides, N. C. 2012. IMG/M: the integrated metagenome data management and comparative analysis system. Nucleic Acids Res 40:D123-9.

115. Markowitz, V. M., Ivanova, N. N., Szeto, E., Palaniappan, K., Chu, K., Dalevi, D., Chen, I. M., Grechkin, Y., Dubchak, I., Anderson, I., Lykidis, A., Mavromatis, K., Hugenholtz, P. \& Kyrpides, N. C. 2008. IMG/M: a data management and analysis system for metagenomes. Nucleic Acids Research 36:D534-8.

116. Martins, L. F., Antunes, L. P., Pascon, R. C., de Oliveira, J. C., Digiampietri, L. A., Barbosa, D., Peixoto, B. M., Vallim, M. A., Viana-Niero, C., Ostroski, E. H., Telles, G. P., Dias, Z., da Cruz, J. B., Juliano, L., Verjovski-Almeida, S., da Silva, A. M. \& Setubal, J. C. 2013. Metagenomic analysis of a tropical composting operation at the sao paulo zoo park reveals diversity of biomass degradation functions and organisms. PloS One 8:e61928.

117. Mayende, L., Wilhelmi, B. S. \& Pletschke, B. I. 2006. Cellulases (CMCases) and polyphenol oxidases from thermophilic Bacillus spp. isolated from compost. Soil Biology \& Biochemistry 38:2963-2966.

118. McDonald, D., Price, M. N., Goodrich, J., Nawrocki, E. P., DeSantis, T. Z., Probst, A., Andersen, G. L., Knight, R. \& Hugenholtz, P. 2012. An improved Greengenes taxonomy with explicit ranks for ecological and evolutionary analyses of bacteria and archaea. The ISME journal 6:610-8.

119. McDonough, T. J. 1983. WOOD CHEMISTRY - FUNDAMENTALS AND APPLICATIONS - SJOSTROM,E. Journal of the American Chemical Society 105:4503-4503.

120. Meyer, F., Paarmann, D., D'Souza, M., Olson, R., Glass, E. M., Kubal, M., Paczian, T., Rodriguez, A., Stevens, R., Wilke, A., Wilkening, J. \& Edwards, R. A. 2008. The metagenomics RAST server - a public resource for the automatic phylogenetic and functional analysis of metagenomes. BMC bioinformatics 9:386.

121. Mhuantong, W., Charoensawan, V., Kanokratana, P., Tangphatsornruang, S. \& Champreda, V. 2015. Comparative analysis of sugarcane bagasse metagenome reveals unique and conserved biomass-degrading enzymes among lignocellulolytic microbial communities. Biotechnology for Biofuels 8 .

122. Moreno, J., López, M. J., Vargas-García, M. C. \& Suárez-Estrella, F. 2013. Recent Advances in Microbial Aspects of Compost Production and Use. Acta Hortic. (ISHS) 1013:443-457.

123. Neher, D. A., Weicht, T. R., Bates, S. T., Leff, J. W. \& Fierer, N. 2013. Changes in Bacterial and Fungal Communities across Compost Recipes, Preparation Methods, and Composting Times. Plos One 8. 
124. Ohno, M., Shiratori, H., Park, M. J., Saitoh, Y., Kumon, Y., Yamashita, N., Hirata, A., Nishida, H., Ueda, K. \& Beppu, T. 2000. Symbiobacterium thermophilum gen. nov., sp nov., a symbiotic thermophile that depends on coculture with a Bacillus strain for growth. International Journal of Systematic and Evolutionary Microbiology 50:1829-1832.

125. Oliveira, L. C. G., Ramos, P. L., Marem, A., Kondo, M. Y., Rocha, R. C. S., Bertolini, T., Silveira, M. A. V., da Cruz, J. B., de Vasconcellos, S. P., Juliano, L. \& Okamoto, D. N. 2015. Halotolerant bacteria in the Sao Paulo Zoo composting process and their hydrolases and bioproducts. Brazilian Journal of Microbiology 46:347-354.

126. Pace, N. R. 2009. Mapping the Tree of Life: Progress and Prospects. Microbiology and Molecular Biology Reviews 73:565-576.

127. Pace, N. R., Stahl, D. A., Lane, D. J. a. G. J. \& Olsen, G. J. 1985. The analysis of natural microbial populations by ribosomal RNA sequences. Am. Soc. Microbiol. News 51:4-12.

128. Partanen, P., Hultman, J., Paulin, L., Auvinen, P. \& Romantschuk, M. 2010. Bacterial diversity at different stages of the composting process. BMC microbiology 10.

129. Pascon, R. C., Bergamo, R. F., Spinelli, R. X., de Souza, E. D., Assis, D. M., Juliano, L. \& Vallim, M. A. 2011. Amylolytic microorganism from sao paulo zoo composting: isolation, identification, and amylase production. Enzyme Res 2011:679624.

130. Pati, A., Labutti, K., Pukall, R., Nolan, M., Glavina Del Rio, T. et al. 2010. Complete genome sequence of Sphaerobacter thermophilus type strain (S 6022). Stand Genomic Sci 2:49-56.

131. Penton, C. R., Vadakattu, V. S. R. G., Yu, J. \& Tiedje, J. M. 2016. Size Matters: Assessing Optimum Soil Sample Size for Fungal and Bacterial Community Structure Analyses Using High Throughput Sequencing of rRNA Gene Amplicons. Frontiers in Microbiology 7.

132. Pérez, J., Muñoz-Dorado, J., De la Rubia, T. \& Martínez, J. 2002. Biodegradation and biological treatments of cellulose, hemicellulose and lignin: an overview, vol. 5 .

133. Peters, S., Koschinsky, S., Schwieger, F. \& Tebbe, C. C. 2000. Succession of microbial communities during hot composting as detected by PCR-singlestrand-conformation polymorphism-based genetic profiles of small-subunit rRNA genes. Applied and Environmental Microbiology 66:930-936.

134. Poretsky, R., Rodriguez-R, L. M., Luo, C. W., Tsementzi, D. \& Konstantinidis, K. T. 2014. Strengths and Limitations of 16S rRNA Gene Amplicon Sequencing in Revealing Temporal Microbial Community Dynamics. Plos One 9.

135. Poretsky, R. S., Bano, N., Buchan, A., LeCleir, G., Kleikemper, J., Pickering, M., Pate, W. M., Moran, M. A. \& Hollibaugh, J. T. 2005. Analysis of microbial gene transcripts in environmental samples. Applied and Environmental Microbiology 71:4121-4126. 
136. Price, M. N., Dehal, P. S. \& Arkin, A. P. 2010. FastTree 2--approximately maximum-likelihood trees for large alignments. PLoS One 5:e9490.

137. Proft, T. 2009. Microbial Toxins: Current Research and Future Trends. Caister Academic Press.

138. Rahmanpour, R., Rea, D., Jamshidi, S., Fulop, V. \& Bugg, T. D. H. 2016. Structure of Thermobifida fusca DyP-type peroxidase and activity towards Kraft lignin and lignin model compounds. Archives of Biochemistry and Biophysics 594:54-60.

139. Rajendhran, J. \& Gunasekaran, P. 2011. Microbial phylogeny and diversity: small subunit ribosomal RNA sequence analysis and beyond. Microbiol Res 166:99-110.

140. Ranjan, R., Rani, A., Metwally, A., Macgee, H.S., Perkins, D.L. Analysis of the microbiome: Advantages of whole genome shotgun versus $16 \mathrm{~S}$ amplicon sequencing. 2016. Biochemical and Biophysical research communication 967977.

141. Rasche, F., Knapp, D., Kaiser, C., Koranda, M., Kitzler, B., ZechmeisterBoltenstern, S., Richter, A. \& Sessitsch, A. 2011. Seasonality and resource availability control bacterial and archaeal communities in soils of a temperate beech forest. Isme Journal 5:389-402.

142. Rashid, G. M. M., Taylor, C. R., Liu, Y. Q. X., Zhang, X. Y., Rea, D., Fulop, V. \& Bugg, T. D. H. 2015. Identification of Manganese Superoxide Dismutase from Sphingobacterium sp. T2 as a Novel Bacterial Enzyme for Lignin Oxidation. Acs Chemical Biology 10:2286-2294.

143. Rastogi, G., Bhalla, A., Adhikari, A., Bischoff, K. M., Hughes, S. R., Christopher, L. P. \& Sani, R. K. 2010. Characterization of thermostable cellulases produced by Bacillus and Geobacillus strains. Bioresource technology 101:8798-8806.

144. Riley, M. A. 2011. Bacteriocin-Mediated Competitive Interactions of Bacterial Populations and Communities, p. 13-26. In D. Drider \& S. Rebuffat (ed.), Prokaryotic Antimicrobial Peptides. Springer-Verlag New York, New York, USA.

145. Rinke, C., Schwientek, P., Sczyrba, A., Ivanova, N. N., Anderson, I. J. et al. 2013. Insights into the phylogeny and coding potential of microbial dark matter. Nature 499:431-7.

146. Ryckeboer, J., Mergaert, J., Coosemans, J., Deprins, K. \& Swings, J. 2003a. Microbiological aspects of biowaste during composting in a monitored compost bin. Journal of Applied Microbiology 94:127-137.

147. Ryckeboer, J., Mergaert, J., Vaes, K., Klammer, S., De Clercq, D., Coosemans, J., Insam, H. \& Swings, J. 2003b. A survey of bacteria and fungi occurring during composting and self-heating processes. Annals of Microbiology 53:349-410.

148. Rynk, R., van de Kamp, M., Willson, G. B., Singley, M. E., Richard, T. L., Kolega, J. J., Gouin, F. R., Laliberty-Jr, L., Kay, D., Murphy, D. W., Hoitink, H. A. J. \& Brinton, W. F. 1992. On-Farm Composting Handbook, Northeast 
Regional Agricultural Engineering Service - Cooperative Extension, Ed. , NRAES-54, 185 pag. Northeast Regional Agricultural Engineering Service, Ithaca, NY.

149. Schloss, P. D., Gevers, D. \& Westcott, S. L. 2011. Reducing the Effects of PCR Amplification and Sequencing Artifacts on 16S rRNA-Based Studies. PloS one 6.

150. Schloss, P. D., Hay, A. G., Wilson, D. B., Gossett, J. M. \& Walker, L. P. 2005. Quantifying bacterial population dynamics in compost using 16S rRNA gene probes. Applied Microbiology and Biotechnology 66:457-63.

151. Schloss, P. D. \& Westcott, S. L. 2011. Assessing and Improving Methods Used in Operational Taxonomic Unit-Based Approaches for 16S rRNA Gene Sequence Analysis. Applied and Environmental Microbiology 77:3219-3226.

152. Schroeder, A., Mueller, O., Stocker, S., Salowsky, R., Leiber, M., Gassmann, M., Lightfoot, S., Menzel, W., Granzow, M. \& Ragg, T. 2006. The RIN: an RNA integrity number for assigning integrity values to RNA measurements. BMC Mol Biol 7:3.

153. Shade, A., Read, J. S., Youngblut, N. D., Fierer, N., Knight, R., Kratz, T. K., Lottig, N. R., Roden, E. E., Stanley, E. H., Stombaugh, J., Whitaker, R. J., Wu, C. H. \& McMahon, K. D. 2012. Lake microbial communities are resilient after a whole-ecosystem disturbance. Isme Journal 6:2153-2167.

154. Shakya, M., Quince, C., Campbell, J. H., Yang, Z. K., Schadt, C. W. \& Podar, M. 2013. Comparative metagenomic and rRNA microbial diversity characterization using archaeal and bacterial synthetic communities. Environmental Microbiology 15:1882-1899.

155. Shi, Y., Tyson, G. W. \& DeLong, E. F. 2009. Metatranscriptomics reveals unique microbial small RNAs in the ocean's water column. Nature 459:266-9.

156. Simmons, C. W., Reddy, A. P., D'Haeseleer, P., Khudyakov, J., Billis, K., Pati, A., Simmons, B. A., Singer, S. W., Thelen, M. P. \& VanderGheynst, J. S. 2014. Metatranscriptomic analysis of lignocellulolytic microbial communities involved in high-solids decomposition of rice straw. Biotechnology for Biofuels $7: 13$.

157. Solden, L., Lloyd, K., Wrighton, K. 2016. The bright side of microbial dark matter: lessons learned from the uncultivated majority. Current Opinion in Microbiology 31:217-226.

158. Simon, C. \& Daniel, R. 2011. Metagenomic Analyses: Past and Future Trends. Applied and Environmental Microbiology 77:1153-1161.

159. Steger, K., Jarvis, A., Vasara, T., Romantschuk, M. \& Sundh, I. 2007a. Effects of differing temperature management on development of Actinobacteria populations during composting. Research in Microbiology 158:617-624.

160. Steger, K., Sjogren, A. M., Jarvis, A., Jansson, J. K. \& Sundh, I. 2007b. Development of compost maturity and Actinobacteria populations during fullscale composting of organic household waste. Journal of applied microbiology 103:487-498. 
161. Storey, S., Ni Chualain, D., Doyle, O., Clipson, N. \& Doyle, E. 2015. Comparison of bacterial succession in green waste composts amended with inorganic fertiliser and wastewater treatment plant sludge. Bioresource Technology 179:71-77.

162. Takaku, H., Kodaira, S., Kimoto, A., Nashimoto, M. \& Takagi, M. 2006. Microbial communities in the garbage composting with rice hull as an amendment revealed by culture-dependent and -independent approaches. Journal of Bioscience and Bioengineering 101:42-50.

163. Tian, B. Y., Cao, Y. \& Zhang, K. Q. 2015. Metagenomic insights into communities, functions of endophytes, and their associates with infection by root-knot nematode, Meloidogyne incognita, in tomato roots. Sci Rep 5:17087.

164. Tiquia, S. M. 2005. Microbiological parameters as indicators of compost maturity. Journal of Applied Microbiology 99:816-828.

165. Tiquia, S. M., Ichida, J. M., Keener, H. M., Elwell, D. L., Burtt, E. H. \& Michel, F. C. 2005. Bacterial community profiles on feathers during composting as determined by terminal restriction fragment length polymorphism analysis of 16S rDNA genes. Applied Microbiology and Biotechnology 67:412-419.

166. Tkachuk, V. L., Krause, D. O., Knox, N. C., Hamm, A. C., Zvomuya, F., Ominski, K. H. \& McAllister, T. A. 2014. Targeted 16S rRNA high-throughput sequencing to characterize microbial communities during composting of livestock mortalities. Journal of Applied Microbiology 116:1181-1194.

167. Toseland, A., Moxon, S., Mock, T. \& Moulton, V. 2014. Metatranscriptomes from diverse microbial communities: assessment of data reduction techniques for rigorous annotation. BMC Genomics 15:7.

168. Toth, A., Barna, T., Nagy, I., Horvath, B., Tancsics, A., Kriszt, B., Baka, E., Fekete, C. \& Kukolya, J. 2013. Draft Genome Sequence of the Lignocellulose Decomposer Thermobifida fusca Strain TM51. Genome Announc 1.

169. Tringe, S. G. \& Hugenholtz, P. 2008. A renaissance for the pioneering $16 \mathrm{~S}$ rRNA gene. Current opinion in microbiology 11:442-6.

170. Tringe, S. G. \& Rubin, E. M. 2005. Metagenomics: DNA sequencing of environmental samples. Nature Reviews Genetics 6:805-814.

171. Tuomela, M., Vikman, M., Hatakka, A. \& Itavaara, M. 2000. Biodegradation of lignin in a compost environment: a review. Bioresource technology 72:169-183.

172. Tyson, G. W., Chapman, J., Hugenholtz, P., Allen, E. E., Ram, R. J., Richardson, P. M., Solovyev, V. V., Rubin, E. M., Rokhsar, D. S. \& Banfield, J. F. 2004. Community structure and metabolism through reconstruction of microbial genomes from the environment. Nature 428:37-43.

173. Ueda, K., Yamashita, A., Ishikawa, J., Shimada, M., Watsuji, T. O., Morimura, K., Ikeda, H., Hattori, M. \& Beppu, T. 2004. Genome sequence of Symbiobacterium thermophilum, an uncultivable bacterium that depends on microbial commensalism. Nucleic Acids Res 32:4937-44. 
174. Urich, T., Lanzen, A., Qi, J., Huson, D. H., Schleper, C. \& Schuster, S. C. 2008. Simultaneous Assessment of Soil Microbial Community Structure and Function through Analysis of the Meta-Transcriptome. Plos One 3:13.

175. Van Dyk, J. S. \& Pletschke, B. I. 2012. A review of lignocellulose bioconversion using enzymatic hydrolysis and synergistic cooperation between enzymes-Factors affecting enzymes, conversion and synergy. Biotechnology Advances 30:1458-1480.

176. Vargas-Garcia, M. C., Suarez-Estrella, F., Lopez, M. J. \& Moreno, J. 2010. Microbial population dynamics and enzyme activities in composting processes with different starting materials. Waste Management 30:771-778.

177. Velikodvorskaya, G. A., Chekanovskaya, L. A., Lunina, N. A., Sergienko, O. V., Lunin, V. G., Dvortsov, I. A. \& Zverlov, V. V. 2013. Family 28 carbohydrate-binding module of the thermostable endo-1,4-beta-glucanase CeID from Caldicellulosiruptor bescii maximizes enzyme activity and irreversibly binds to amorphous cellulose. Molecular Biology 47:581-586.

178. Venter, J. C., Remington, K., Heidelberg, J. F., Halpern, A. L., Rusch, D. et al. 2004. Environmental genome shotgun sequencing of the Sargasso Sea. Science 304:66-74.

179. Ventorino, V., Aliberti, A., Faraco, V., Robertiello, A., Giacobbe, S., Ercolini, D., Amore, A., Fagnano, M. \& Pepe, O. 2015. Exploring the microbiota dynamics related to vegetable biomasses degradation and study of lignocellulose-degrading bacteria for industrial biotechnological application. Scientific Reports 5.

180. Wang, C., Dong, D., Wang, H. S., Muller, K., Qin, Y., Wang, H. L. \& Wu, W. X. 2016. Metagenomic analysis of microbial consortia enriched from compost: new insights into the role of Actinobacteria in lignocellulose decomposition. Biotechnology for Biofuels 9:17.

181. Wang, Q., Garrity, G. M., Tiedje, J. M. \& Cole, J. R. 2007. Naive Bayesian classifier for rapid assignment of rRNA sequences into the new bacterial taxonomy. Applied and Environmental Microbiology 73:5261-5267.

182. Xia, L. C., Steele, J. A., Cram, J. A., Cardon, Z. G., Simmons, S. L., Vallino, J. J., Fuhrman, J. A. \& Sun, F. 2011. Extended local similarity analysis (eLSA) of microbial community and other time series data with replicates. Bmc Systems Biology 5.

183. Xia, Y., Wang, Y., Fang, H. H. P., Jin, T., Zhong, H. \& Zhang, T. 2014. Thermophilic microbial cellulose decomposition and methanogenesis pathways recharacterized by metatranscriptomic and metagenomic analysis. Scientific Reports 4.

184. Xie, W., Wang, F., Guo, L., Chen, Z., Sievert, S. M., Meng, J., Huang, G., Li, Y., Yan, Q., Wu, S., Wang, X., Chen, S., He, G., Xiao, X. \& Xu, A. 2011. Comparative metagenomics of microbial communities inhabiting deep-sea hydrothermal vent chimneys with contrasting chemistries. The ISME journal 5:414-26. 
185. Yabe, S., Aiba, Y., Sakai, Y., Hazaka, M., Kawahara, K. \& Yokota, A. 2013. Sphingobacterium thermophilum sp nov., of the phylum Bacteroidetes, isolated from compost. International Journal of Systematic and Evolutionary Microbiology 63:1584-1588.

186. Yang, G. Q., Chen, M., Yu, Z., Lu, Q. \& Zhou, S. G. 2013. Bacillus composti sp nov and Bacillus thermophilus sp nov., two thermophilic, Fe(III)-reducing bacteria isolated from compost. International Journal of Systematic and Evolutionary Microbiology 63:3030-3036.

187. Yarza, P., Yilmaz, P., Pruesse, E., Glockner, F. O., Ludwig, W., Schleifer, K. H., Whitman, W. B., Euzeby, J., Amann, R. \& Rossello-Mora, R. 2014. Uniting the classification of cultured and uncultured bacteria and archaea using $16 S$ rRNA gene sequences. Nature Reviews Microbiology 12:635-645.

188. Yi, J., Wu, H. Y., Wu, J., Deng, C. Y., Zheng, R. \& Chao, Z. 2012. Molecular phylogenetic diversity of Bacillus community and its temporal-spatial distribution during the swine manure of composting. Applied Microbiology and Biotechnology 93:411-421.

189. Yu, H., Zeng, G. M., Huang, H. L., Xi, X. M., Wang, R. Y., Huang, D. L., Huang, G. H. \& Li, J. B. 2007. Microbial community succession and lignocellulose degradation during agricultural waste composting. Biodegradation 18:793-802.

190. Zainudin, M. H. M., Hassan, M. A., Shah, U. K. M., Abdullah, N., Tokura, M., Yasueda, H., Shirai, Y., Sakai, K. \& Baharuddin, A. S. 2014. Bacterial Community Structure and Biochemical Changes Associated With Composting of Lignocellulosic Oil Palm Empty Fruit Bunch. Bioresources 9:316-335.

191. Zhang, L. L., Zhang, H. Q., Wang, Z. H., Chen, G. J. \& Wang, L. S. 2016. Dynamic changes of the dominant functioning microbial community in the compost of a $90-\mathrm{m}(3)$ aerobic solid state fermentor revealed by integrated meta-omics. Bioresource Technology 203:1-10.

192. Zhang, X., Zhong, Y., Yang, S., Zhang, W., Xu, M., Ma, A., Zhuang, G., Chen, G. \& Liu, W. 2014. Diversity and dynamics of the microbial community on decomposing wheat straw during mushroom compost production. Bioresource Technology 170:183-195.

193. Zhao, Y. Y., Meng, K., Luo, H. Y., Huang, H. Q., Yuan, T. Z., Yang, P. L. \& Yao, B. 2013. Molecular and biochemical characterization of a new alkaline active multidomain xylanase from alkaline wastewater sludge. World Journal of Microbiology \& Biotechnology 29:327-334. 


\section{Apêndice 1}

Tabela S1: Espécies de bactérias mais abundantes nos metatranscritomas da ZC4. CDSs anotadas pelo IMG e classificadas com o programa MyTaxa. Os resultados de cada amostra referem-se a abundância relativa de CDSs expressas em cada mil, apenas as 30 mais abundantes estão representadas. A última coluna mostra o número absoluto de CDS para cada espécie em todas as amostras.

\begin{tabular}{|c|c|c|c|c|c|c|c|c|c|}
\hline Espécies & $\begin{array}{l}\text { D01 } \\
\% 0\end{array}$ & $\begin{array}{l}\text { D03 } \\
\% o\end{array}$ & $\begin{array}{l}\text { D07 } \\
\% \text { o }\end{array}$ & $\begin{array}{l}\text { D15 } \\
\% \text { o }\end{array}$ & $\begin{array}{l}\text { D30 } \\
\% 0\end{array}$ & $\begin{array}{l}\text { D64 } \\
\% 0\end{array}$ & $\begin{array}{c}\text { D78 } \\
\% \text { o }\end{array}$ & $\begin{array}{l}\text { D99 } \\
\% \text { o }\end{array}$ & $\begin{array}{l}\text { Total } \\
\text { por } \\
\text { espécie }\end{array}$ \\
\hline $\begin{array}{l}\text { Symbiobacterium } \\
\text { thermophilum }\end{array}$ & 34,95 & 71,00 & 121,06 & 61,24 & 14,09 & 60,80 & 21,11 & 2,50 & 15847 \\
\hline $\begin{array}{l}\text { Rhodothermus } \\
\text { marinus }\end{array}$ & 2,47 & 4,92 & 25,12 & 89,06 & 86,42 & 12,70 & 92,76 & 5,94 & 10026 \\
\hline $\begin{array}{l}\text { Thermobacillus } \\
\text { composti }\end{array}$ & 55,14 & 27,01 & 18,84 & 43,29 & 63,02 & 16,61 & 23,43 & 1,48 & 9490 \\
\hline $\begin{array}{l}\text { Thermaerobacter } \\
\text { marianensis }\end{array}$ & 8,61 & 12,89 & 80,70 & 77,05 & 21,73 & 14,47 & 29,94 & 5,17 & 9082 \\
\hline $\begin{array}{l}\text { Thermobispora } \\
\text { bispora }\end{array}$ & 42,26 & 40,66 & 62,69 & 18,08 & 26,14 & 12,94 & 17,39 & 6,66 & 9009 \\
\hline $\begin{array}{l}\text { Streptosporangium } \\
\text { roseum }\end{array}$ & 28,86 & 28,70 & 37,25 & 12,08 & 19,14 & 9,37 & 8,88 & 7,68 & 6037 \\
\hline $\begin{array}{l}\text { Paenibacillus } \\
\text { mucilaginosus }\end{array}$ & 56,62 & 15,43 & 16,61 & 17,76 & 14,49 & 13,86 & 11,08 & 1,31 & 5955 \\
\hline Solibacillus silvestris & 33,63 & 27,03 & 4,44 & 1,28 & 0,69 & 50,86 & 0,68 & 2,25 & 5620 \\
\hline Brevibacillus brevis & 21,49 & 50,10 & 15,89 & 17,83 & 6,71 & 12,31 & 4,78 & 0,68 & 5311 \\
\hline $\begin{array}{l}\text { Pseudomonas } \\
\text { mendocina }\end{array}$ & 5,17 & 1,00 & 0,56 & 0,26 & 0,93 & 29,21 & 0,42 & 145,27 & 5302 \\
\hline $\begin{array}{l}\text { Thermosediminibacter } \\
\text { oceani }\end{array}$ & 10,70 & 14,08 & 36,99 & 32,46 & 2,91 & 18,88 & 4,99 & 0,42 & 4880 \\
\hline $\begin{array}{l}\text { Lysinibacillus } \\
\text { sphaericus }\end{array}$ & 28,12 & 23,56 & 4,34 & 1,31 & 0,71 & 42,55 & 0,89 & 1,36 & 4775 \\
\hline Sorangium cellulosum & 1,15 & 14,29 & 13,55 & 31,53 & 51,63 & 2,31 & 15,97 & 0,81 & 4619 \\
\hline $\begin{array}{l}\text { Klebsiella } \\
\text { pneumoniae }\end{array}$ & 2,97 & 0,10 & 0,05 & 0,00 & 0,03 & 0,31 & 0,05 & 182,68 & 4463 \\
\hline $\begin{array}{l}\text { Sphaerobacter } \\
\text { thermophilus }\end{array}$ & 2,74 & 12,58 & 15,99 & 4,89 & 14,38 & 4,35 & 24,53 & 31,05 & 3463 \\
\hline Thermobifida fusca & 2,70 & 2,76 & 4,51 & 0,70 & 61,46 & 3,44 & 17,12 & 5,17 & 3405 \\
\hline Bacillus coagulans & 22,19 & 15,43 & 11,04 & 10,51 & 2,48 & 14,45 & 2,94 & 0,59 & 3361 \\
\hline Pseudomonas putida & 12,23 & 1,28 & 0,42 & 0,38 & 0,95 & 3,23 & 0,53 & 91,28 & 2995 \\
\hline
\end{tabular}


ANEXO

\begin{tabular}{|c|c|c|c|c|c|c|c|c|c|}
\hline Kyrpidia tusciae & 9,24 & 11,94 & 13,64 & 15,08 & 7,80 & 8,15 & 7,20 & 0,81 & 2850 \\
\hline $\begin{array}{l}\text { Geobacillus } \\
\text { thermodenitrificans }\end{array}$ & 16,34 & 18,55 & 7,74 & 6,17 & 2,43 & 11,32 & 2,00 & 0,42 & 2766 \\
\hline $\begin{array}{l}\text { Geobacillus sp, } \\
\text { WCH70 }\end{array}$ & 17,35 & 13,77 & 10,48 & 7,67 & 2,48 & 8,15 & 1,89 & 0,93 & 2621 \\
\hline $\begin{array}{l}\text { Paenibacillus sp, } \\
\text { JDR-2 }\end{array}$ & 19,17 & 5,87 & 4,41 & 4,82 & 8,72 & 12,60 & 7,25 & 2,12 & 2619 \\
\hline Mahella australiensis & 2,45 & 9,03 & 15,75 & 17,70 & 4,94 & 8,90 & 9,35 & 0,76 & 2570 \\
\hline $\begin{array}{l}\text { Gemmatimonas } \\
\text { aurantiaca }\end{array}$ & 2,16 & 7,32 & 10,48 & 7,76 & 16,94 & 3,74 & 25,53 & 0,68 & 2437 \\
\hline $\begin{array}{l}\text { Clostridium } \\
\text { thermocellum }\end{array}$ & 2,47 & 11,06 & 10,80 & 9,74 & 3,70 & 13,65 & 6,36 & 0,34 & 2329 \\
\hline $\begin{array}{l}\text { Geobacillus sp, } \\
\text { Y4,1MC1 }\end{array}$ & 17,83 & 10,30 & 9,43 & 7,19 & 1,72 & 5,50 & 1,84 & 0,34 & 2253 \\
\hline Clostridium acidurici & 1,96 & 13,39 & 5,95 & 6,87 & 0,58 & 18,42 & 2,00 & 0,13 & 2149 \\
\hline $\begin{array}{l}\text { Anoxybacillus } \\
\text { flavithermus }\end{array}$ & 11,33 & 10,72 & 7,81 & 6,96 & 1,88 & 7,56 & 2,10 & 0,21 & 2021 \\
\hline $\begin{array}{l}\text { Thermomonospora } \\
\text { curvata }\end{array}$ & 5,08 & 5,99 & 8,76 & 2,14 & 11,34 & 4,54 & 7,04 & 12,30 & 2013 \\
\hline Bacillus megaterium & 7,64 & 6,90 & 5,11 & 5,33 & 2,33 & 7,37 & 1,89 & 19,09 & 1977 \\
\hline
\end{tabular}




\section{Apêndice 2}

Tabela S2: Número de CDSs dos metatranscritôma da ZC4 anotadas pelo CAZy.

\begin{tabular}{|c|c|c|c|c|c|c|c|c|c|}
\hline $\begin{array}{c}\text { CAZy } \\
\text { families }\end{array}$ & $\begin{array}{c}\text { CAZy } \\
\text { enzymes }\end{array}$ & D01 & D03 & D07 & D15 & D30 & D64 & D78 & D99 \\
\hline \multirow{3}{*}{ Celulossomo } & SLH & 393 & 302 & 255 & 188 & 201 & 536 & 132 & 21 \\
\hline & cohesin & 10 & 15 & 4 & 4 & 5 & 19 & 1 & 0 \\
\hline & dockerin & 4 & 8 & 1 & 0 & 6 & 6 & 3 & 0 \\
\hline \multirow[t]{35}{*}{ CBM } & CBM1 & 0 & 0 & 1 & 0 & 1 & 0 & 0 & 0 \\
\hline & CBM2 & 19 & 19 & 26 & 21 & 43 & 8 & 47 & 14 \\
\hline & CBM3 & 9 & 6 & 3 & 2 & 6 & 8 & 4 & 0 \\
\hline & CBM4 & 5 & 8 & 3 & 7 & 9 & 18 & 10 & 0 \\
\hline & CBM5 & 3 & 3 & 0 & 3 & 1 & 2 & 1 & 0 \\
\hline & CBM6 & 15 & 19 & 12 & 11 & 15 & 18 & 9 & 1 \\
\hline & CBM8 & 2 & 1 & 1 & 3 & 0 & 2 & 0 & 0 \\
\hline & CBM9 & 6 & 11 & 6 & 10 & 17 & 20 & 17 & 1 \\
\hline & CBM11 & 0 & 2 & 2 & 2 & 0 & 0 & 0 & 0 \\
\hline & CBM12 & 6 & 2 & 1 & 0 & 1 & 1 & 1 & 1 \\
\hline & CBM13 & 6 & 2 & 5 & 4 & 6 & 5 & 8 & 2 \\
\hline & CBM14 & 0 & 1 & 0 & 0 & 0 & 1 & 0 & 2 \\
\hline & CBM15 & 2 & 0 & 0 & 0 & 0 & 1 & 0 & 0 \\
\hline & CBM16 & 12 & 14 & 14 & 17 & 18 & 11 & 8 & 3 \\
\hline & CBM17 & 0 & 1 & 0 & 1 & 0 & 1 & 0 & 0 \\
\hline & CBM18 & 1 & 0 & 0 & 0 & 0 & 0 & 1 & 0 \\
\hline & CBM19 & 1 & 0 & 0 & 0 & 0 & 0 & 0 & 0 \\
\hline & CBM20 & 6 & 7 & 9 & 6 & 3 & 8 & 3 & 1 \\
\hline & CBM21 & 0 & 0 & 0 & 0 & 0 & 1 & 0 & 0 \\
\hline & CBM22 & 8 & 5 & 11 & 8 & 16 & 14 & 9 & 2 \\
\hline & CBM23 & 0 & 1 & 1 & 1 & 5 & 5 & 0 & 0 \\
\hline & CBM24 & 0 & 0 & 0 & 0 & 0 & 0 & 1 & 0 \\
\hline & CBM25 & 6 & 4 & 5 & 4 & 8 & 3 & 7 & 3 \\
\hline & CBM26 & 4 & 2 & 1 & 0 & 0 & 3 & 0 & 0 \\
\hline & CBM27 & 0 & 0 & 0 & 1 & 0 & 1 & 0 & 0 \\
\hline & CBM28 & 0 & 0 & 0 & 0 & 0 & 1 & 0 & 0 \\
\hline & CBM30 & 1 & 1 & 1 & 1 & 1 & 5 & 2 & 0 \\
\hline & CBM31 & 0 & 1 & 0 & 0 & 0 & 0 & 0 & 0 \\
\hline & CBM32 & 26 & 18 & 27 & 22 & 22 & 43 & 14 & 9 \\
\hline & CBM34 & 8 & 15 & 15 & 8 & 2 & 9 & 1 & 1 \\
\hline & CBM35 & 11 & 15 & 19 & 16 & 20 & 19 & 8 & 6 \\
\hline & CBM36 & 2 & 3 & 1 & 2 & 0 & 4 & 1 & 0 \\
\hline & CBM37 & 11 & 5 & 3 & 6 & 2 & 8 & 1 & 1 \\
\hline & CBM38 & 0 & 1 & 0 & 0 & 0 & 0 & 0 & 0 \\
\hline & CBM39 & 1 & 1 & 0 & 0 & 0 & 1 & 0 & 0 \\
\hline
\end{tabular}




\begin{tabular}{|c|c|c|c|c|c|c|c|c|c|}
\hline & CBM40 & 0 & 8 & 4 & 8 & 5 & 4 & 6 & 3 \\
\hline & CBM41 & 4 & 0 & 1 & 0 & 2 & 3 & 0 & 0 \\
\hline & CBM42 & 2 & 0 & 0 & 0 & 0 & 0 & 0 & 0 \\
\hline & CBM43 & 0 & 1 & 2 & 1 & 0 & 2 & 0 & 0 \\
\hline & CBM44 & 17 & 23 & 10 & 11 & 15 & 4 & 12 & 2 \\
\hline & CBM46 & 3 & 7 & 6 & 3 & 4 & 11 & 1 & 0 \\
\hline & CBM47 & 0 & 0 & 0 & 1 & 1 & 0 & 0 & 0 \\
\hline & CBM48 & 9 & 3 & 10 & 4 & 13 & 5 & 8 & 7 \\
\hline & CBM49 & 0 & 0 & 0 & 0 & 0 & 0 & 1 & 0 \\
\hline & CBM50 & 206 & 250 & 220 & 169 & 198 & 291 & 156 & 71 \\
\hline & CBM51 & 2 & 1 & 3 & 0 & 1 & 2 & 0 & 0 \\
\hline & CBM53 & 1 & 0 & 0 & 1 & 0 & 1 & 0 & 0 \\
\hline & CBM54 & 4 & 3 & 3 & 2 & 5 & 6 & 3 & 0 \\
\hline & CBM56 & 4 & 0 & 0 & 2 & 3 & 3 & 4 & 0 \\
\hline & CBM57 & 1 & 2 & 0 & 3 & 2 & 2 & 1 & 0 \\
\hline & CBM58 & 0 & 2 & 0 & 0 & 0 & 1 & 0 & 0 \\
\hline & CBM59 & 3 & 2 & 3 & 4 & 4 & 4 & 2 & 0 \\
\hline & CBM60 & 1 & 3 & 0 & 0 & 1 & 0 & 0 & 0 \\
\hline & CBM61 & 3 & 6 & 5 & 4 & 2 & 4 & 1 & 0 \\
\hline & CBM62 & 0 & 0 & 0 & 0 & 0 & 1 & 1 & 0 \\
\hline & CBM63 & 0 & 1 & 0 & 1 & 0 & 0 & 1 & 0 \\
\hline & CBM64 & 0 & 1 & 0 & 0 & 0 & 0 & 0 & 0 \\
\hline & CBM65 & 0 & 2 & 0 & 1 & 1 & 3 & 0 & 0 \\
\hline & CBM66 & 9 & 16 & 7 & 14 & 9 & 20 & 5 & 1 \\
\hline & CBM67 & 7 & 6 & 7 & 5 & 3 & 1 & 3 & 0 \\
\hline \multirow[t]{19}{*}{ GH } & GH1 & 12 & 14 & 17 & 19 & 13 & 7 & 7 & 9 \\
\hline & $\mathrm{GH} 2$ & 2 & 2 & 4 & 4 & 2 & 0 & 0 & 1 \\
\hline & GH3 & 24 & 28 & 32 & 32 & 29 & 31 & 14 & 8 \\
\hline & GH4 & 17 & 24 & 17 & 22 & 11 & 26 & 8 & 8 \\
\hline & GH5 & 12 & 10 & 7 & 10 & 13 & 11 & 15 & 3 \\
\hline & GH6 & 8 & 9 & 7 & 11 & 12 & 3 & 8 & 4 \\
\hline & GH7 & 1 & 1 & 0 & 0 & 1 & 0 & 0 & 0 \\
\hline & GH8 & 1 & 1 & 1 & 2 & 6 & 1 & 1 & 4 \\
\hline & GH9 & 2 & 2 & 1 & 4 & 5 & 6 & 3 & 1 \\
\hline & GH10 & 22 & 21 & 28 & 35 & 35 & 25 & 24 & 3 \\
\hline & GH11 & 16 & 15 & 13 & 5 & 10 & 17 & 4 & 2 \\
\hline & GH12 & 3 & 2 & 3 & 4 & 6 & 1 & 5 & 0 \\
\hline & GH13 & 47 & 44 & 34 & 22 & 23 & 52 & 10 & 13 \\
\hline & GH15 & 13 & 9 & 19 & 9 & 10 & 11 & 5 & 2 \\
\hline & GH16 & 7 & 2 & 3 & 3 & 5 & 10 & 3 & 2 \\
\hline & GH17 & 0 & 1 & 0 & 0 & 0 & 2 & 0 & 0 \\
\hline & GH18 & 25 & 23 & 30 & 18 & 5 & 26 & 3 & 2 \\
\hline & GH19 & 1 & 0 & 1 & 1 & 2 & 0 & 2 & 1 \\
\hline & GH20 & 1 & 0 & 1 & 2 & 0 & 1 & 0 & 1 \\
\hline
\end{tabular}




\begin{tabular}{|c|c|c|c|c|c|c|c|c|}
\hline $\mathrm{GH} 22$ & 2 & 0 & 0 & 2 & 2 & 1 & 1 & 0 \\
\hline $\mathrm{GH} 23$ & 29 & 49 & 51 & 26 & 41 & 44 & 16 & 26 \\
\hline $\mathrm{GH} 24$ & 3 & 3 & 4 & 2 & 3 & 1 & 3 & 3 \\
\hline $\mathrm{GH} 25$ & 7 & 3 & 4 & 4 & 3 & 8 & 3 & 2 \\
\hline GH26 & 1 & 2 & 4 & 7 & 4 & 2 & 5 & 0 \\
\hline $\mathrm{GH} 27$ & 0 & 0 & 0 & 1 & 1 & 2 & 1 & 0 \\
\hline $\mathrm{GH} 28$ & 3 & 1 & 3 & 1 & 0 & 4 & 2 & 0 \\
\hline GH29 & 2 & 1 & 5 & 3 & 1 & 1 & 0 & 0 \\
\hline GH30 & 0 & 6 & 6 & 2 & 1 & 1 & 2 & 0 \\
\hline GH31 & 8 & 4 & 20 & 12 & 6 & 2 & 2 & 5 \\
\hline GH32 & 4 & 0 & 1 & 2 & 3 & 1 & 0 & 1 \\
\hline GH33 & 4 & 2 & 1 & 2 & 5 & 0 & 2 & 0 \\
\hline GH35 & 5 & 2 & 4 & 8 & 4 & 2 & 3 & 3 \\
\hline GH36 & 0 & 2 & 1 & 0 & 0 & 1 & 0 & 1 \\
\hline GH37 & 0 & 0 & 0 & 0 & 0 & 0 & 0 & 3 \\
\hline GH38 & 2 & 2 & 5 & 2 & 2 & 2 & 0 & 0 \\
\hline GH39 & 1 & 2 & 4 & 1 & 0 & 2 & 1 & 0 \\
\hline GH42 & 9 & 5 & 7 & 6 & 1 & 3 & 1 & 2 \\
\hline GH43 & 36 & 15 & 25 & 24 & 28 & 31 & 11 & 5 \\
\hline GH44 & 1 & 0 & 0 & 1 & 1 & 0 & 0 & 0 \\
\hline GH45 & 0 & 1 & 1 & 0 & 1 & 0 & 0 & 0 \\
\hline GH48 & 5 & 5 & 3 & 3 & 2 & 5 & 4 & 1 \\
\hline GH51 & 1 & 2 & 5 & 8 & 4 & 2 & 1 & 0 \\
\hline GH52 & 0 & 0 & 1 & 0 & 1 & 1 & 0 & 0 \\
\hline GH53 & 1 & 1 & 0 & 2 & 3 & 1 & 0 & 1 \\
\hline GH54 & 0 & 1 & 1 & 0 & 0 & 0 & 0 & 0 \\
\hline GH57 & 1 & 3 & 8 & 5 & 4 & 1 & 1 & 1 \\
\hline GH62 & 2 & 1 & 1 & 2 & 1 & 0 & 3 & 0 \\
\hline GH64 & 1 & 0 & 0 & 0 & 0 & 1 & 0 & 0 \\
\hline GH65 & 9 & 6 & 4 & 2 & 0 & 4 & 3 & 1 \\
\hline GH66 & 1 & 0 & 1 & 0 & 0 & 1 & 0 & 0 \\
\hline GH67 & 0 & 2 & 5 & 1 & 2 & 2 & 0 & 0 \\
\hline GH68 & 0 & 0 & 0 & 0 & 0 & 3 & 0 & 0 \\
\hline GH72 & 0 & 0 & 0 & 0 & 0 & 3 & 0 & 0 \\
\hline GH73 & 21 & 16 & 6 & 7 & 8 & 25 & 2 & 5 \\
\hline GH74 & 4 & 8 & 17 & 16 & 15 & 9 & 7 & 11 \\
\hline GH75 & 1 & 0 & 0 & 0 & 0 & 0 & 0 & 0 \\
\hline GH76 & 0 & 0 & 1 & 1 & 1 & 3 & 0 & 0 \\
\hline GH77 & 1 & 2 & 0 & 1 & 1 & 1 & 1 & 1 \\
\hline GH78 & 3 & 1 & 5 & 7 & 0 & 2 & 0 & 1 \\
\hline GH81 & 0 & 1 & 0 & 0 & 3 & 0 & 0 & 0 \\
\hline GH82 & 0 & 0 & 0 & 0 & 2 & 0 & 1 & 0 \\
\hline GH84 & 1 & 1 & 1 & 1 & 1 & 2 & 0 & 0 \\
\hline GH87 & 4 & 0 & 0 & 0 & 0 & 0 & 0 & 0 \\
\hline
\end{tabular}




\begin{tabular}{|c|c|c|c|c|c|c|c|c|c|}
\hline & GH88 & 2 & 0 & 0 & 1 & 2 & 0 & 1 & 0 \\
\hline & GH92 & 0 & 0 & 1 & 3 & 0 & 0 & 0 & 0 \\
\hline & GH93 & 0 & 0 & 0 & 1 & 1 & 0 & 0 & 1 \\
\hline & GH94 & 2 & 1 & 2 & 0 & 0 & 2 & 1 & 0 \\
\hline & GH95 & 3 & 0 & 1 & 1 & 1 & 0 & 1 & 0 \\
\hline & GH97 & 0 & 0 & 0 & 1 & 2 & 0 & 2 & 0 \\
\hline & GH99 & 1 & 0 & 1 & 2 & 1 & 0 & 1 & 0 \\
\hline & GH102 & 0 & 1 & 1 & 0 & 0 & 0 & 0 & 3 \\
\hline & GH103 & 2 & 1 & 0 & 0 & 1 & 5 & 0 & 7 \\
\hline & GH104 & 0 & 1 & 0 & 0 & 0 & 1 & 0 & 0 \\
\hline & GH105 & 6 & 0 & 0 & 2 & 1 & 2 & 0 & 3 \\
\hline & GH106 & 2 & 0 & 0 & 2 & 0 & 0 & 0 & 0 \\
\hline & GH108 & 2 & 1 & 3 & 1 & 2 & 0 & 0 & 1 \\
\hline & GH109 & 94 & 81 & 103 & 95 & 132 & 99 & 73 & 27 \\
\hline & GH113 & 2 & 1 & 0 & 0 & 1 & 0 & 0 & 0 \\
\hline & GH114 & 0 & 1 & 1 & 0 & 0 & 0 & 1 & 1 \\
\hline & GH115 & 2 & 1 & 2 & 0 & 3 & 0 & 1 & 0 \\
\hline & GH116 & 1 & 1 & 0 & 0 & 1 & 0 & 1 & 0 \\
\hline & GH117 & 2 & 0 & 0 & 0 & 1 & 0 & 1 & 0 \\
\hline & GH120 & 3 & 4 & 3 & 3 & 1 & 4 & 1 & 0 \\
\hline & GH123 & 0 & 0 & 0 & 1 & 0 & 0 & 0 & 0 \\
\hline & GH125 & 1 & 0 & 2 & 2 & 0 & 1 & 0 & 0 \\
\hline & GH126 & 1 & 0 & 0 & 0 & 0 & 1 & 0 & 0 \\
\hline & GH127 & 4 & 2 & 5 & 7 & 1 & 4 & 1 & 2 \\
\hline & GH128 & 0 & 0 & 0 & 0 & 0 & 1 & 0 & 0 \\
\hline & GH129 & 2 & 0 & 1 & 0 & 1 & 0 & 1 & 0 \\
\hline & GH130 & 21 & 20 & 29 & 19 & 13 & 28 & 5 & 0 \\
\hline & GH132 & 0 & 0 & 0 & 0 & 0 & 1 & 0 & 0 \\
\hline \multirow[t]{16}{*}{ GT } & GT1 & 0 & 1 & 1 & 0 & 0 & 0 & 0 & 0 \\
\hline & GT2 & 78 & 72 & 79 & 85 & 76 & 55 & 40 & 30 \\
\hline & GT3 & 0 & 0 & 0 & 0 & 0 & 2 & 0 & 0 \\
\hline & GT4 & 97 & 91 & 142 & 130 & 125 & 98 & 49 & 46 \\
\hline & GT5 & 3 & 4 & 6 & 5 & 9 & 5 & 2 & 2 \\
\hline & GT7 & 0 & 0 & 1 & 0 & 0 & 0 & 0 & 0 \\
\hline & GT8 & 4 & 6 & 5 & 3 & 2 & 0 & 3 & 0 \\
\hline & GT9 & 0 & 1 & 1 & 3 & 4 & 0 & 0 & 16 \\
\hline & GT12 & 0 & 1 & 0 & 0 & 0 & 4 & 0 & 1 \\
\hline & GT14 & 1 & 0 & 0 & 0 & 0 & 0 & 0 & 0 \\
\hline & GT15 & 0 & 0 & 0 & 0 & 0 & 2 & 0 & 0 \\
\hline & GT19 & 6 & 9 & 13 & 12 & 4 & 13 & 3 & 5 \\
\hline & GT20 & 4 & 5 & 7 & 6 & 8 & 2 & 4 & 5 \\
\hline & GT21 & 0 & 2 & 3 & 2 & 1 & 1 & 0 & 0 \\
\hline & GT25 & 0 & 0 & 0 & 0 & 0 & 0 & 0 & 1 \\
\hline & GT26 & 16 & 18 & 21 & 18 & 18 & 19 & 15 & 3 \\
\hline
\end{tabular}




\begin{tabular}{|c|c|c|c|c|c|c|c|c|c|}
\hline & GT27 & 3 & 1 & 3 & 3 & 2 & 0 & 1 & 0 \\
\hline & GT28 & 30 & 24 & 26 & 20 & 11 & 35 & 5 & 5 \\
\hline & GT29 & 1 & 0 & 1 & 0 & 1 & 0 & 0 & 0 \\
\hline & GT30 & 1 & 1 & 1 & 2 & 4 & 4 & 2 & 4 \\
\hline & GT31 & 0 & 0 & 0 & 0 & 0 & 1 & 0 & 1 \\
\hline & GT32 & 0 & 0 & 1 & 0 & 1 & 2 & 0 & 0 \\
\hline & GT34 & 0 & 0 & 0 & 0 & 0 & 1 & 0 & 0 \\
\hline & GT35 & 2 & 3 & 0 & 2 & 2 & 2 & 2 & 2 \\
\hline & GT39 & 1 & 1 & 4 & 0 & 3 & 4 & 1 & 0 \\
\hline & GT44 & 2 & 2 & 0 & 0 & 0 & 1 & 0 & 0 \\
\hline & GT45 & 1 & 0 & 0 & 0 & 0 & 0 & 0 & 0 \\
\hline & GT46 & 0 & 1 & 0 & 0 & 0 & 0 & 0 & 0 \\
\hline & GT48 & 0 & 0 & 0 & 0 & 0 & 1 & 0 & 0 \\
\hline & GT51 & 52 & 47 & 52 & 28 & 32 & 64 & 16 & 19 \\
\hline & GT55 & 0 & 0 & 0 & 1 & 1 & 0 & 0 & 1 \\
\hline & GT56 & 0 & 0 & 0 & 0 & 0 & 0 & 0 & 1 \\
\hline & GT62 & 0 & 0 & 0 & 1 & 0 & 2 & 0 & 0 \\
\hline & GT66 & 0 & 0 & 0 & 0 & 0 & 1 & 1 & 0 \\
\hline & GT70 & 0 & 0 & 1 & 1 & 0 & 1 & 0 & 0 \\
\hline & GT73 & 0 & 0 & 1 & 0 & 0 & 0 & 0 & 1 \\
\hline & GT76 & 1 & 1 & 1 & 0 & 0 & 0 & 0 & 0 \\
\hline & GT78 & 0 & 1 & 0 & 0 & 1 & 0 & 1 & 0 \\
\hline & GT81 & 4 & 5 & 15 & 5 & 8 & 0 & 3 & 1 \\
\hline & GT83 & 1 & 1 & 5 & 2 & 0 & 0 & 0 & 1 \\
\hline & GT84 & 0 & 0 & 1 & 1 & 0 & 0 & 0 & 0 \\
\hline & GT87 & 1 & 0 & 1 & 0 & 2 & 0 & 1 & 1 \\
\hline & GT90 & 1 & 0 & 0 & 0 & 0 & 0 & 0 & 0 \\
\hline & GT94 & 6 & 4 & 5 & 2 & 1 & 0 & 1 & 1 \\
\hline $\mathrm{CE}$ & CE1 & 42 & 46 & 61 & 46 & 45 & 53 & 14 & 23 \\
\hline & CE2 & 2 & 1 & 0 & 0 & 2 & 2 & 0 & 0 \\
\hline & CE3 & 10 & 14 & 9 & 7 & 13 & 9 & 6 & 4 \\
\hline & CE4 & 61 & 73 & 83 & 55 & 41 & 61 & 28 & 18 \\
\hline & CE5 & 0 & 0 & 2 & 0 & 1 & 0 & 0 & 0 \\
\hline & CE6 & 1 & 0 & 3 & 4 & 1 & 2 & 0 & 0 \\
\hline & CE7 & 6 & 4 & 5 & 6 & 8 & 4 & 7 & 3 \\
\hline & CE8 & 1 & 1 & 2 & 3 & 1 & 1 & 0 & 1 \\
\hline & CE9 & 8 & 10 & 23 & 11 & 5 & 17 & 2 & 1 \\
\hline & CE10 & 22 & 23 & 26 & 23 & 22 & 34 & 11 & 14 \\
\hline & CE11 & 18 & 17 & 12 & 10 & 22 & 20 & 10 & 4 \\
\hline & CE12 & 11 & 4 & 2 & 3 & 5 & 4 & 3 & 0 \\
\hline & CE14 & 22 & 20 & 35 & 21 & 15 & 25 & 10 & 11 \\
\hline & CE15 & 2 & 1 & 5 & 5 & 7 & 1 & 3 & 0 \\
\hline & CE16 & 1 & 0 & 0 & 0 & 1 & 1 & 0 & 0 \\
\hline PL & PL1 & 13 & 4 & 2 & 3 & 5 & 0 & 4 & 1 \\
\hline
\end{tabular}




\begin{tabular}{|c|c|c|c|c|c|c|c|c|c|}
\hline & PL3 & 8 & 4 & 1 & 2 & 2 & 0 & 2 & 0 \\
\hline & PL4 & 0 & 0 & 0 & 0 & 0 & 0 & 0 & 0 \\
\hline & PL6 & 1 & 1 & 0 & 0 & 0 & 0 & 0 & 1 \\
\hline & PL9 & 4 & 0 & 2 & 5 & 4 & 0 & 2 & 0 \\
\hline & PL10 & 2 & 0 & 0 & 2 & 3 & 0 & 2 & 0 \\
\hline & PL11 & 4 & 0 & 2 & 2 & 1 & 0 & 1 & 0 \\
\hline & PL12 & 1 & 0 & 1 & 0 & 2 & 0 & 2 & 1 \\
\hline & PL14 & 0 & 1 & 1 & 1 & 3 & 0 & 1 & 0 \\
\hline & PL15 & 0 & 0 & 1 & 1 & 4 & 0 & 3 & 1 \\
\hline & PL17 & 1 & 0 & 1 & 2 & 3 & 0 & 2 & 0 \\
\hline & PL18 & 0 & 1 & 0 & 0 & 0 & 0 & 0 & 1 \\
\hline & PL20 & 0 & 1 & 0 & 0 & 0 & 0 & 0 & 0 \\
\hline & PL21 & 0 & 0 & 0 & 1 & 0 & 0 & 0 & 0 \\
\hline & PL22 & 4 & 4 & 3 & 5 & 4 & 0 & 1 & 1 \\
\hline AA & AA2 & 13 & 10 & 3 & 6 & 6 & 18 & 2 & 14 \\
\hline & AA3 & 1 & 0 & 1 & 1 & 1 & 3 & 0 & 0 \\
\hline & AA4 & 7 & 5 & 10 & 7 & 2 & 3 & 0 & 1 \\
\hline & AA6 & 19 & 23 & 18 & 15 & 10 & 57 & 7 & 23 \\
\hline & AA7 & 0 & 0 & 7 & 1 & 1 & 0 & 4 & 6 \\
\hline & AA9 & 0 & 0 & 2 & 0 & 0 & 2 & 0 & 0 \\
\hline & AA10 & 7 & 6 & 5 & 6 & 4 & 4 & 9 & 7 \\
\hline
\end{tabular}

